\title{
Informe de los Objetivos de Desarollo Sostenible 2016
}

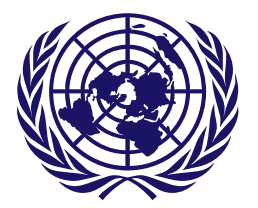

Naciones Unidas

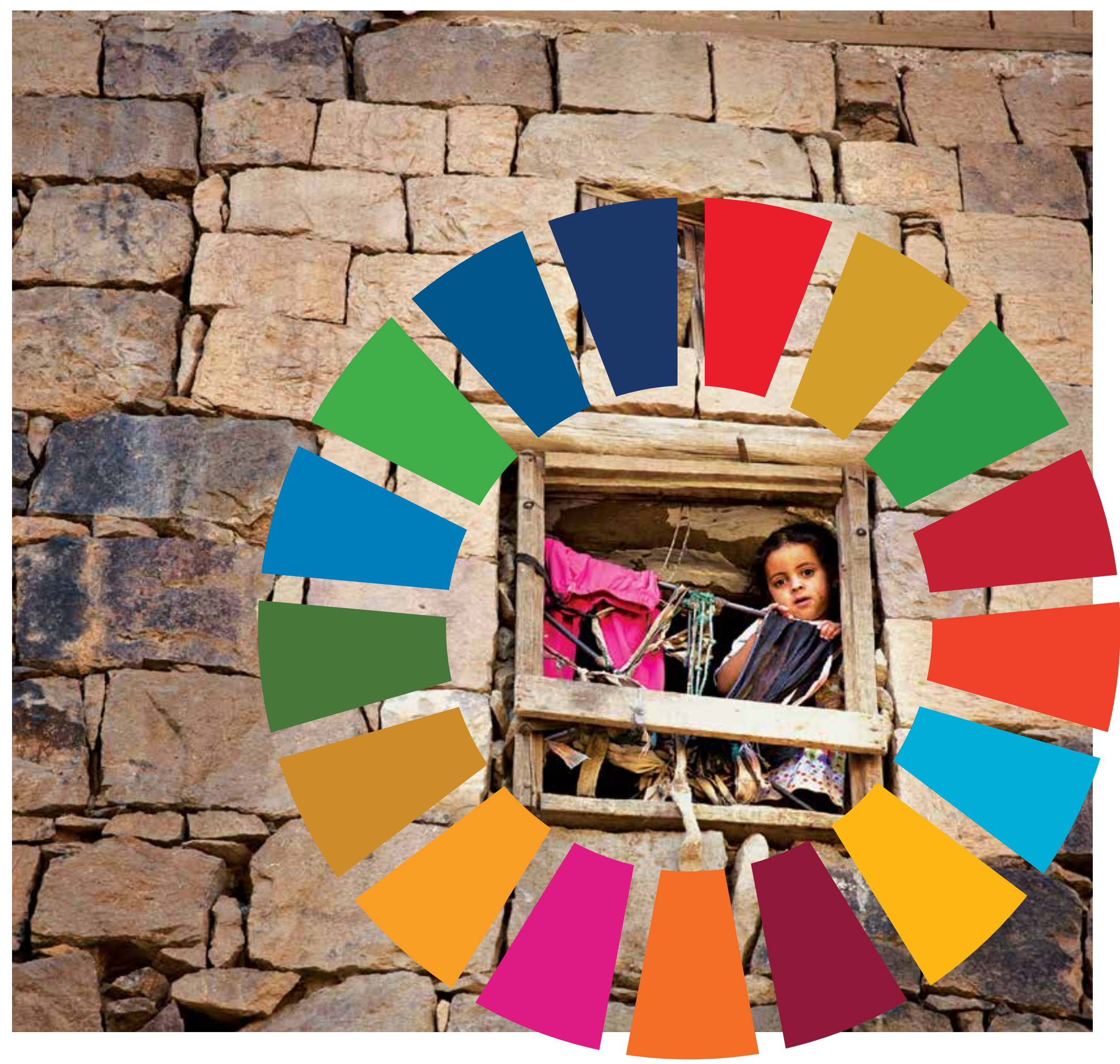




\section{Índice}

Prefacio

Panorama general

Objetivo 1: Fin de la pobreza

Objetivo 2: Hambre cero

Objetivo 3: Salud y bienestar

Objetivo 4: Educación de calidad

Objetivo 5: Igualdad de género

Objetivo 6: Agua limpia y saneamiento

Objetivo 7: Energía asequible y no contaminante

Objetivo 8: Trabajo decente y crecimiento económico

Objetivo 9. Industria, innovación e infraestructura

Objetivo 10: Reducción de las desigualdades

Objetivo 11: Ciudades y comunidades sostenibles

Objetivo 12: Producción y consumo responsables

Objetivo 13: Acción por el clima

Objetivo 14: Vida submarina

Objetivo 15: Vida de ecosistemas terrestres

Objetivo 16: Paz, justicia e instituciones sólidas

Objetivo 17: Alianzas para lograr los objetivos

No dejar a nadie atrás

Nota para el lector 


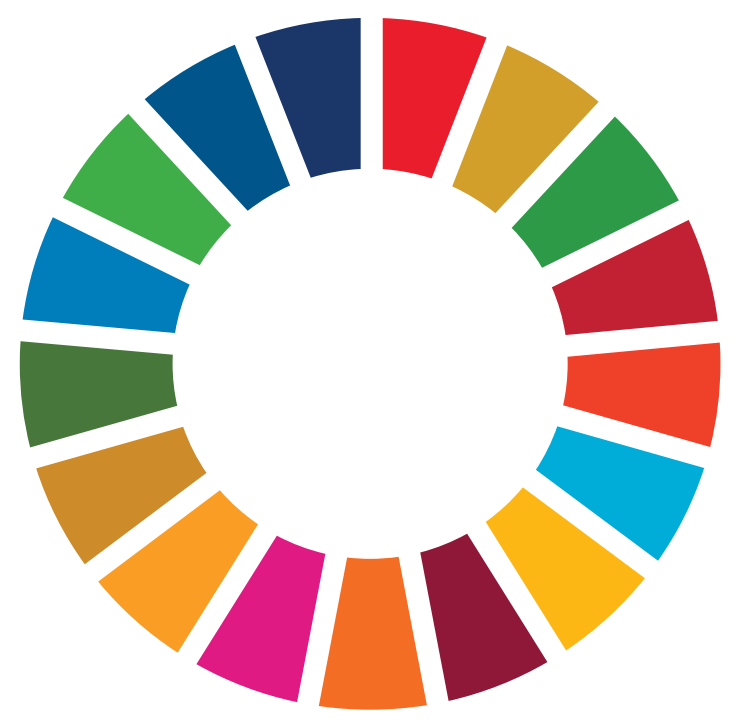

\section{Informe de los Objetivos de Desarollo Sostenible 2016}

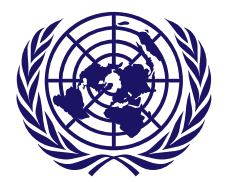




\section{Prefacio}

El 10 de enero de 2016, el mundo comenzó a implementar oficialmente la Agenda 2030 para el Desarrollo Sostenible. El plan de acción para la transformación está basado en 17 Objetivos de Desarrollo Sostenible que abordan los urgentes desafíos globales en el curso de los próximos quince años.

Esta agenda es un conjunto de directrices para las personas y el planeta que se construirá sobre el éxito de los Objetivos de Desarrollo del Milenio y asegurará el progreso social y económico sostenible en todo el mundo. No solamente busca erradicar la pobreza extrema, sino integrar y equilibrar las tres dimensiones del desarrollo sostenible -económico, social y ambiental- en una visión global e integral.

Es vital que comencemos la implementación con un sentido de oportunidad y propósito, basándonos en evaluaciones precisas de dónde se encuentra el mundo ahora.

Esa es la meta de este informe. Presenta un panorama general de los 17 objetivos, utilizando datos disponibles en la actualidad para señalar las brechas y los desafíos más significativos.

Los datos más recientes muestran que aproximadamente una de cada ocho personas todavía vivía en extrema pobreza; casi 800 millones de personas padecían hambre;

los nacimientos de casi una cuarta parte de los niños menores de 5 años no habían sido registrados; 1.100 millones de personas vivían sin electricidad; y la falta de agua afectaba a más de 2.000 millones de personas.
Estas estadísticas muestran la importancia de los esfuerzos coordinados de la generación de datos a nivel mundial que proporcionen información confiable y oportuna para el seguimiento sistemático y las evaluaciones del progreso.

Los objetivos son aplicables para todas las sociedades. Incluso los países más ricos todavía no han empoderado completamente a la mujer ni eliminado la discriminación. Todas las naciones deberán aplicar los ODS en sus políticas y planes nacionales, si es que queremos alcanzarlos.

Este primer informe es un punto de arranque. Con una acción mundial colectiva podemos aprovechar las oportunidades que se nos presentan y, juntos, cumplir la promesa de la Agenda 2030 de no dejar a nadie atrás.

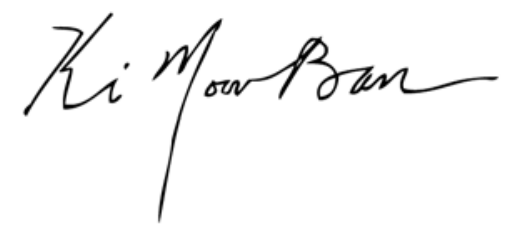

BAN KI-MOON

Secretario General, Naciones Unidas 


\section{Panorama general}

Este informe inaugural de los Objetivos de Desarrollo Sostenible (ODS) mundiales es una descripción inicial de dónde se encuentra el mundo al principio de nuestro recorrido colectivo hacia el 2030. El informe analiza los indicadores que se han seleccionado del marco de indicadores mundiales para los que se dispone de datos como ejemplos para destacar algunos vacíos y desafíos críticos. La lista de los indicadores de los ODS, acordados por la Comisión de Estadística de las Naciones Unidas en marzo de 2016, estará sujeta a ajustes y perfeccionamiento a medida que se mejoren los métodos y los datos disponibles.
Cada recorrido tiene un comienzo y un final. Para trazar este recorrido y establecer los hitos clave a lo largo del camino se requieren datos desglosados accesibles, oportunos y fiables. Los requerimientos de datos para los indicadores mundiales tienen tan poco precedente como los ODS mismos, y constituyen un enorme desafío para todos los países. No obstante, cumplir estos requerimientos mediante la creación de capacidades estadísticas nacionales es un paso esencial para establecer dónde estamos en este momento y mostrar el camino por delante, de manera que podamos acercar nuestra visión colectiva a la realidad.

\section{Objetivo 1: Poner fin a la pobreza en todas sus formas y en todo el mundo}

El Objetivo 1 aboga por poner fin a la pobreza en todas sus manifestaciones, incluida la pobreza extrema, en el curso de los próximos 15 años. Todas las personas, en todas partes, incluidas las más pobres y vulnerables, deberían contar con un nivel de vida básico y beneficios de protección social.

- Entre los años 2002 y 2012, la proporción de la población mundial que vivía por debajo del umbral de pobreza extrema se redujo a la mitad, de $26 \%$ a $13 \%$. Aun así, la pobreza continúa siendo generalizada en África subsahariana, donde más del $40 \%$ de las personas vivían con menos de 1,90 dólares por día en 2012.

- En 2015, 10\% de los trabajadores del mundo y sus familias vivían con menos de 1,90 dólares por persona por día, un descenso de los 28\% del 2000.

- Las personas jóvenes entre 15 y 24 años de edad tienen mayor probabilidad de encontrarse entre los trabajadores pobres: $16 \%$ de todos los jóvenes empleados vivían por debajo del umbral de pobreza en 2015, en comparación con el $9 \%$ de los trabajadores adultos.

- Cerca de una de cada cinco personas recibió algún tipo de asistencia social o beneficios de protección social en los países de bajos ingresos, en comparación con dos de cada tres personas en los países de ingresos medianos altos.
1 de cada 8 personas vivían en la pobreza extrema en 2012

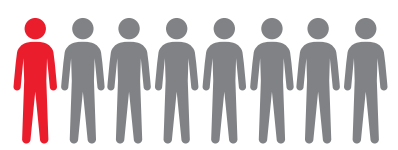

\section{Prestaciones de asistencia social o protección social}

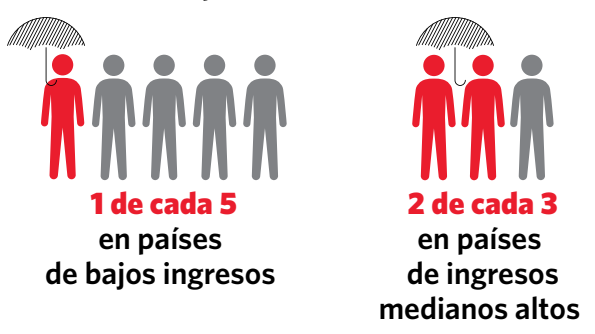




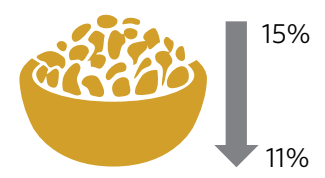

La población mundial que padece

hambre disminuyó del $15 \%$ al $11 \%$

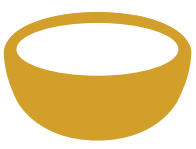

Casi 800 millones de personas aún padecen hambre

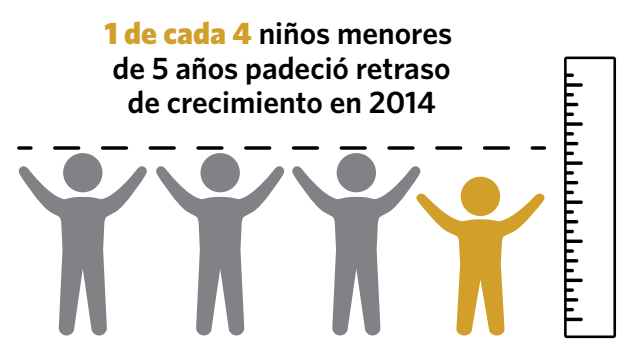

El Objetivo 2 busca poner fin al hambre y a todas las formas de malnutrición, y alcanzar la producción sostenible de alimentos para el año 2030. Se fundamenta en la idea de que todos deberían tener acceso a suficiente alimento nutritivo, lo que requiere la extensa promoción de la agricultura sostenible, duplicar la productividad agrícola, aumentar las inversiones y contar con mercados de alimentos que funcionen adecuadamente.

- La proporción de la población que sufre de hambre disminuyó a nivel mundial del 15\% en el período 2000-2002, al 11\% en el período 2014-2016. No obstante, casi 800 millones de personas en todo el mundo todavía no cuentan con acceso a alimentos adecuados.

- Más de la mitad de la población adulta en África subsahariana sufrió inseguridad alimentaria moderada o grave en 2015; el nivel fue grave para una cuarta parte de los adultos de la región.

- Uno de cada cuatro niños menores de 5 años padeció retraso de crecimiento en 2014 , lo que se estima en 158,6 millones de niños.

- La proporción de niños menores de 5 años con sobrepeso ha aumentado en casi un $20 \%$ entre los años 2000 y 2014. Aproximadamente 41 millones de niños de este grupo etario en todo el mundo sufrían de sobrepeso en el 2014; casi la mitad vivían en Asia.

\section{Objetivo 3: Garantizar una vida sana y promover el bienestar de todos a todas las edades}
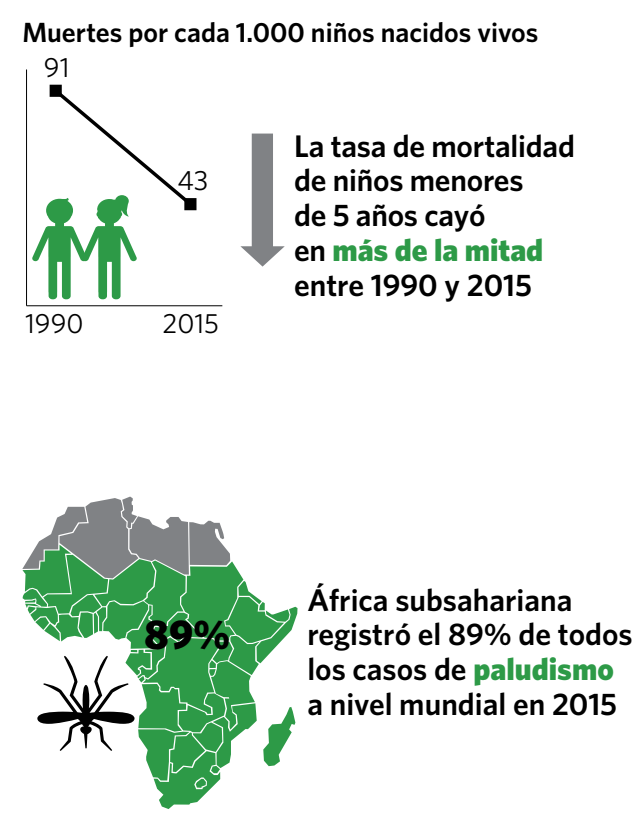

El Objetivo 3 está dirigido a asegurar la salud y el bienestar de todos a todas las edades mediante la mejora de la salud reproductiva, materna e infantil; poner fin a las epidemias de las principales enfermedades transmisibles; reducir las enfermedades no transmisibles y ambientales; alcanzar la cobertura sanitaria universal; y asegurar el acceso a medicamentos y vacunas seguros, asequibles y eficaces.

- Entre los años 1990 y 2015, la tasa de mortalidad materna mundial se redujo en un $44 \%$ y la tasa de mortalidad de niños menores de 5 años cayó en más de la mitad. No obstante, se estima que 5,9 millones de niños menores de 5 años murieron en 2015 , en su mayoría por causas prevenibles.

- La incidencia del VIH, el paludismo y la tuberculosis disminuyó a nivel mundial entre los años 2000 y 2015. En 2015, sin embargo, 2,1 millones de personas contrajeron infecciones nuevas de $\mathrm{VIH}$ y se estima que 214 millones de personas se enfermaron de paludismo. Casi la mitad de la población mundial está en riesgo de contraer paludismo, pero el $89 \%$ de todos los casos se registraron en África subsahariana.

- A nivel mundial, en 2015, aproximadamente tres de cada cuatro mujeres en edad reproductiva ( 15 a 49 años) que estaban casadas o en pareja satisfacían sus necesidades de planificación familiar mediante el uso de métodos anticonceptivos modernos.

- En 2012, casi dos terceras partes de las muertes causadas por enfermedades no transmisibles en personas menores de 70 años se atribuyeron a enfermedades cardiovasculares y cáncer. 


\section{Objetivo 4: Garantizar una educación inclusiva y equitativa de calidad}

\section{y promover oportunidades de aprendizaje permanente para todos}

El Objetivo 4 se enfoca en la adquisición de las competencias básicas y de orden superior; en un acceso mayor y más equitativo a la educación y formación técnica y profesional, así como a la enseñanza superior; en la capacitación técnica durante toda la vida, así como en el conocimiento, las habilidades y los valores necesarios para funcionar adecuadamente y contribuir a la sociedad.

- En 2013, 59 millones de niños en edad de asistir a la escuela primaria, no lo hacían.

- Las encuestas en 63 países de ingresos bajos y medianos, entre los años 2008 y 2012, muestran que los niños del 20\% de los hogares más pobres tenían más de cuatro veces más probabilidades de no asistir a la escuela, que sus pares más ricos.

- Los datos de 38 países en las regiones desarrolladas muestran que, en la mayoría de estos países, $75 \%$ o más de los jóvenes alcanzaron al menos una competencia mínima en lectura y/o matemáticas. Esto solo se observó en 5 de los 22 países en desarrollo con datos disponibles.

- En 2013, todavía había 757 millones de adultos (de 15 años o más) que no sabían leer ni escribir, de los cuales dos tercios eran mujeres.

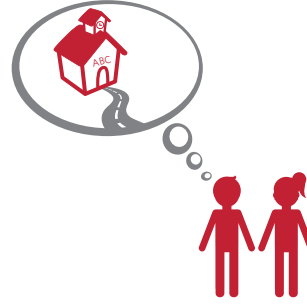

59 milliones de niños en edad de asistir a la escuela primaria, no lo hacían en 2013

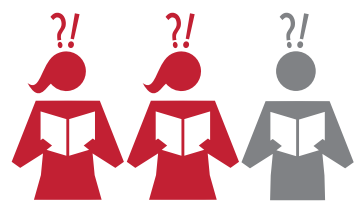

757 millones de adultos no sabían leer ni escribir en 2013 , de los cuales dos tercios eran mujeres

\section{Objetivo 5: Lograr la igualdad de género y empoderar a todas las mujeres y las niñas}

El Objetivo 5 está dirigido a empoderar a las mujeres y las niñas de manera que puedan alcanzar todo su potencial, lo que requiere eliminar todas las formas de discriminación y violencia en su contra, incluyendo las prácticas nocivas. Busca asegurar que ellas cuenten con todas las oportunidades de salud sexual y reproductiva y de derechos reproductivos, reciban un debido reconocimiento por su trabajo no remunerado, tengan pleno acceso a recursos productivos y disfruten de una participación equitativa con los hombres en la vida pública, económica y política.

- En todo el mundo, la proporción de mujeres entre 20 y 24 años de edad que informaron estar casadas antes de cumplir los 18 años disminuyó de 32\% alrededor de 1990 a 26\% alrededor de 2015.

- En los 30 países en los que se concentra la práctica de la mutilación genital femenina, más de una tercera parte de las niñas entre 15 y 19 años han sido sometidas a este procedimiento.

- De acuerdo a las encuestas sobre el uso del tiempo realizadas entre los años 2000 y 2014 en 59 países, las mujeres informan que dedicaron 19\% de su tiempo cada día a trabajo no remunerado, en comparación con el $8 \%$ de los hombres.

- La proporción de escaños ocupados por mujeres en las cámaras baja y unicameral de los parlamentos nacionales aumentó a 23\% en 2016: un aumento de 6 puntos porcentuales en el curso de la última década.
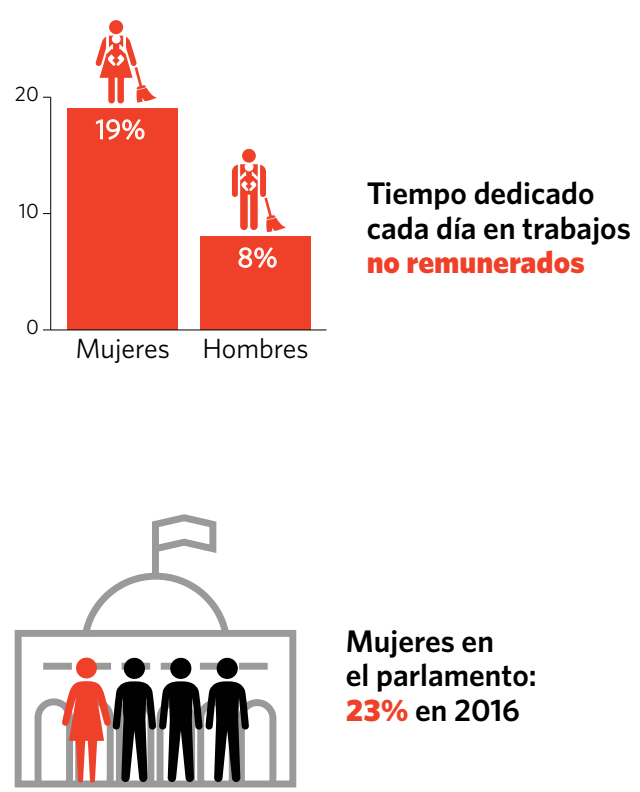

Mujeres en el parlamento: 23\% en 2016 


\section{Objetivo 6: Garantizar la disponibilidad y la gestión sostenible del agua}

\section{y el saneamiento para todos}

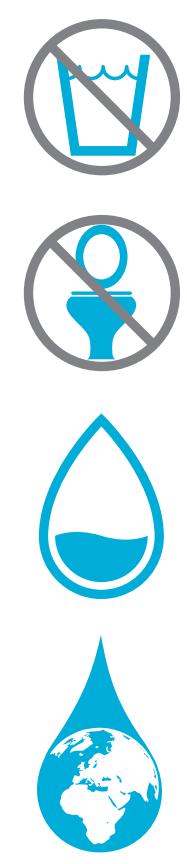

663 milliones de personas aún usan suministros de agua no mejorada

2.4 millones de personas no cuentan con servicios de saneamiento mejorado

2000 millones de personas en todo el mundo afectadas por el estrés por la escasez de agua

Planes de gestión integrada de los recursos hídricos en todas las regiones del mundo
El Objetivo 6 va más allá del agua potable, el saneamiento y la higiene, para abordar también la calidad y sostenibilidad de los recursos hídricos. Alcanzar este Objetivo, que es esencial para la supervivencia de las personas y del planeta, significa ampliar la cooperación internacional y recibir el apoyo de las comunidades locales para mejorar la gestión del agua y del saneamiento.

- En 2015, 6.600 millones de personas, o 91\% de la población mundial, contaban con mejoras en el suministro de agua potable, en comparación con el $82 \%$ en el 2000. Sin embargo, se estima que en 2015, 663 millones de personas todavía no contaban con mejoras en el suministro de agua potable o usaban aguas superficiales.

- Entre 2000 y 2015, la proporción de la población mundial que contaba con mejoras en las instalaciones sanitarias aumentó de 59\% a 68\%. Sin embargo, se están dejando atrás a unos 2,4 mil millones de personas. Entre ellas, 946 millones no disponían de instalación alguna y continuaban practicando la defecación al aire libre.

- El estrés por la escasez de agua afecta a más de dos mil millones de personas en todo el mundo, una cifra que se proyecta que aumentará.

- En todas las regiones del mundo se está llevando a cabo la gestión integrada de los recursos hídricos.

\section{Objetivo 7: Garantizar el acceso a una energía asequible, fiable, sostenible}

y moderna para todos
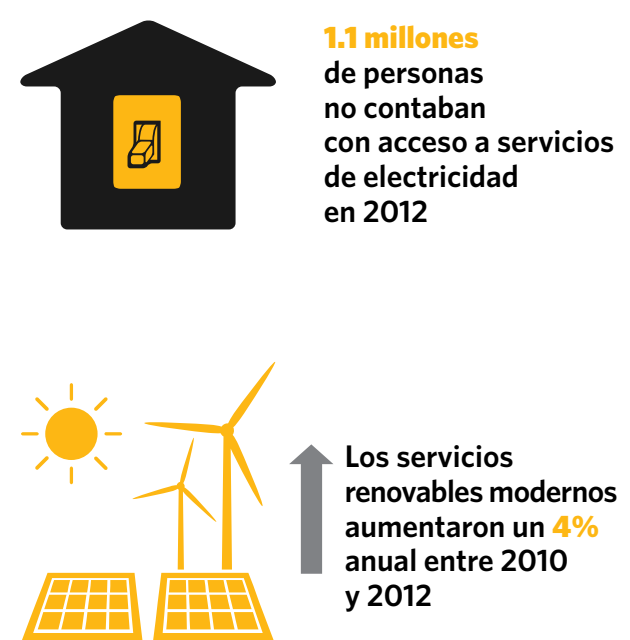

El Objetivo 7 busca promover un acceso más amplio a la energía y aumentar el uso de energía renovable, incluyendo a través de la mejora de la cooperación internacional y la ampliación de la infraestructura y tecnología para la energía limpia.

La proporción de la población global con acceso a la energía eléctrica ha aumentado de manera sostenida, de un $79 \%$ en el 2000 a un $85 \%$ en el 2012. A pesar de las mejoras, 1.100 millones de personas todavía no contaban con este servicio esencial en 2012.

En 2014, unas tres mil millones de personas -más del 40\% de la población mundial-dependía de combustibles contaminantes o insalubres para cocinar.

- Las fuentes renovables modernas aumentaron rápidamente a una tasa de 4\% al año entre 2010 y 2012.

Del 2000 al 2012, la intensidad energética mundial mejoró en 1,3\% anual. Alrededor del 68\% del ahorro en energía entre 2010 y 2012 proviene de regiones en desarrollo, siendo Asia oriental su mayor contribuyente. 


\section{Objetivo 8: Promover el crecimiento económico sostenido, ínclusivo}

y sostenible, el empleo pleno y productivo y el trabajo decente para todos

El crecimiento económico sostenido, inclusivo y sostenible es un requisito previo para la prosperidad mundial. El Objetivo 8 está dirigido a promover oportunidades para un empleo pleno y productivo y trabajo decente para todos, al tiempo que se erradica el trabajo forzoso, la trata de personas y el trabajo infantil.

- La tasa promedio de crecimiento anual del producto interno bruto (PIB) real per cápita en los países menos adelantados (PMA) disminuyó de 4,7\% en el curso del período comprendido entre 2005 y 2009, a 2,6\% en 2010. Esto fue menos de la mitad de la tasa objetivo de $7 \%$ anual.

- Aunque entre 2005 y 2015, la productividad laboral en las regiones en desarrollo aumentó, el valor para las regiones desarrolladas seguía siendo más del doble del de cualquier región en desarrollo, y unas 20 veces mayor que los valores para África subsahariana y Asia meridional.

- En 2015, la tasa de desempleo para las mujeres era de 6,7\% en comparación con el 5,8\% para los hombres. Las desigualdades por género fueron más pronunciadas en Asia occidental y África septentrional, donde la tasa de desempleo de las mujeres fue más del doble que la de los hombres.

- Aunque la proporción de adultos con cuentas bancarias aumentó en 20\% en cuatro años, unas dos mil millones de personas todavía no cuentan con este importante servicio financiero.

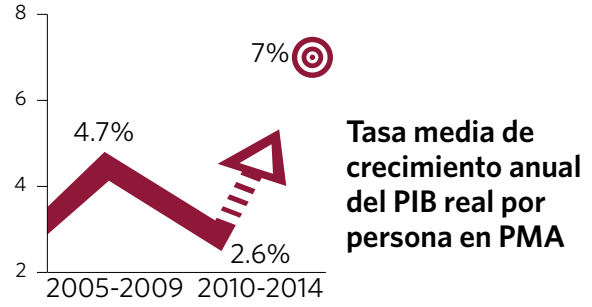

Las mujeres tenían el doble de probabilidades de estar desempleadas que los hombres en Asia occidental y África septentrional

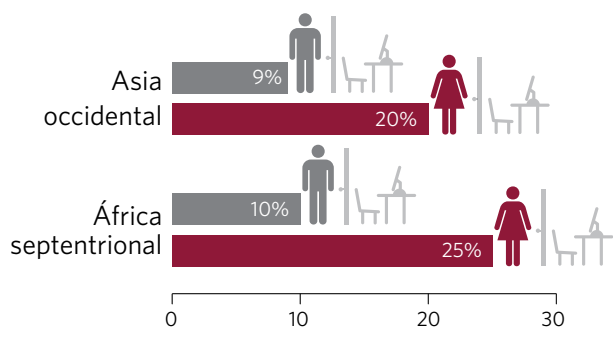

\section{Objetivo 9: Construir infraestructuras resilientes, promover la industrialización inclusiva y sostenible y fomentar la innovación}

El Objetivo 9 se enfoca en la promoción del desarrollo de infraestructura, industrialización e innovación. Esto puede cumplirse a través de la mejora de apoyo técnico, tecnológico y financiero, investigación y desarrollo, y mayor acceso a información y tecnología de comunicación, a nivel nacional e internacional.

- En 2015, el valor agregado por manufactura per cápita fue inferior a 100 dólares por año en los PMA, en comparación con casi 5.000 dólares en las regiones desarrolladas.

- De 2000 a 2013, la eficiencia energética y los combustibles y tecnologías más limpios han disminuido las emisiones de dióxido de carbono por unidad de valor agregado en $13 \%$ a nivel mundial.

- En 2013, la inversión mundial en investigación y desarrollo (I+D) se ubicaba en 1,7 billones de dólares (paridad de poder adquisitivo, PPA), ascendiendo de 732 mil millones de dólares en el año 2000. Las regiones desarrolladas dedicaron casi $2,4 \%$ de su PIB a I+D en 2013, mientras que el promedio para los PMA y los países en desarrollo sin litoral se ubicó en menos de 0,3\%.

- La tecnología de tercera generación (3G) alcanzó el 89\% de la población urbana, pero solo el 29\% de la población rural en 2015.
Valor agregado por manufactura per cápita en 2015

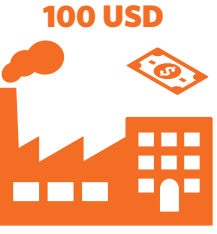

PMA
5,000 USD

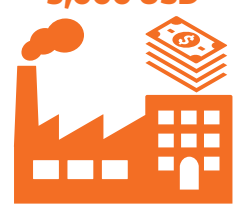

Regiones desarrolladas
Cobertura móvil $3 \mathrm{G}$ de banda ancha en 2015 a nivel mundial

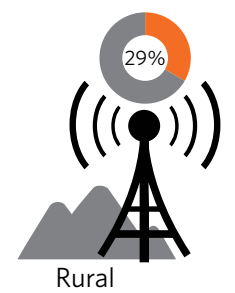

\section{$89 \%$}

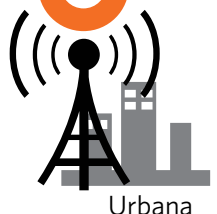




\section{Objetivo 10: Reducir la desigualdad en los países y entre ellos}

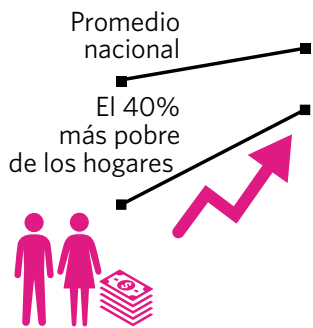

El ingreso per cápita en 56 de 94 países aumentó más rápidamente en los hogares más pobres

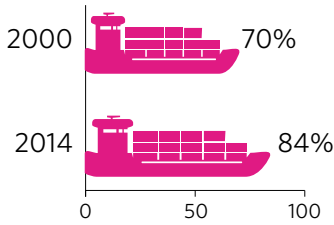

Participación de importaciones libres de impuestos de los PMA a países desarrollados
El Objetivo 10 aboga por reducir la desigualdad de ingresos, así como aquellas desigualdades basadas en sexo, edad, discapacidad, raza, clase, etnia, religión y oportunidad, tanto en los países como entre ellos. También tiene por cometido asegurar una migración segura, ordenada y regular, y aborda problemas relacionados con la representación de los países en desarrollo en la toma de decisiones mundiales y la asistencia para el desarrollo.

- En 56 de 94 países con datos para el período entre los años 2007 y 2012, los ingresos per cápita del $40 \%$ más pobre de los hogares creció más rápidamente que el promedio nacional.

- La proporción de importaciones de los países menos adelantados y los países en desarrollo a los países desarrollados que se beneficiaron de las franquicias aduaneras aumentó entre 2000 y 2014, de $70 \%$ a $84 \%$ y de $65 \%$ a $79 \%$ respectivamente.

- El costo por enviar dinero a través de fronteras internacionales promediaba un 7,5\% del monto remitido en 2015: más del doble de la cifra objetivo de $3 \%$.

\section{Objetivo 11: Lograr que las ciudades y los asentamientos humanos sean inclusivos, seguros, resilientes y sostenibles}
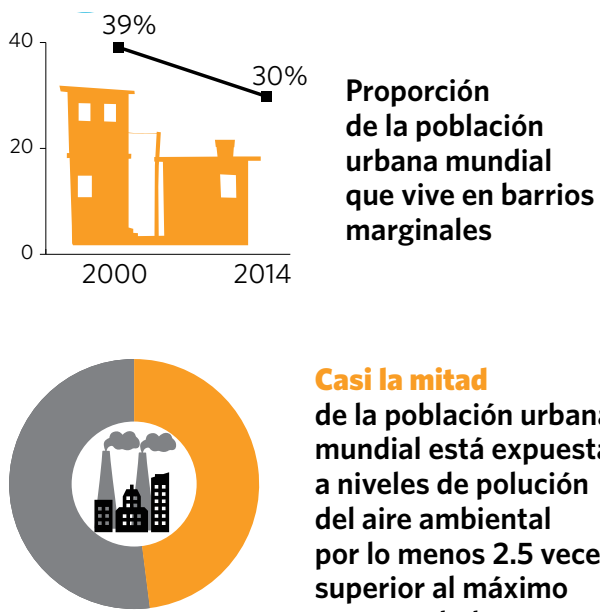

Casi la mitad de la población urbana mundial está expuesta a niveles de polución del aire ambiental por lo menos 2.5 veces superior al máximo recomendado
El Objetivo 11 tiene el cometido de renovar y planificar las ciudades y otros asentamientos humanos de manera tal que fomente la cohesión de la comunidad y la seguridad personal, al tiempo que estimula la innovación y el empleo.

- En 2014, 880 millones de personas vivían en barrios marginales urbanos (o 30\% de la población urbana mundial) en comparación con el 39\% en el año 2000.

- En muchas ciudades de rápido crecimiento en todo el mundo, la población se mueve hacia afuera, mucho más allá de los límites administrativos.

- En el 2014, casi la mitad de la población urbana en todo el mundo estaba expuesta a niveles de contaminación del aire al menos 2,5 veces mayores a las normas de seguridad establecidas por la Organización Mundial de la Salud.

- En el 2015, 142 países se encontraban desarrollando políticas urbanas a nivel nacional; de estos, 82 países ya se encontraban en proceso de implementación y 23 alcanzaron la etapa de supervisión y evaluación.

\section{Objetivo 12: Garantizar modalidades de consumo y producción sostenibles}

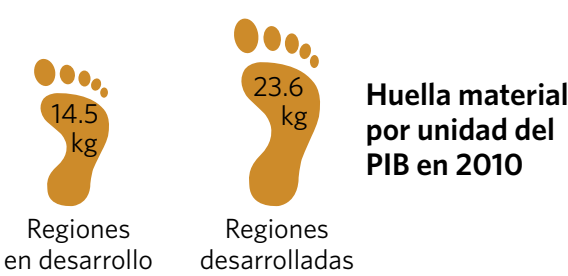

Cantidad de partes en convenciones sobre residuos y otros productos químicos peligrosos

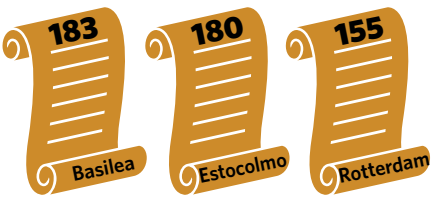

El Objetivo 12 está dirigido a promover regímenes de consumo y producción sostenibles a través de diversas medidas que incluyen políticas específicas y acuerdos internacionales sobre la gestión de materiales que son tóxicos para el medio ambiente.

- En 2010, la huella material por unidad del PIB material (cantidad de materia prima utilizada) por las regiones desarrolladas se ubicó en 23,6 kilogramos por unidad de PIB, en comparación con el 14,5 kilogramos por unidad de PIB en las regiones en desarrollo.

- Ese mismo año, el consumo nacional de materiales per cápita en las regiones desarrolladas fue $72 \%$ más alto que el de las regiones en desarrollo.

- Salvo por seis excepciones, todos los Estados Miembros de las Naciones Unidas son firmantes de al menos uno de los convenios (Basilea, Rotterdam o Estocolmo) dedicados a la gestión de desechos peligrosos y otros químicos. 


\section{Objetivo 13: Adoptar medidas urgentes para combatir el cambio climático}

\section{y sus efectos}

El cambio climático representa la principal amenaza al desarrollo, y sus efectos extendidos y sin precedentes desproporcionadamente afectan a los más pobres y vulnerables. Es necesario tomar acciones urgentes no solo para combatir el cambio climático y sus efectos, sino también para fortalecer la resiliencia para responder a los peligros relacionados con el clima y los desastres naturales.

- En abril de 2016, 175 Estados Miembros firmaron el histórico Acuerdo de París que prepara el terreno para una ambiciosa acción por el clima por parte de todos para asegurar que la temperatura mundial no aumente más de 2 grados Celsius.

- Un promedio de 83.000 personas murieron y 211 millones se vieron afectadas cada año como resultado de un desastre natural ocurrido entre los años 2000 y 2013.

- En 2015, solo 83 países informaron contar con disposiciones legislativas y/o normativas establecidas para manejar el riesgo de desastre.
Acuerdo de París sobre el cambio climático de 2015
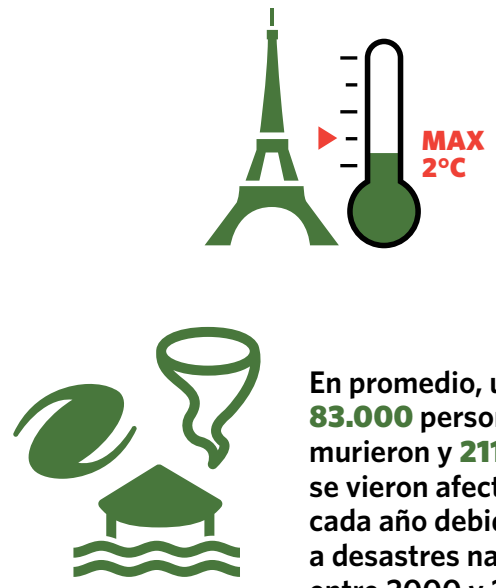

En promedio, unas 83.000 personas murieron y 211 milliones se vieron afectadas cada año debido a desastres naturales, entre 2000 y 2013

\section{Objetivo 14: Conservar y utilizar sosteniblemente los océanos, los mares y los recursos marinos para el desarrollo sostenible}

Este Objetivo busca promover la conservación y el uso sostenible de los ecosistemas marino y costero, prevenir la contaminación de los mares y aumentar los beneficios económicos para los pequeños estados insulares en desarrollo y los PMA mediante el uso sostenible de recursos marinos.

- Los recursos marinos son particularmente importantes para quienes habitan en comunidades costeras, que en 2010 representaban el 37\% de la población mundial.

- La proporción de poblaciones marinas de peces a nivel mundial dentro de niveles biológicamente sostenibles decayó del 90\% en 1974 al 69\% en 2013.

- En 2014, el 8,4\% del ambiente marino bajo jurisdicción nacional (hasta 200 millas náuticas desde la costa) estaba bajo protección. Entre 2000 y 2016, la porción de áreas clave de biodiversidad marina que estaban completamente cubiertas por zonas protegidas aumentó de 15\% a 19\%.

- Los cinco grandes ecosistemas marinos en mayor riesgo de eutrofización costera son la Bahía de Bengala, el Mar de la China oriental, el Golfo de México, la plataforma del norte de Brasil y el Mar de la China meridional; áreas que proporcionaban servicios derivados de los ecosistemas para una población costera de 781 millones de personas en 2010.
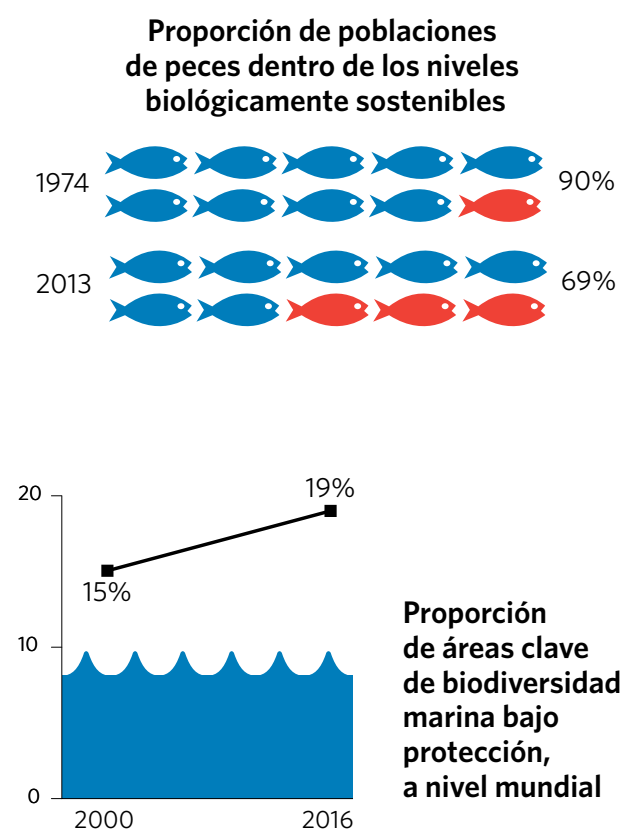


\section{Objetivo 15: Proteger, restablecer y promover el uso sostenible de los}

ecosistemas terrestres, gestionar sosteniblemente los bosques,

luchar contra la desertificación, detener e invertir la degradación

de las tierras y detener la pérdida de biodiversidad
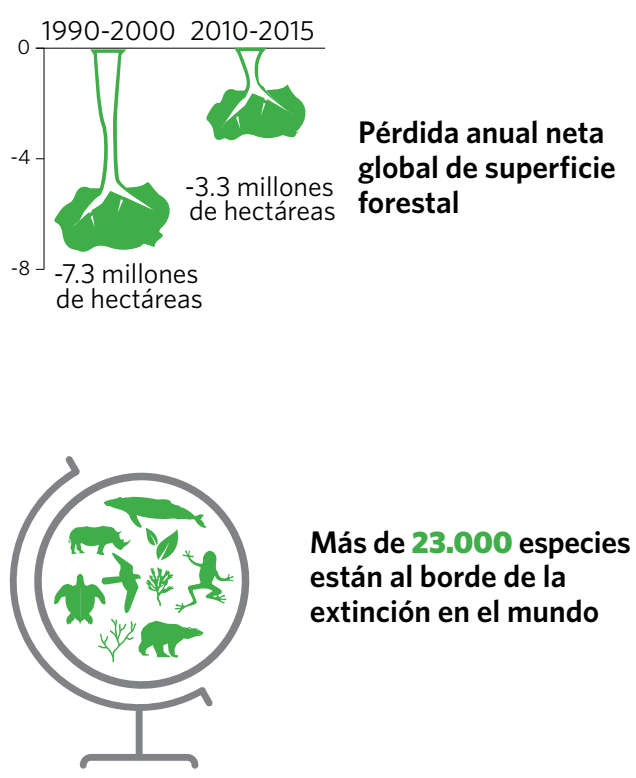

Más de 23.000 especies están al borde de la extinción en el mundo
El Objetivo 15 se enfoca en la gestión de los bosques de manera sostenible, la restauración de tierras degradadas y en combatir con éxito la desertificación, disminuyendo los hábitats naturales degradados y deteniendo la pérdida de biodiversidad. Todos estos esfuerzos combinados asegurarán que se preserven los medios de vida de aquellos que dependen directamente de los bosques y otros ecosistemas, que la biodiversidad prospere y que los beneficios de estas fuentes naturales puedan ser disfrutados por las generaciones futuras.

- La pérdida neta de superficie forestal se redujo de 7,3 millones de hectáreas por año en la década de 1990 a 3,3 millones de hectáreas anuales durante el período comprendido entre 2010 y 2015.

- A nivel mundial, el porcentaje de áreas clave de biodiversidad terrestres, interiores de agua dulce y de montañas que están completamente cubiertas por zonas protegidas aumentó de $16,5 \%$ a $19,3 \%$, de $13,8 \%$ a $16,6 \%$, y de $18,1 \%$ a $20,1 \%$ respectivamente, entre los años 2000 y 2016.

- Al 2015, se conocía que más de 23.000 especies de plantas, hongos y animales enfrentaban una alta probabilidad de extinción. Las actividades humanas están causando la extinción de especies a tasas tres veces más altas que las normales en toda la historia de la Tierra.

- Desde 1999, se han denunciado al menos 7.000 especies de animales y plantas por su comercio ilegal, lo que afecta a 120 países.

\section{Objetivo 16: Promover sociedades pacificas e inclusivas para el desarrollo} sostenible, facilitar el acceso a la justicia para todos y construir a todos los niveles instituciones eficaces e inclusivas que rindan cuentas
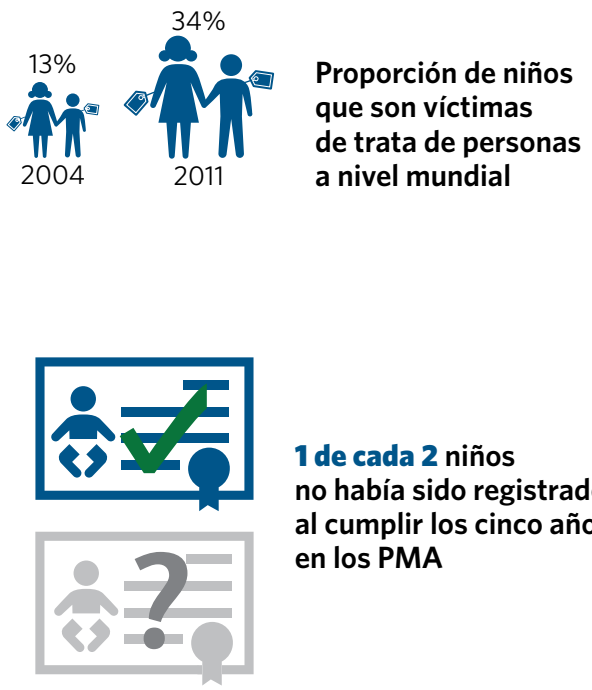

1 de cada 2 niños no había sido registrado al cumplir los cinco años en los PMA
El Objetivo 16 concibe sociedades pacíficas e inclusivas basadas en el respeto de los derechos humanos, el estado de derecho, una buena gestión pública a todos los niveles, e instituciones eficaces y responsables. Muchos países todavía se enfrentan a violencia prolongada y conflictos armados; demasiadas personas no están bien apoyadas debido a instituciones débiles y carecen de acceso a justicia, información y otras libertades fundamentales.

- Entre 2008 y 2014, la tasa de homicidios en los países en desarrollo fue el doble de la de los países desarrollados.

- En el punto más alto de 2011, 34\% de las víctimas de la trata de personas a nivel mundial fueron niños: un aumento a partir de 13\% en 2004.

- Mundialmente, 30\% de las personas detenidas en el período entre 2012 y 2014 no habían recibido sentencia.

- Los nacimientos de más de uno de cada cuatro niños menores de 5 años en todo el mundo todavía siguen sin registrarse. En los PMA, uno de cada dos niños no había sido registrado al cumplir los cinco años. 


\section{Objetivo 17: Fortalecer los medios de implementación y revitalizar la Alianza Mundial para el Desarrollo Sostenible}

La Agenda 2030 requiere alianzas mundiales revitalizadas y mejoradas que movilicen todos los recursos disponibles de gobiernos, la sociedad civil, el sector privado, el sistema de las Naciones Unidas y otros actores. Aumentar el apoyo a los países en desarrollo, en particular a los PMA, los países en desarrollo sin litoral y los pequeños estados insulares en desarrollo, es fundamental para lograr un progreso equitativo para todos.

- La asistencia oficial para el desarrollo (AOD) ascendió en total a 131.600 millones de dólares en 2015, lo que era 6,9\% superior en términos reales que en 2014 y representa el nivel más alto alcanzado hasta el momento.

- La relación entre el servicio de deuda y la exportación bajó significativamente en el período 2000 a 2012, descendiendo de 11,7 en el año 2000 a menos de 2,7 en 2012.

- En 2015, la penetración de la banda ancha fija de Internet alcanzó un 29\% en las regiones desarrolladas, pero solamente un $7,1 \%$ en las regiones en desarrollo y un $0,5 \%$ en los PMA.

- Aunque la proporción de exportaciones de mercancías de los PMA en exportaciones totales casi se duplicó entre los años 2000 y 2014, todavía representa solo una pequeña fracción de las exportaciones mundiales en 2014, de 1,1\%.

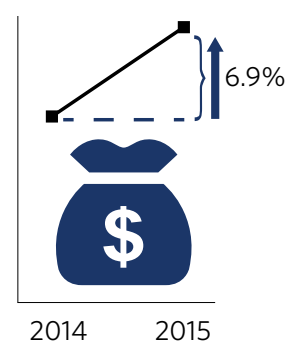

2014
La AOD sumó 131.600 millones de dólares estadounidenses en 2015 , un aumento de $6,9 \%$ en términos reales desde 2014

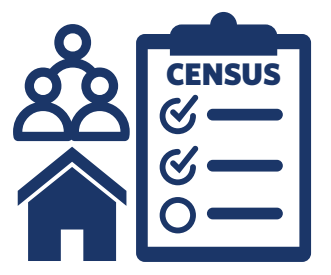

El $90 \%$ de todos los países realizaron censos de población y viviendas durante el período 2006-2015

- Noventa por ciento de todos los países y $88 \%$ de los países en desarrollo realizaron un censo de población y vivienda en el período entre 2006 y 2015, lo que significa una fuente esencial de datos.

\section{Asegurarse de no dejar a nadie atrás}

Al lanzar la Agenda 2030 para el Desarrollo Sostenible, los Estados Miembros reconocieron que la dignidad de la persona es fundamental y que los Objetivos y metas de la Agenda deberían cumplirse para todos los países y pueblos, y para todos los segmentos de la sociedad. Además, se empeñarán en alcanzar primero a aquellos que están más atrás. Ir más allá de la retórica en este aspecto no será un asunto simple, ya que los datos desglosados nos indican que los beneficios del desarrollo están lejos de compartirse de manera equitativa.

- En 2015, la tasa de desempleo de los jóvenes (personas entre 15 y 24 años de edad) se encontraba en 15\% a nivel mundial: más de tres veces la tasa para los adultos (4.6\%).

- A nivel mundial en 2015, los nacimientos en el $20 \%$ de los hogares más ricos tenían dos veces más probabilidades de ser atendidos por personal sanitario especializado que los del $20 \%$ de los hogares más pobres ( $89 \%$ en comparación con el 43\%).

- Los niños de los hogares más pobres tienen dos veces más posibilidad de sufrir retraso de crecimiento que los de los hogares más ricos.

- Casi el 80\% de la población urbana tiene acceso a agua corriente en comparación con una tercera parte de la población rural.
- Los PMA, los países en desarrollo sin litoral y los pequeños estados insulares en desarrollo, todos informaron una prevalencia de subalimentación que fue sustancialmente superior a la de las regiones en desarrollo en su totalidad (13,6, 9,8 y 5,1 puntos porcentuales más altos, respectivamente) en 2014-2016.

El principio fundamental de la Agenda para el 2030 es no dejar a nadie atrás. Sin embargo, sin datos e indicadores que aborden grupos específicos dentro de una población, incluyendo los más vulnerables, no será posible implementar totalmente los compromisos asumidos en los ODS. Ya se ha comenzado a realizar un esfuerzo a nivel mundial para mejorar la disponibilidad de datos y su uso, incluso a través de mejoras en la integración de recursos de datos. Pero hay mucho trabajo por delante. La comunidad estadística mundial está dispuesta para transformar y modernizar la manera en que este trabajo se está realizando de modo que se satisfagan plenamente las necesidades actuales y se cumpla nuestra promesa a las generaciones presente y futuras.

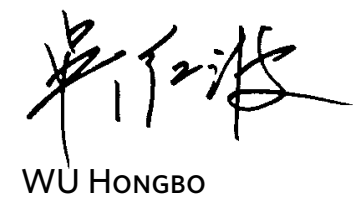

Secretario General Adjunto de Asuntos Económicos y Sociales 


\section{Objetivo 1: Poner fin a la pobreza en todas sus formas y en todo el mundo}

Al firmar la Agenda 2030, los gobiernos de todo el mundo se comprometieron a poner fin a la pobreza en todas sus manifestaciones, incluso en sus formas más extremas, en el curso de los próximos 15 años. Resolvieron que todas las personas, en todas partes, deberían contar con un nivel de vida básico. Esto incluye beneficios de protección social para los más pobres y vulnerables, y asegurar que las personas afectadas por conflictos y desastres naturales reciban el apoyo adecuado, incluyendo el acceso a servicios básicos.
Proporción de la población que vive con menos de 1,90 dólares al día, 2002 y 2012 (porcentaje)

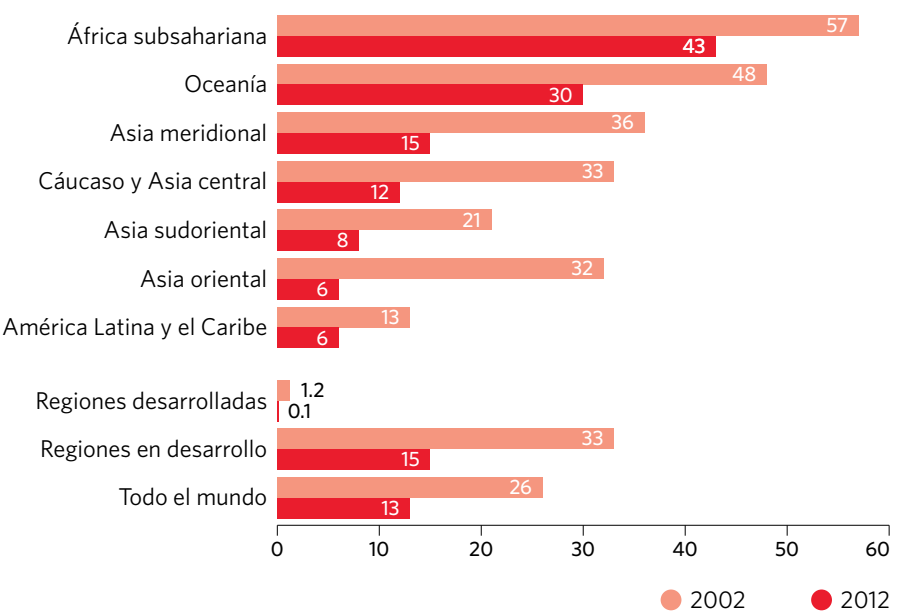

Nota: Las estimaciones regionales para África septentrional y Asia occidental no pudieron calcularse ya que los datos disponibles no cuentan con suficiente cobertura de población.

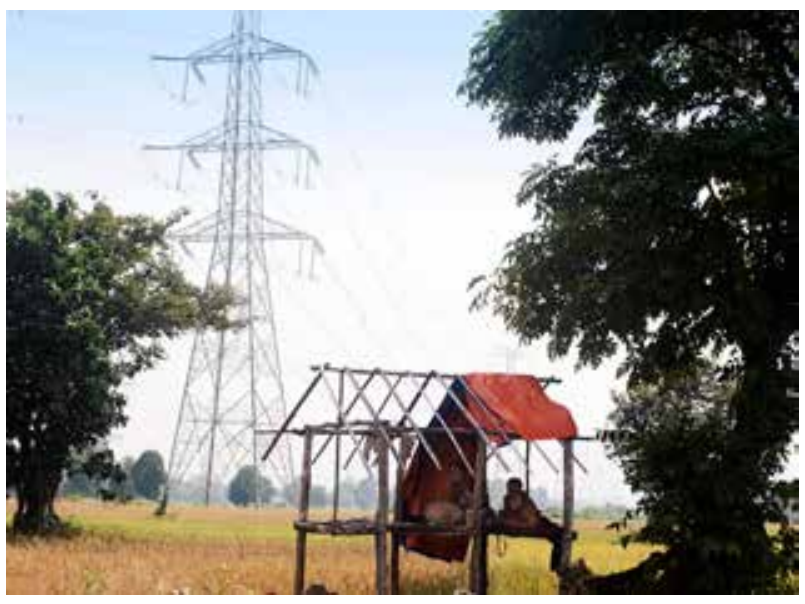

La pobreza se ha reducido a la mitad en el curso de una década, pero una de cada ocho personas en todo el mundo todavía vivía en pobreza extrema en 2012

El umbral internacional de la pobreza se define actualmente como 1,90 dólares por persona por día, utilizando la paridad del poder adquisitivo de 2011. En la década de 2002 a 2012, la proporción de la población mundial que vivía por debajo del umbral de pobreza se redujo a la mitad, de $26 \%$ a $13 \%$. Si las tasas de crecimiento económico observadas durante esos 10 años prevalecen durante los próximos 15, la tasa mundial para la pobreza extrema probablemente descienda a $4 \%$ para el 2030, suponiendo que el crecimiento beneficie a todos los grupos de ingresos de manera equitativa. La pobreza continúa siendo generalizada en África subsahariana, donde más del $40 \%$ de las personas vivían con menos de 1,90 dólares en 2012. 


\section{Entre los trabajadores pobres, los jóvenes tienen mayor probabilidad de verse afectados por la pobreza extrema}

En 2015, 10\% de los trabajadores del mundo y sus familias vivían con menos de 1,90 dólares por persona por día, a partir de $28 \%$ en el 2000 . Las personas jóvenes entre los 15 y 24 años tienen mayor probabilidad de encontrarse entre los trabajadores pobres: $16 \%$ de todos los jóvenes empleados vivían por debajo del umbral de pobreza en 2015, en comparación con el $9 \%$ de los trabajadores adultos. Una tercera parte de todos los trabajadores en África subsahariana y más del $18 \%$ de los trabajadores en Asia meridional se ubicaban entre los trabajadores pobres ese año.
Proporción de la población empleada que vive con menos de 1,90 dólares por día, total, jóvenes y adultos, 2000 y 2015 (porcentaje)

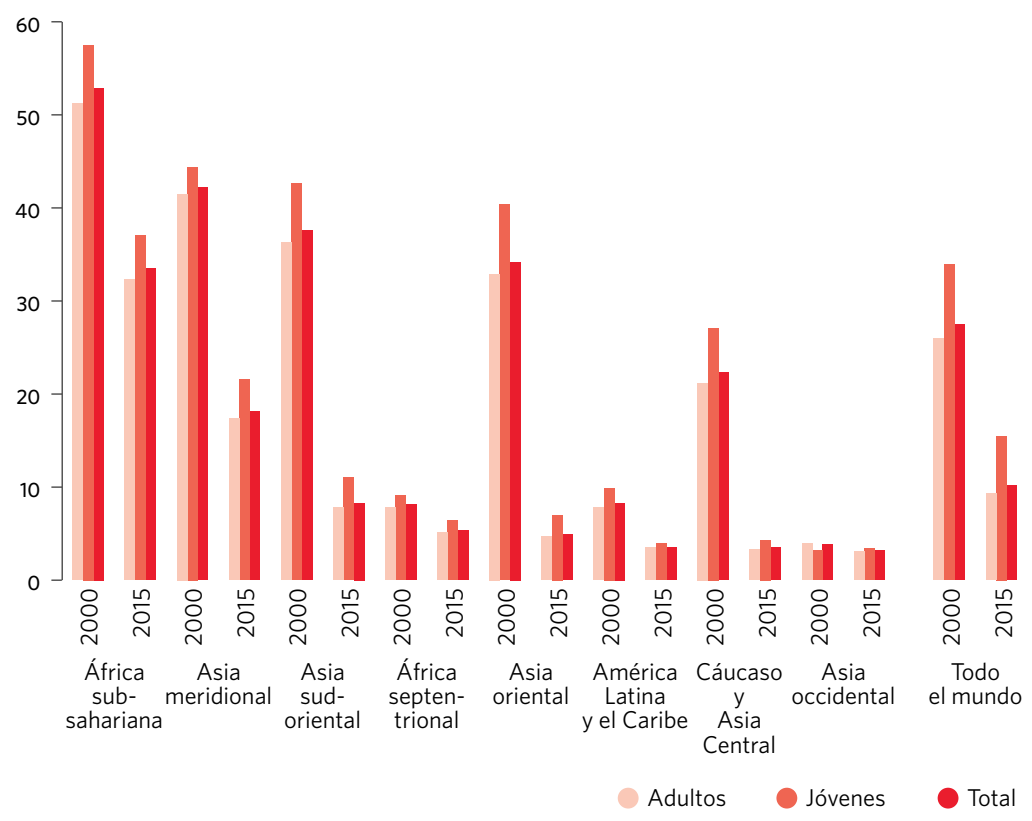

\section{Cerca de una de cada cinco personas recibe algún tipo de beneficio de protección social en los países de bajos ingresos}

\section{Una manera de continuar reduciendo la pobreza es} mediante la mejora de la cobertura de los programas de protección social y dirigiendo los beneficios a los más pobres y más vulnerables. Los programas de protección social incluyen asistencia social como transferencias de efectivo, alimentación escolar y asistencia alimentaria dirigida. Los programas de seguro social y mercado laboral son otras formas de protección social, que cubren pensiones por edad avanzada y discapacidad, beneficios por maternidad, seguro de desempleo, capacitaciones y subsidios de sueldos, entre otros. La mayoría de las personas pobres permanecen fuera de los sistemas de protección social, en particular en los países más pobres: cerca de una de cada cinco personas recibe algún tipo de prestación en los países de bajos ingresos, en comparación con dos de cada tres de los países de ingresos medianos-altos.
Proporción de la población que recibe prestaciones de protección social, año más reciente disponible entre 2000 y 2014 (porcentaje)

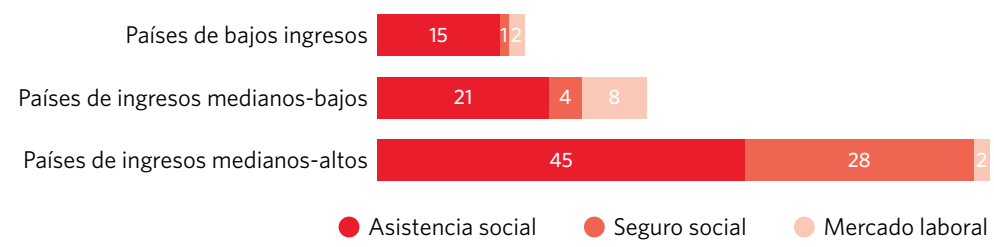




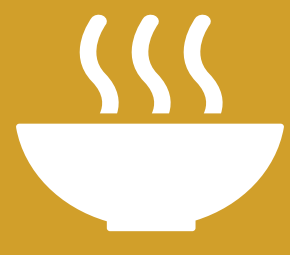

\section{Objetivo 2: Poner fin al hambre, lograr la seguridad alimentaria y la mejora de la nutrición y promover la agricultura sostenible}

El Objetivo 2 busca soluciones sostenibles para poner fin al hambre en todas sus formas para el año 2030 y alcanzar la seguridad alimentaria. La meta es asegurar que todos, en todas partes, tengan suficiente alimento de buena calidad para llevar una vida saludable. Lograr este objetivo requerirá un mejor acceso a los alimentos y la promoción amplia de la agricultura sostenible. Esto conlleva mejoras en la productividad y los ingresos de los agricultores en pequeña escala; el acceso equitativo a las tierras, la tecnología y los mercados; sistemas de producción de alimentos sostenibles y prácticas agrícolas resilientes. También requiere el aumento de la inversión a través de la cooperación internacional para estimular la capacidad productiva de la agricultura en países en desarrollo.

Cantidad y proporción de personas con subalimentación, 2000-2002 y 2014-2016 (millones y porcentajes)

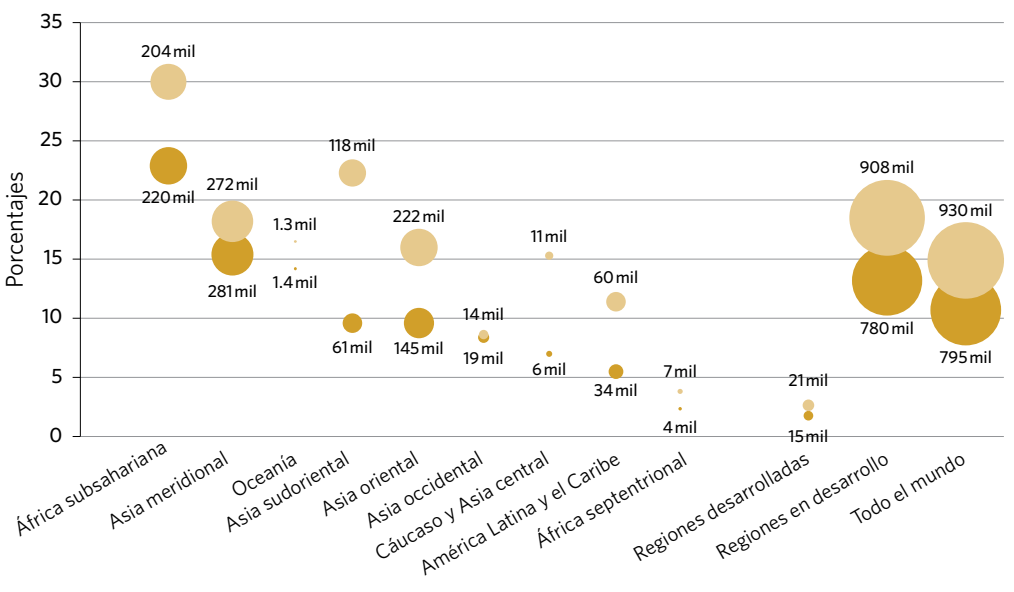

2000-2002 2014-2016

Nota: La posición vertical de los círculos representa el porcentaje de la población con subalimentación. El tamaño de los círculos representa la cantidad de personas con subalimentación. La proporción de personas con subalimentación es inferior al 5\% para África septentrional y Regiones desarrolladas para ambos períodos.

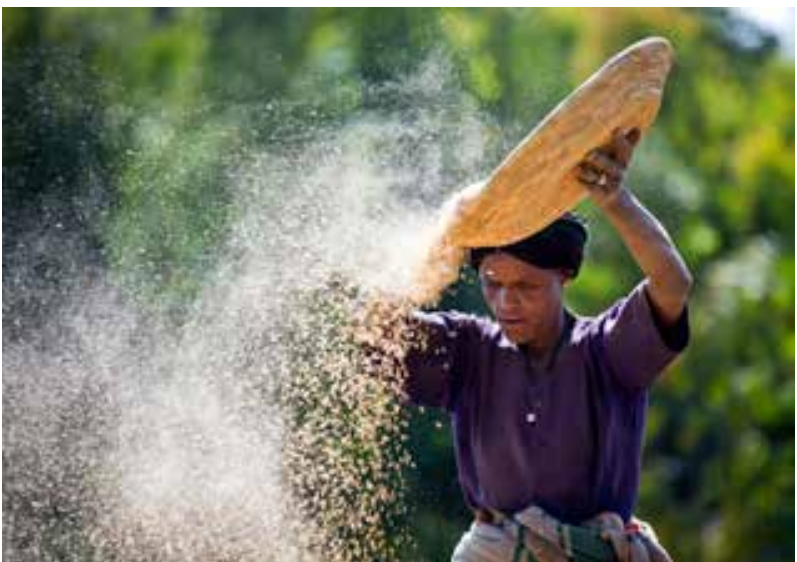

\section{A pesar del progreso, más de 790 millones de personas en todo el mundo padecen hambre}

La lucha contra el hambre ha logrado algún progreso en los últimos 15 años. A nivel mundial, la prevalencia del hambre bajó del 15\% en el período 2000-2002 al 11\% en 2014-2016. Sin embargo, más de 790 millones de personas todavía no cuentan con un acceso regular a alimentos adecuados. Si las tendencias actuales continúan, el objetivo de cero hambre estará lejos de alcanzarse en 2030. La persistencia del hambre ya no es un tema de disponibilidad de alimentos. Más bien, en muchos países que no lograron alcanzar la meta del hambre de los Objetivos de Desarrollo del Milenio, desastres naturales e inducidos por el hombre o la inestabilidad política han resultado en una inseguridad alimentaria que afecta a grandes grupos de la población. Las estimaciones preliminares de la Escala de Experiencia de Inseguridad Alimentaria, disponible para unos 150 países en 2014 y 2015, revelan que la mayor prevalencia de inseguridad alimentaria se encuentra en África subsahariana. Más de la mitad de la población adulta en dicha región enfrentó niveles moderados o severos de inseguridad alimentaria, y una cuarta parte enfrentó niveles graves. Asia meridional se ubica en el segundo lugar de mayor prevalencia: allí alrededor del 25\% de los adultos experimentan niveles de inseguridad alimentaria moderada o grave y el $12 \%$ experimenta niveles graves. 


\section{La desnutrición crónica o el retraso de crecimiento todavía afecta a uno de cada cuatro niños menores de 5 años}

En 2014, se estima que 158,6 millones de niños menores de 5 años padecieron retrasos en el crecimiento, una forma crónica de desnutrición definida por una altura inadecuada para la edad. La desnutrición crónica pone a los niños en mayor riesgo de morir por infecciones comunes, aumenta la frecuencia y gravedad de infecciones y contribuye a un retraso en la recuperación. También se vincula con una capacidad cognitiva deteriorada y un menor desempeño escolar y laboral. A nivel mundial, la proporción de niños con retraso de crecimiento ha disminuido en todas las regiones salvo en Oceanía. Asia meridional ha realizado el mayor progreso entre 2000 y 2014, pero la región todavía cuenta con el mayor número de niños con retraso de crecimiento en el mundo: 63.9 millones. En África subsahariana, el crecimiento de la población superó el progreso: la cantidad de niños con retraso de crecimiento aumentó de un estimado de 50,1 millones en 2000 a 57,3 millones en 2014. Juntos, Asia meridional y África subsahariana representaron tres cuartos de los niños menores de 5 años afectados por retraso de crecimiento en 2014.

\section{La proporción de niños menores de 5 años con sobrepeso ha aumentado en casi un $20 \%$}

A nivel mundial, la proporción de niños menores de 5 años que padecen sobrepeso aumentó de 5,1\% en 2000 a $6,1 \%$ en 2014. El sobrepeso es un problema creciente que afecta a casi todas las regiones. África septentrional tiene la mayor prevalencia de niños menores de 5 años con sobrepeso (16\%), seguida por el Cáucaso y Asia central (12,4\%). A nivel mundial, 41 millones de niños en este grupo etario tienen sobrepeso; casi la mitad de ellos viven en Asia y una cuarta parte vive en África.
Proporción de niños menores de 5 años con retraso de crecimiento, 2000 y 2014 (porcentaje)

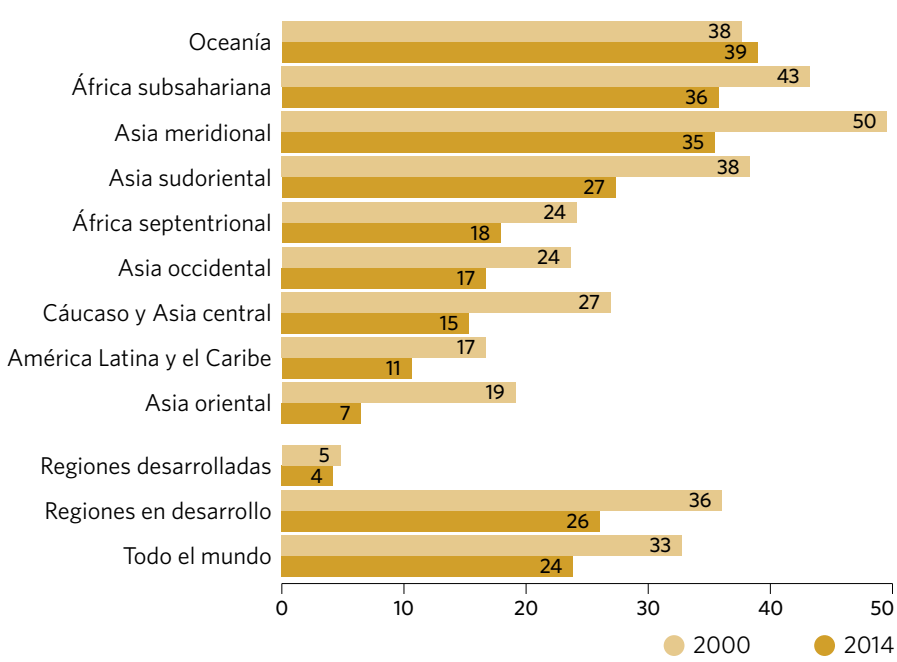

Proporción de niños menores de 5 años con sobrepeso, 2000 y 2014 (porcentaje)

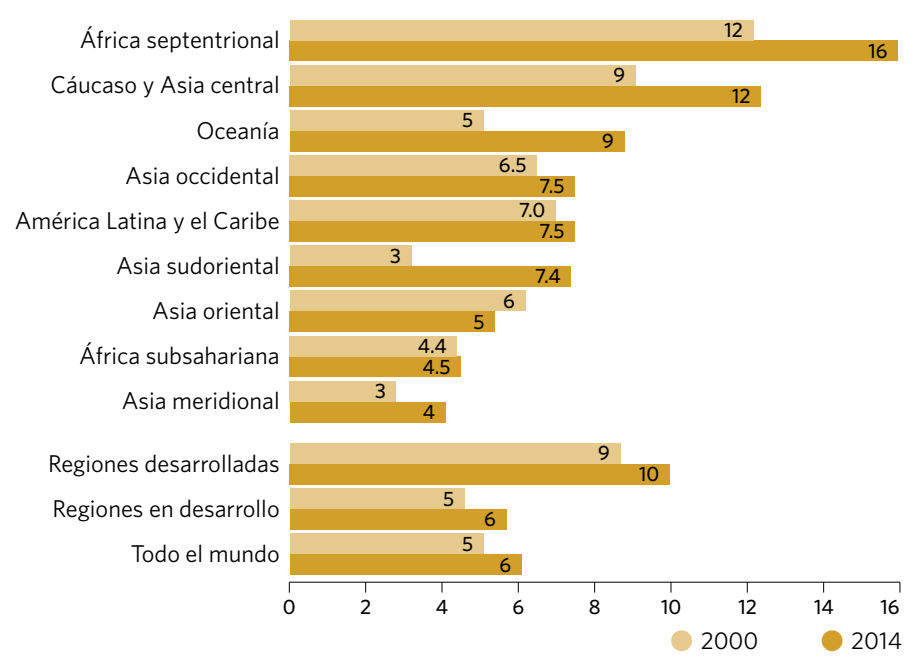

Nota: La cobertura de la población para regiones desarrolladas es menor al 50\% para todos los períodos entre 2000 y 2014.

\section{La participación de la agricultura en los gastos gubernamentales queda cada vez más rezagada en su contribución económica}

La capacidad productiva de la agricultura depende de inversiones de fuentes públicas y privadas, nacionales y extranjeras. Las recientes tendencias en los gastos gubernamentales no han sido favorables. El índice de orientación agrícola (IOA) (la participación de la agricultura en los gastos gubernamentales dividido por su participación en el PIB) cayó de 0,37 a 0,33 entre 2001 y 2013 en los países en desarrollo. El descenso fue interrumpido solo durante la crisis de precios de alimentos de 2006 a 2008, cuando los gobiernos aumentaron los gastos en agricultura. Desde fines de la década de 1990, la ayuda a la agricultura en los países en desarrollo ha languidecido en cerca del $8 \%$ del total, disminuyendo de un pico de $20 \%$ a mediados de los años 80 cuando los donantes se enfocaban más en mejorar la gobernabilidad, crear capital social y apuntalar los estados frágiles.
Proporción de la agricultura en los gastos gubernamentales, participación de la agricultura en el PIB (porcentaje) e índice de orientación agrícola (IOA) para el mundo, regiones desarrolladas y en desarrollo, 2001-2013

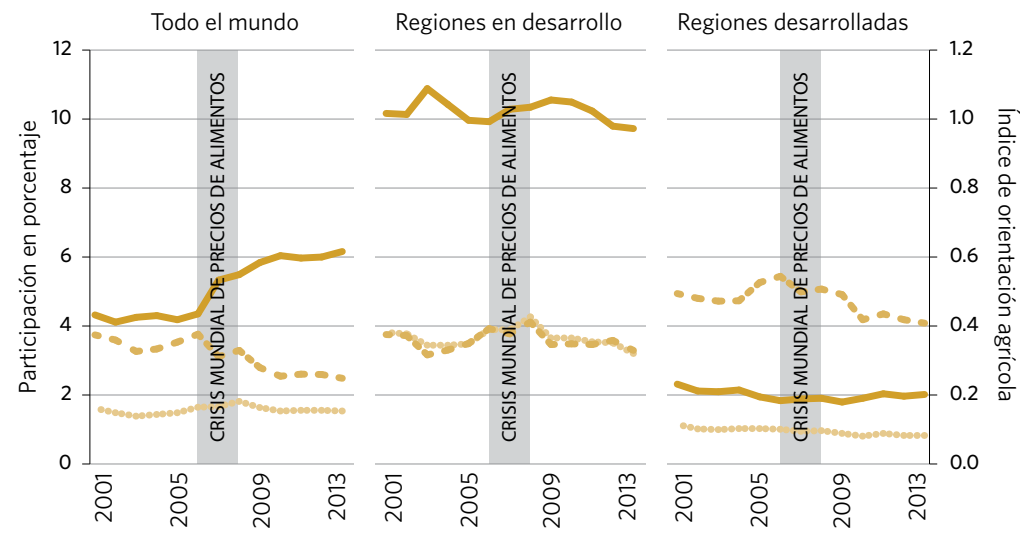

- Participación de la agricultura en el PIB (eje izquierdo)

.000. Participación de la agricultura en los gastos gubernamentales (eje izquierdo)

- Índice de orientación agrícola (eje derecho) 


\section{Objetivo 3: Garantizar una vida sana y promover el bienestar de todos a todas las edades}

El Objetivo 3 aspira a garantizar la salud y el bienestar para todos, en cada etapa de la vida. La meta es mejorar la salud reproductiva, materna e infantil; poner fin a las epidemias de VIH/SIDA, paludismo, tuberculosis y las enfermedades tropicales desatendidas; reducir las enfermedades no transmisibles y ambientales; alcanzar la cobertura sanitaria universal y asegurar el acceso universal a medicamentos y vacunas seguros, asequibles y eficaces. Con tal fin, los líderes de todo el mundo se han comprometido a apoyar la investigación y desarrollo, aumentar el financiamiento para la salud y fortalecer la capacidad de todos los países para reducir y controlar los riesgos para la salud.

Tasa de mortalidad materna, 1990-2015

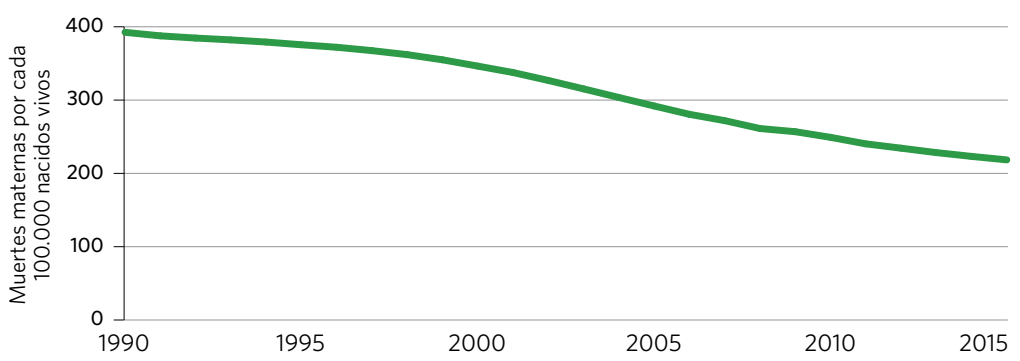

Tasa de mortalidad neonatal y de niños menores de 5 años, 1990-2015

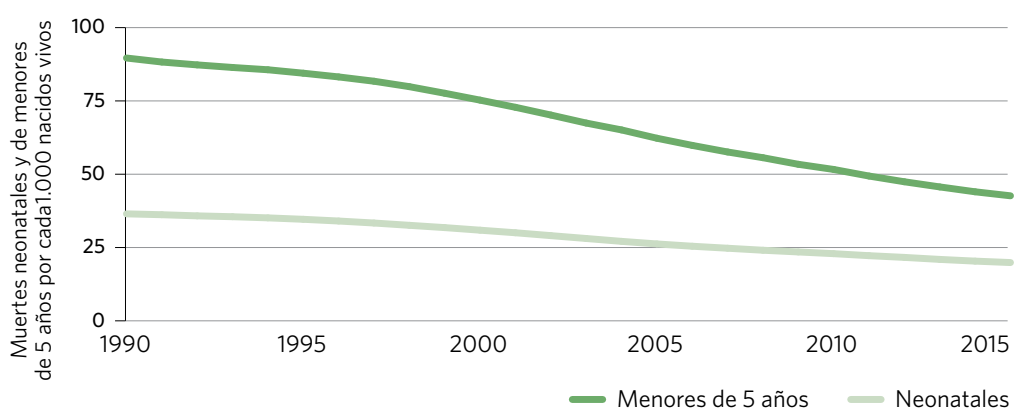

Las tasas de mortalidad materna, neonatal e infantil han disminuido drásticamente desde 1990, pero continúan siendo inaceptablemente altas

Entre 1990 y 2015, la tasa de mortalidad materna a nivel mundial disminuyó en un $44 \%$ a un estimado de 216 muertes por cada 100.000 niños nacidos vivos, sin alcanzar los Objetivos de Desarrollo del Milenio (ODM) y muy lejos del objetivo de 70 muertes maternas por cada 100.000 niños nacidos vivos establecidos por la Agenda para el 2030. Casi todas las muertes maternas ocurren en entornos de bajos recursos y pueden prevenirse, entre otros, mediante el acceso a servicios de higiene sexual y salud reproductiva apropiados. A nivel mundial, en 2015, aproximadamente tres de cada cuatro mujeres en edad reproductiva ( 15 a 49 años) que estaban casadas o en pareja satisfacían sus necesidades de planificación familiar mediante el uso de métodos anticonceptivos modernos. Solo tres de cada cuatro nacimientos se llevó a cabo con la asistencia de personal especializado en partos.

La tasa de mortalidad de niños menores de 5 años cayó rápidamente entre 1990 y 2015, disminuyendo por más de la mitad hasta 43 por cada 1000 niños nacidos vivos. Aun así, esto estuvo por debajo de la reducción de dos tercios previsto en los ODM y se estima que 5,9 millones de niños menores de 5 años murieron en 2015. La mayoría de estas muertes era prevenible. Durante este período de 25 años, el progreso en la supervivencia infantil en niños entre 1 a 59 meses superó los avances en la reducción de la mortalidad neonatal. Como resultado, una parte creciente de las muertes de niños menores de 5 años ocurre en el primer mes de vida (45\% en 2015). 


\section{La incidencia de las principales enfermedades transmisibles está disminuyendo, aunque cientos de millones de personas todavía padecen nuevas infecciones cada año}

La incidencia de VIH, paludismo y tuberculosis disminuyó a nivel mundial entre los años 2000 y 2015, lo que indica que se alcanzó el ODM 6. Sin embargo, dar fin a estas epidemias requerirá esfuerzos renovados. En 2015, la cantidad de nuevas infecciones de $\mathrm{VIH}$ a nivel mundial fue 0,3 por cada 1000 personas no infectadas, y se estima que 2,1 millones de personas se infectaron ese año. La incidencia del VIH fue más alta en África subsahariana, con 1,5 nuevos casos por cada 1000 personas no infectadas. En 2014, se informó de 9,6 millones de casos nuevos de tuberculosis (133 por cada 100.000 personas) en todo el mundo, correspondiendo el $58 \%$ de ellos a Asia sudoriental y el Pacífico occidental. Casi la mitad de la población mundial está en riesgo de paludismo; en 2015, la tasa de incidencia fue de 91 nuevos casos por cada 1000 personas en riesgo: un estimativo de 214 millones de casos. África subsahariana representó el $89 \%$ de todos los casos de paludismo a nivel mundial, con una tasa de incidencia de 235 por 1000 personas en riesgo.
Tasas de incidencia de VIH, paludismo y tuberculosis a nivel mundial, 2000-2015

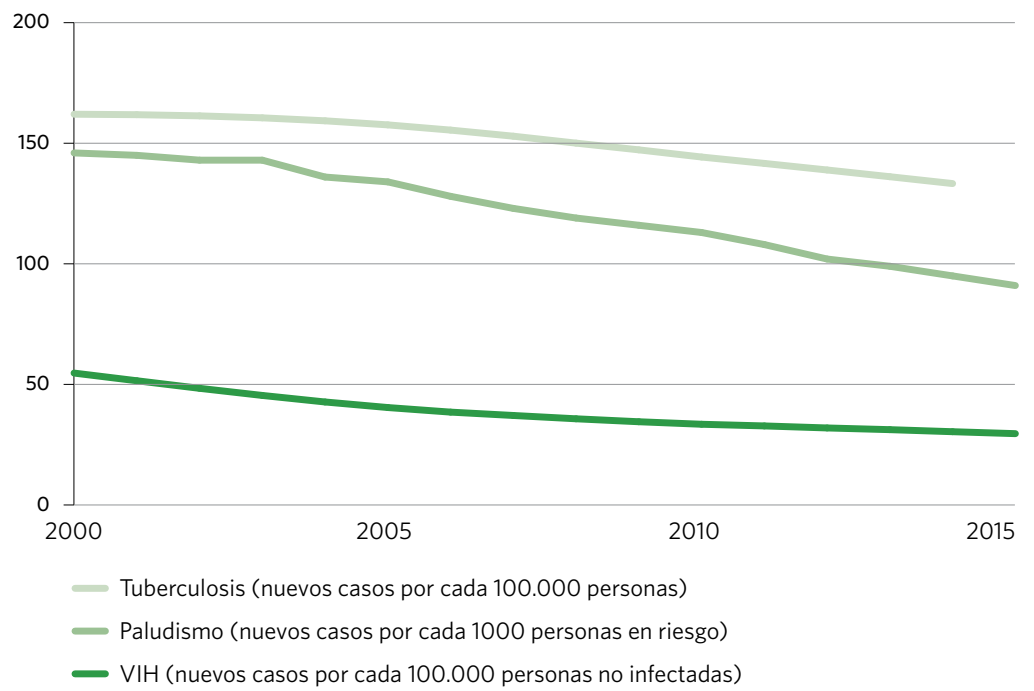

\section{Las enfermedades cardiovasculares y el cáncer representan casi dos terceras partes de las muertes vinculadas a enfermedades no transmisibles en personas menores de 70 años}

En 2012, las enfermedades no transmisibles (ENT) eran responsables de aproximadamente 38 millones de muertes por año, lo que representa el $68 \%$ de todas las muertes a nivel mundial. Entre las muertes en la población menor de 70 años, a las que comúnmente se refiere como "muertes prematuras", las ENT representaron el $52 \%$ de todas las muertes. Más de tres cuartas partes de las muertes prematuras por ENT fueron causadas por enfermedades cardiovasculares, cáncer, diabetes y enfermedades respiratorias crónicas. A nivel mundial, la mortalidad prematura de estas cuatro ENT principales disminuyó en un 15\% entre los años 2000 y 2012.
Proporción de muertes prematuras ${ }^{\star}$ debidas a enfermedades no transmisibles, por tipo, 2012 (porcentaje)

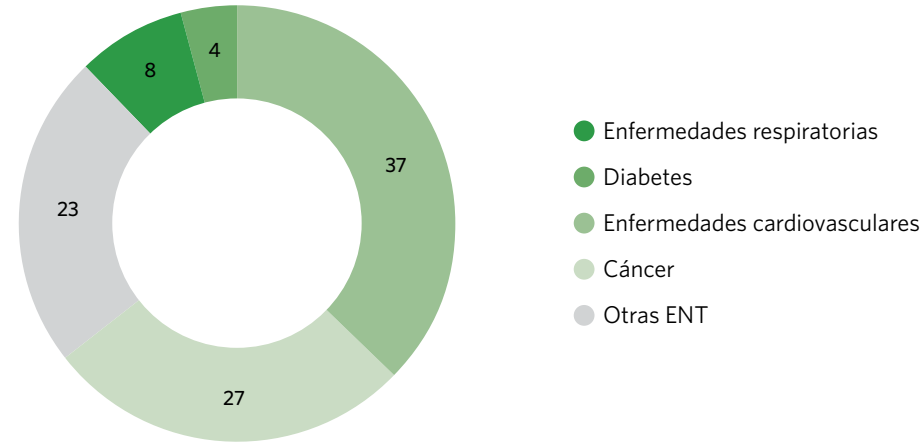

* Muertes prematuras se refiere a muertes en la población menor de 70 años. Nota: Debido a los redondeos, los porcentajes en la gráfica no suman 100.

\section{Las muertes por accidentes de tráfico en países de altos ingresos han descendido desde el año 2000, al tiempo que han aumentado significativamente en países de ingresos bajos y medianos}

Alrededor de 1,25 millones de personas murieron en accidentes de tráfico en 2013: un promedio de 3.400 cada día. Además, miles de millones de personas sufren lesiones o discapacidades cada año debido a accidentes de tráfico, siendo los niños, los peatones, los ciclistas y los adultos mayores los más vulnerables. Reducir a la mitad la cantidad de muertes y lesiones causadas por accidentes de tráfico a nivel mundial para el año 2020 es un objetivo ambicioso teniendo en cuenta el drástico aumento en la cantidad de vehículos que casi se duplicó entre los años 2000 y 2013.
Cantidad de muertes en accidentes de tráfico (miles) y vehículos en países de ingresos altos, bajos y medianos, 2000-2013

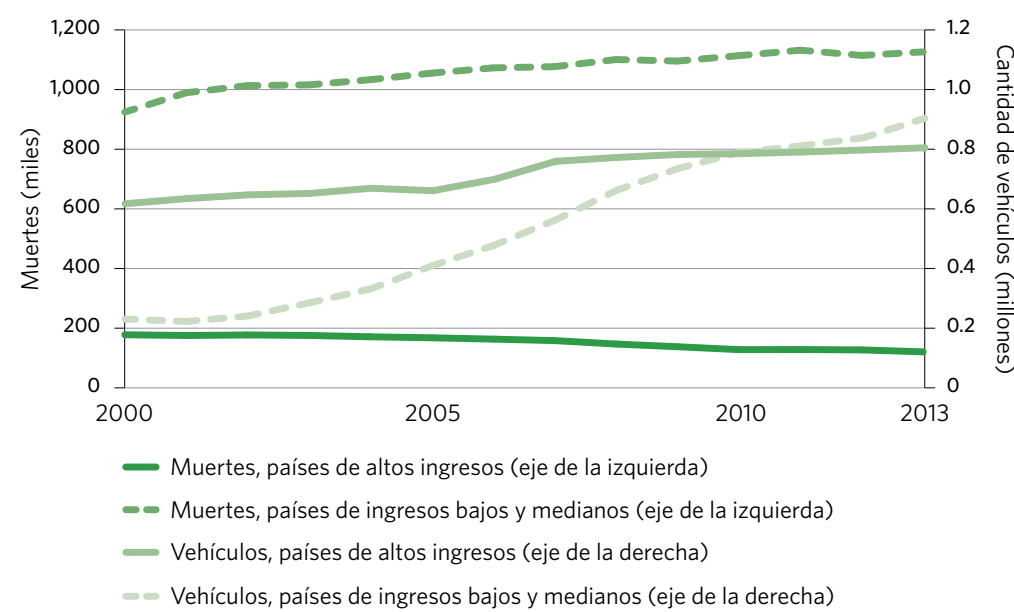




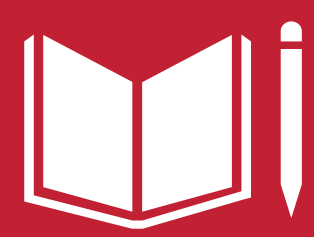

\section{Objetivo 4: Garantizar una educación inclusiva y equitativa de calidad y promover oportunidades de aprendizaje permanente para todos}

El Objetivo 4 busca asegurar que todas las personas tengan acceso a una educación de calidad y oportunidades de aprendizaje permanentes. El objetivo se enfoca en la adquisición de las competencias básicas y de orden superior en todas las etapas de la enseñanza y el desarrollo; en un acceso mayor y más equitativo a una educación de calidad en todos los niveles, así como en una educación y formación técnica y profesional (EFTP); y en el conocimiento, las habilidades y los valores necesarios para desempeñarse adecuadamente y contribuir a la sociedad.

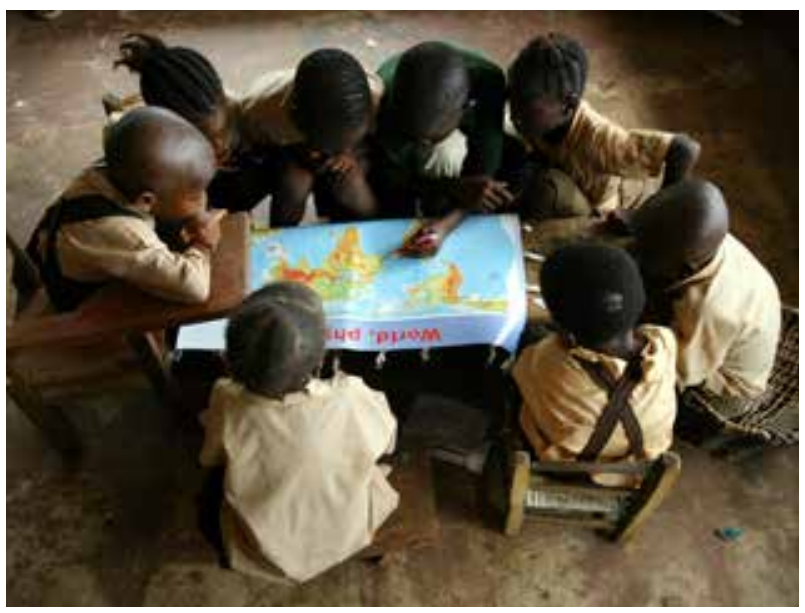

Los niños tienen menos probabilidades de asistir a la escuela si viven en zonas rurales, son pobres o sus padres tienen poca o nula educación

A pesar del progreso, el mundo no ha logrado alcanzar el Objetivo de Desarrollo del Milenio con respecto a la enseñanza primaria universal en 2015. En 2013, el último año con datos disponibles, 59 millones de niños en edad de asistir a la escuela primaria y 65 millones de adolescentes en edad de asistir a la escuela secundaria inferior no lo hacían; la mayoría eran niñas. Los datos de encuestas en 63 países de ingresos bajos o medianos, entre los años 2008 y 2012, muestran que los niños en edad de recibir educación primaria del $20 \%$ de los hogares más pobres tenían cuatro veces más probabilidades de no asistir a la escuela, en comparación con sus pares más ricos. Los niños-y en particular las niñas-de hogares con un jefe de hogar con un nivel de educación inferior a primaria tenían más de cuatro veces la probabilidad de no asistir a la escuela en comparación con aquellos en hogares cuyo jefe de hogar recibió una educación secundaria o superior. 


\section{Las competencias básicas ofrecen fundamentos sólidos para que los jóvenes continúen aprendiendo a lo largo de sus vidas}

Una educación de calidad debe conducir a la adquisición de competencias básicas, tales como la alfabetización y aritmética elemental, y competencias de nivel superior. La última etapa de la enseñanza secundaria inferior por lo general coincide con el final de la educación obligatoria. A esa altura, los estudiantes deberían ser capaces de dominar conocimientos teóricos y prácticos especializados, contar con aptitudes personales y sociales, y disponer de un fundamento sólido para continuar aprendiendo durante el resto de sus vidas. Los datos de 38 países en las regiones desarrolladas muestran que, en la mayoría de estos países, cerca del 75\% de los jóvenes alcanzaron al menos una competencia mínima en lectura y/o matemáticas; esto solo se observó en 5 de los 22 países con datos en las regiones en desarrollo.
Proporción de jóvenes a finales de la enseñanza secundaria inferior que alcanza al menos los niveles mínimos de competencia en lectura y matemáticas, países seleccionados, 2012 (porcentaje)

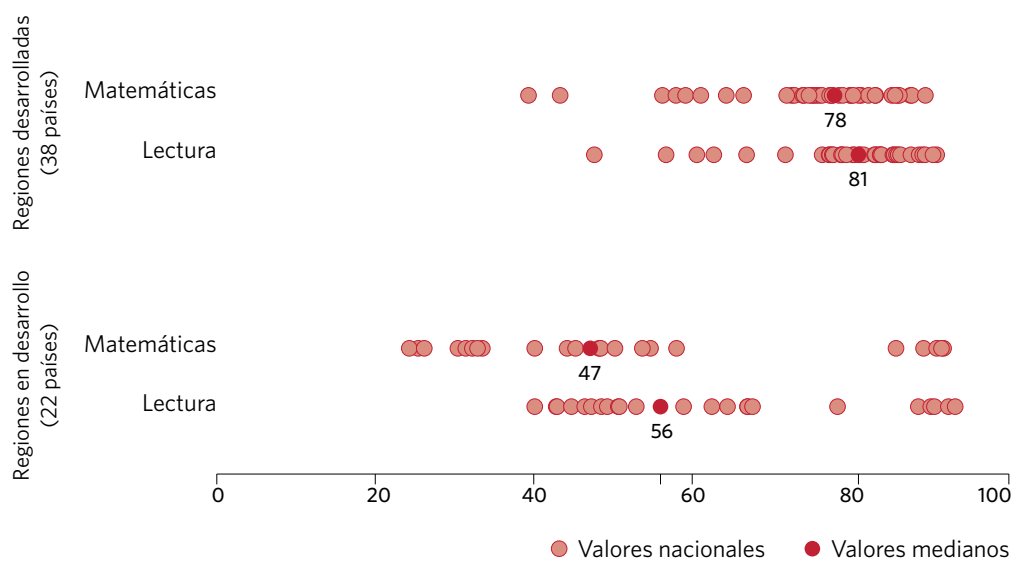

\section{Más de la mitad de los de niños entre 3 y 4 años de edad en países seleccionados tienen un desarrollo bien encauzado en cuanto a la salud, el aprendizaje y el bienestar psicosocial}

El desarrollo durante la primera infancia es multidimensional y abarca diversos aspectos del bienestar del niño: físico, social, emocional y mental. Independientemente de las variaciones en el ritmo de desarrollo de los niños, todos tienen el derecho inherente a desarrollarse a su máximo potencial. En 54 de 58 países con datos disponibles para el período de 2009 a 2015, al menos la mitad de los niños en edades entre 3 y 4 años estaban bien encauzados en cuanto a su desarrollo en al menos tres de las siguientes áreas: alfabetización-aritmética, desarrollo físico, desarrollo socio-emocional y aprendizaje.
Proporción de niños de 36 a 59 meses cuyo desarrollo está bien encauzado en a menos tres de las siguientes áreas: alfabetización-aritmética, desarrollo físico, desarrollo socio-emocional y aprendizaje, 2009-2015 (porcentaje)

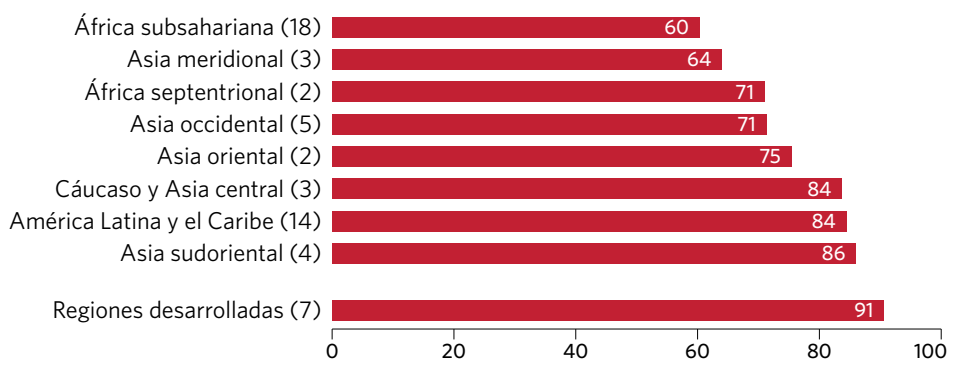

Nota: Datos disponibles para 58 países en el período de 2009 a 2015 que cubren el $18 \%$ de la población mundial. Los números entre paréntesis indican la cantidad de países con datos disponibles en la región.

\section{Oportunidades de aprendizaje de muchos tipos deberían extenderse durante toda la vida}

La educación para el desarrollo sostenible y la ciudadanía mundial aborda requisitos urgentes y generales de la sociedad tales como "vivir juntos" y la "relación con la naturaleza". Estas son vías cruciales para un futuro sostenible y pacífico para todos.

También se promueve el acceso equitativo a la educación y formación técnica y profesional (EFTP) y a la educación superior. Aunque las inscripciones a la EFTP en secundaria superior aumentaron en un tercio entre 2000 y 2013 , el porcentaje cayó de $26 \%$ a $22 \%$. La enseñanza terciaria se ha expandido rápidamente en el mismo período: las inscripciones se duplicaron a nivel mundial y aumentaron en 2,5 veces en regiones en desarrollo, siendo la cantidad de inscripciones de hombres y mujeres casi igual. Sin embargo, en 2013 a nivel mundial, todavía había 757 millones de adultos que no sabían leer ni escribir, de los cuales dos tercios eran mujeres.

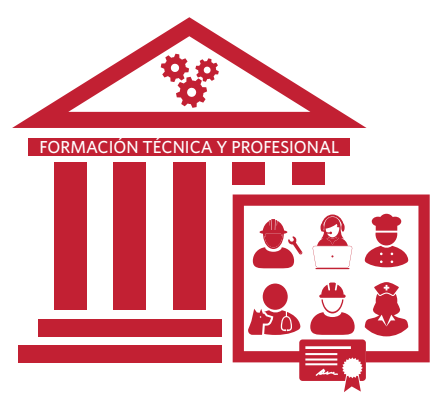

Las inscripciones en la educación y formación técnica y profesional (EFTP) de la enseñanza secundaria superior aumentó casi un tercio entre 2000 y 2013

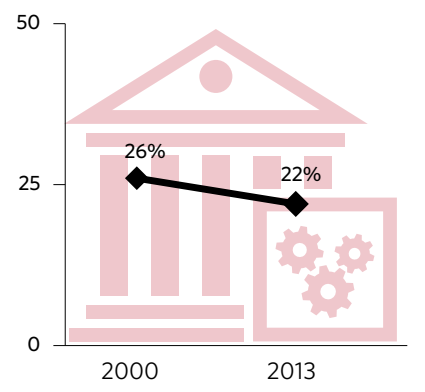

La participación de la EFTP en el total de inscripciones de la enseñanza secundaria disminuyó de $\mathbf{2 6 \%}$ a $22 \%$ 


\section{Objetivo 5: Lograr la igualdad de género y empoderar a todas las mujeres y las niñas}

Empoderar a mujeres y niñas para alcanzar su máximo potencial requiere igualdad de oportunidades con hombres y niños. Esto significa eliminar todas las formas de discriminación y violencia en su contra, incluyendo la violencia por parte de sus compañeros íntimos, la violencia sexual y las prácticas nocivas como el matrimonio infantil y la mutilación genital femenina (MGF). Asegurar que las mujeres tengan mejor acceso a empleos remunerados, salud sexual y reproductiva y derechos reproductivos, y poder real para la toma de decisiones en esferas públicas y privadas, asegurará aún más que el desarrollo sea equitativo y sostenible.

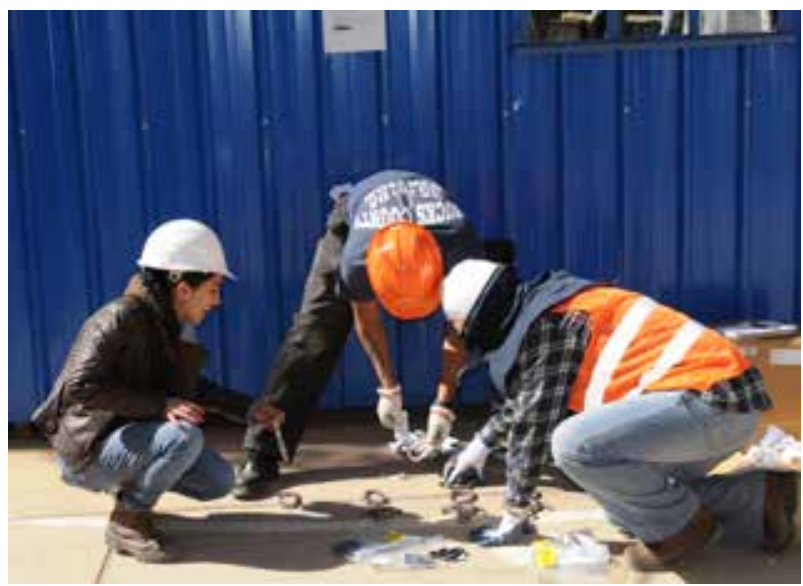

Proporción de mujeres de entre 20 y 24 años que estaban casadas o mantenían una unión estable antes de cumplir los 15 años y antes de cumplir los 18 años, 1990 y 2015 (porcentaje)

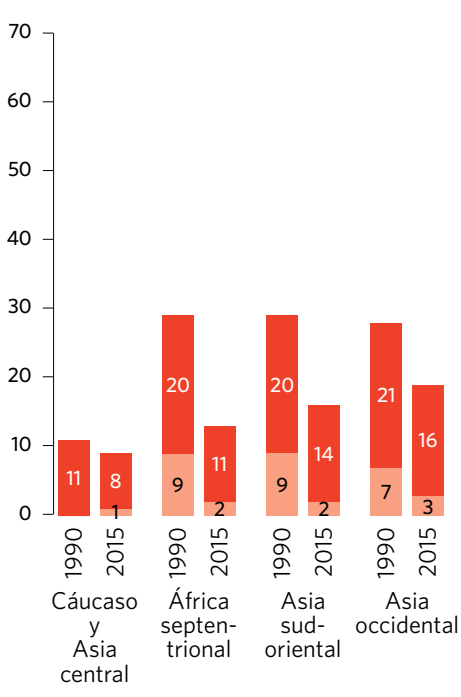

- Casadas/en unión estable antes de cumplir los 15 años

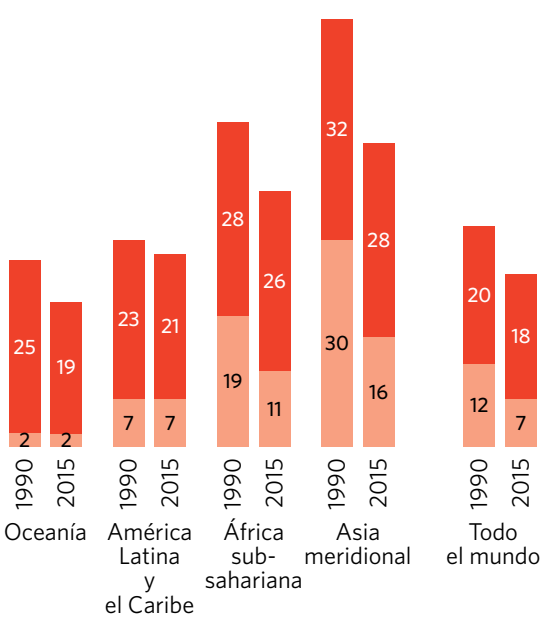

- Casadas/en unión estable después de cumplir los 15 años, pero antes de cumplir 18
Nota: Los datos para el 2015 refieren a los últimos datos disponibles recopilados entre 2010 y 2014 Debido a los redondeos, los porcentajes en la gráfica no suman los totales.
Las tasas de matrimonio infantil en general han disminuido pero permanecen en niveles inaceptables en Asia meridional y África subsahariana

La práctica del matrimonio infantil está disminuyendo lentamente. En todo el mundo, la proporción de mujeres entre 20 y 24 años de edad que informaron haber contraído matrimonio antes de cumplir los 18 años disminuyó de 32\% alrededor de 1990 a 26\% alrededor de 2015. El matrimonio infantil es más común en Asia meridional y África subsahariana, con tasas de $44 \%$ y $37 \%$ respectivamente. De hecho, los 10 países con las tasas más altas en el mundo se encuentran en estas dos regiones. Las tasas de matrimonios de niñas menores de 15 años también son más altas en Asia meridional y África subsahariana, ascendiendo a $16 \%$ y $11 \%$ respectivamente. Sin embargo, las normas sociales pueden cambiar y lo hacen. El matrimonio de niñas menores de 15 años disminuyó a nivel mundial de $12 \%$ en 1990 a $7 \%$ en la actualidad, aunque persisten desigualdades a través de las regiones e incluso los países. El mayor progreso en la reducción del matrimonio infantil en general se ha registrado en África septentrional, donde la proporción de casamientos infantiles cayó por más de la mitad en los últimos 25 años, de 29\% a 13\%. 


\section{A pesar del progreso, más de una de cada tres niñas en edades de 15 a 19, en los 30 países en que se concentra esta práctica, han sufrido mutilación genital femenina}

La MGF es una violación a los derechos humanos que afecta a niñas y mujeres en todo el mundo, en particular en países en los que es una norma social arraigada. Al menos 200 millones de mujeres y niñas han sido mutiladas en 30 países en los que se concentra la práctica y que tienen datos de prevalencia representativos. Las tasas de MGF en general han descendido en más del $25 \%$ en el curso de las últimas tres décadas. No obstante, no todos los países han logrado un progreso y el ritmo de descenso ha sido desigual. En la actualidad, en estos 30 países, más de una de cada tres niñas en edades entre 15 y 19 años han sido sometidas a este procedimiento en comparación con una de cada dos a mediados de la década de 1980.

Diferentes formas de violencia, incluyendo violencia física, sexual, psicológica y económica, así como el tráfico y otras formas de explotación sexual, afectan a millones de mujeres y niñas en todo el mundo. Esto no solo constituye una grave violación a los derechos humanos, sino que también inhibe el proceso de desarrollo. Datos disponibles comparables de 52 países (que incluyen un solo país de las regiones desarrolladas) indican que el $21 \%$ de las niñas y mujeres en edades entre 15 y 49 años sufrieron y/o sufren violencia sexual de manos de su compañero íntimo en los 12 meses anteriores a la entrevista.
Proporción de niñas y mujeres entre 15 y 19 años que han sufrido mutilación genital femenina en los 30 países en los que se concentra esta práctica, 1985-2015 (porcentaje)

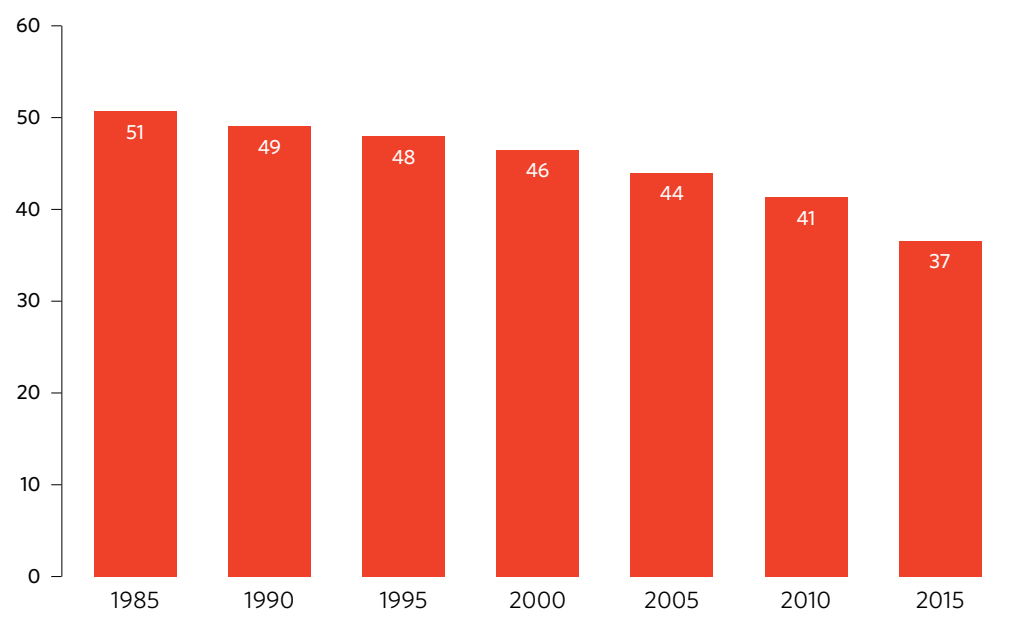

\section{Las mujeres en los países en desarrollo dedican cuatro veces más horas a trabajos no remunerados que los hombres}

En cada región, las mujeres y las niñas realizan la mayor parte del trabajo no remunerado, lo que incluye la atención a otras personas y tareas domésticas tales como cocinar y limpiar. Las mujeres informan que, en promedio, dedicaron $19 \%$ de su tiempo cada día a trabajo no remunerado, en comparación con el $8 \%$ de los hombres. Las responsabilidades de la atención a otras personas y las labores domésticas no remuneradas, en combinación con el trabajo remunerado, significa que las mujeres y las niñas trabajan más horas que los hombres y los niños, y que tienen menos tiempo para el descanso, el cuidado de sí mismas, el apredizaje y otras actividades.
Proporción de tiempo dedicado a trabajo remunerado y no remunerado en países seleccionados, hombres y mujeres, 2000-2014 (porcentaje de tiempo dedicado por día)

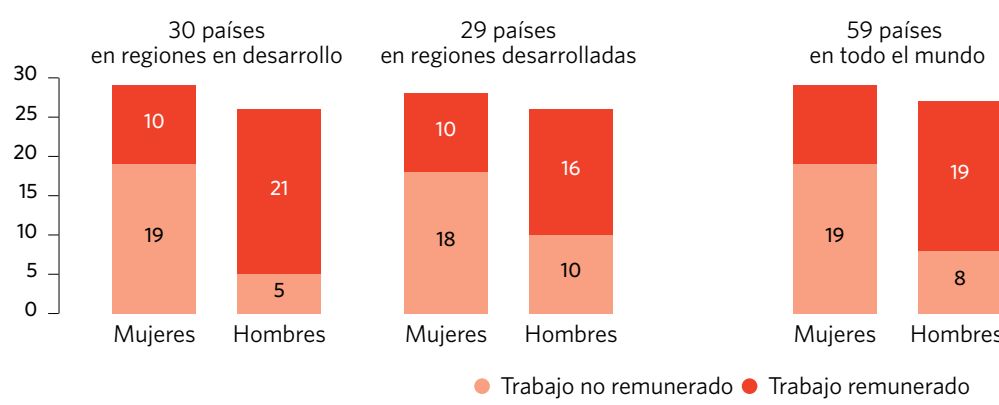

Nota: La información se basa en las encuestas sobre el uso del tiempo realizadas entre los años 2000 y 2014 en 59 países: 30 en regiones en desarrollo y 29 en regiones desarrolladas.

\section{Las mujeres solo ocupan el $23 \%$ de los escaños del parlamento en todo el mundo}

La proporción de escaños ocupados por mujeres en las cámaras baja y unicameral de los parlamentos nacionales ascendió a $23 \%$ en 2016 . Esto representa en promedio un aumento de 0,6 puntos porcentuales por año desde 2006 y un aumento de 6 puntos porcentuales en el curso de una década. El lento progreso en esta área contrasta con el más rápido desarrollo de las mujeres en cargos de liderazgo parlamentario. En 2016, la cantidad de mujeres presidentes de parlamentos aumentó de 43 a 49 (de 273 puestos en total); las mujeres representaron el $18 \%$ de todos los presidentes de parlamento en enero de 2016
Proporción de escaños ocupados por mujeres en las cámaras baja y unicameral de los parlamentos nacionales, 2016 (porcentaje)

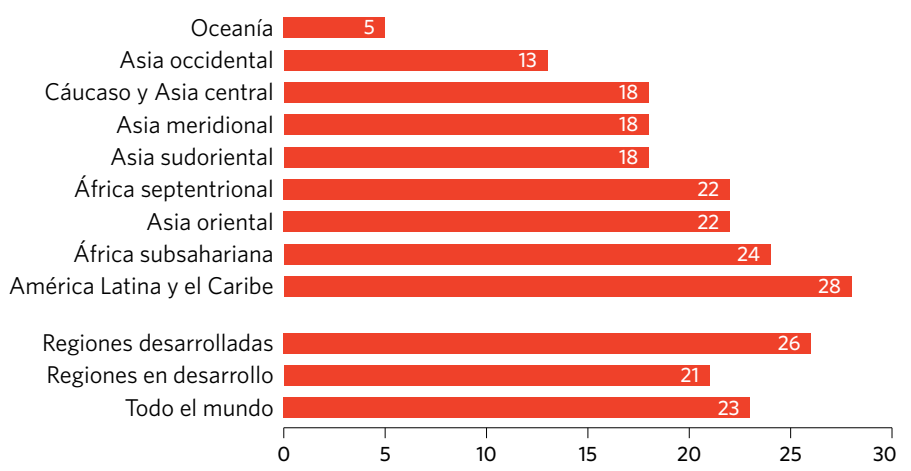




\section{Objetivo 6: Garantizar la disponibilidad y la gestión sostenible del agua y el saneamiento para todos}

El Objetivo 6 de Desarrollo Sostenible va más allá del agua potable, el saneamiento y la higiene, para abordar también la calidad y sostenibilidad de los recursos hídricos que son esenciales para la supervivencia de las personas y del planeta. La Agenda 2030 reconoce la importancia central de los recursos de agua para el desarrollo sostenible y el papel vital que juega la mejora en el suministro de agua potable, el saneamiento y la higiene en el progreso de otras áreas, entre las que se incluyen la salud, la educación y la disminución de la pobreza.

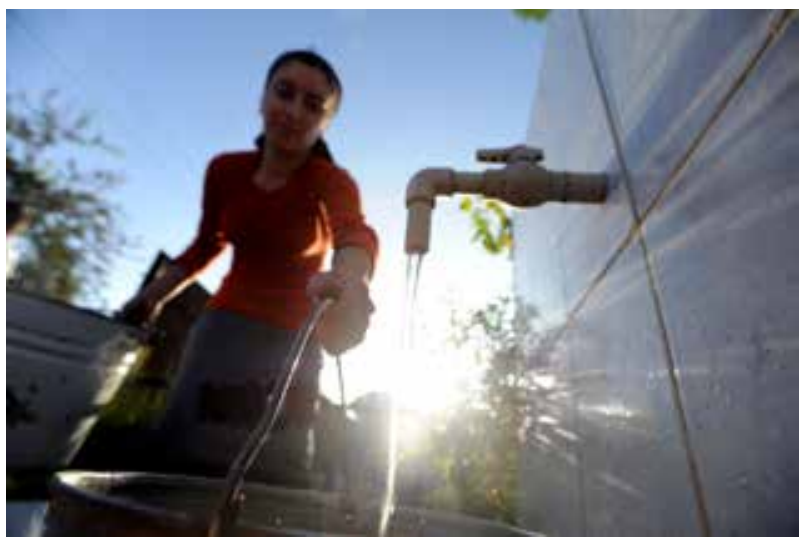

Nivel de estrés por la escasez de agua: extracción de agua dulce como proporción de los recursos de agua dulce disponibles, alrededor de 2012 (porcentaje)

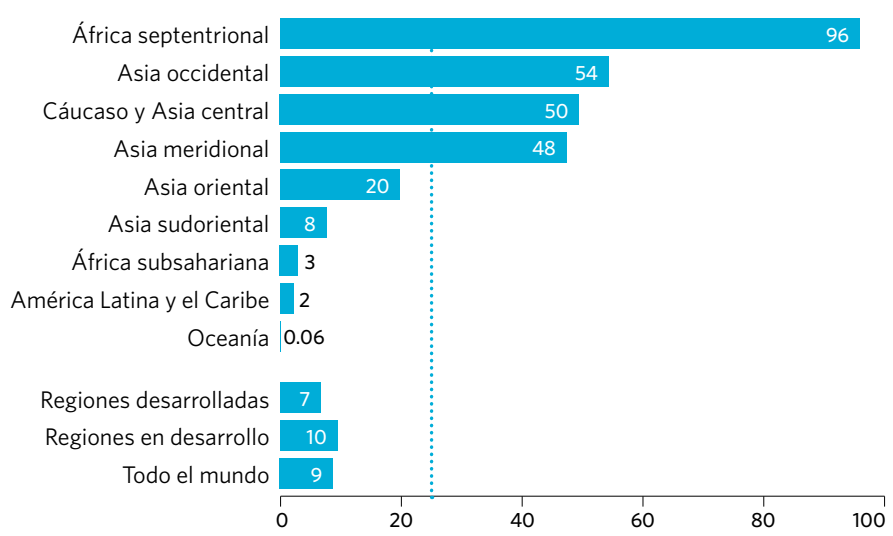

25\%: Umbral que marca el inicio de las etapas de estrés por escasez de agua

\section{Un número cada vez mayor de países enfrentan el estrés por la escasez de agua que ahora afecta a más de 2 mil millones de personas a nivel mundial}

La gestión holística del ciclo de agua significa considerar el nivel de "estrés por la escasez de agua", calculado como la proporción entre el total de agua dulce extraída por todos los sectores principales y el total de recursos de agua dulce renovables en un país o región en particular. Actualmente, el estrés por la escasez de agua afecta a más de dos mil millones de personas en todo el mundo, una cifra que se proyecta que aumentará. La escasez de agua ya afecta a países en cada continente y obstaculiza la sostenibilidad de los recursos naturales, además del desarrollo económico y social. Aunque muchas regiones están por debajo del umbral del $25 \%$ que marca el inicio de las etapas de estrés físico por la escasez de agua, se pueden encontrar enormes diferencias dentro y entre los países. En 2011, 41 países experimentaban estrés por escasez de agua, lo que significa un aumento a partir de los 36 países en 1998. De estos, 10 países (en la Península Arábica, Asia central y África septentrional) extrajeron más de $100 \%$ de sus recursos renovables de agua dulce. 


\section{Más del $\mathbf{9 0 \%}$ de las personas en todo el mundo cuentan con mejoras en el suministro de agua potable, pero no todas las fuentes se administran de manera segura}

En 2015, 6.600 millones de personas, o 91\% de la población mundial, contaban con mejoras en el suministro de agua potable, en comparación con el 82\% en 2000. Se estima que 663 millones de personas todavía no contaban con mejoras en el suministro de agua potable o usaban aguas superficiales en 2015. Aunque la cobertura era de alrededor de $90 \%$ o más en todas las regiones, excepto África subsahariana y Oceanía, persisten amplias desigualdades dentro y entre los países. Por otra parte, no todos los suministros de agua mejorados se gestionan de manera segura. Por ejemplo, en 2012, se estimaba que al menos 1.800 millones de personas estaban expuestas a agua potable contaminada con materia fecal.
Proporción de la población que cuenta con mejoras en el suministro de agua potable, 2000 y 2015 (porcentaje)

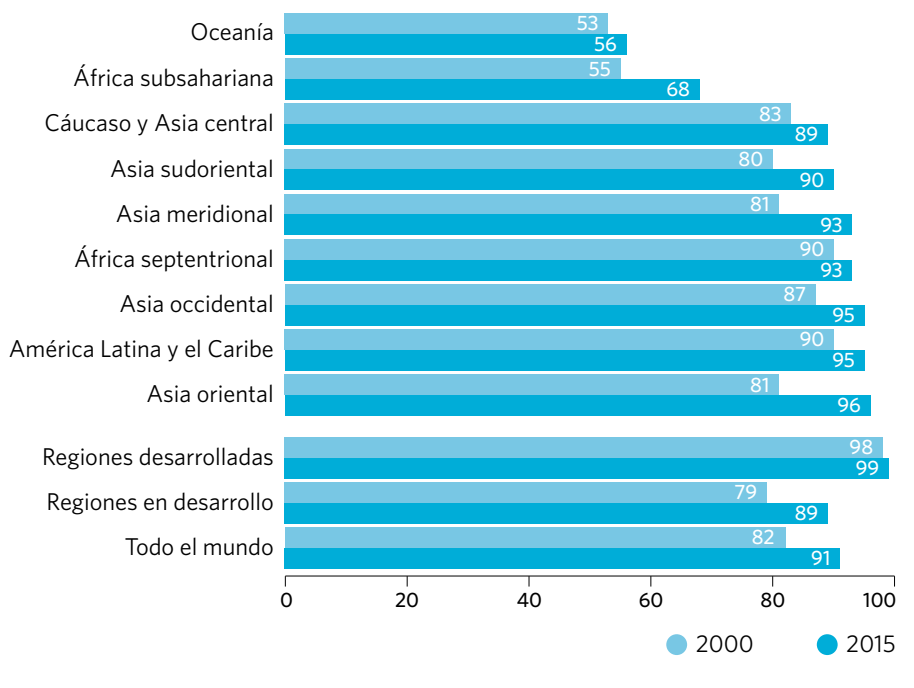

\section{Las instalaciones de saneamiento} inadecuadas todavía son una realidad para una tercera parte de la población mundial

Entre 2000 y 2015, la proporción de la población mundial que contaba con mejoras en las instalaciones de saneamiento aumentó de 59\% a 68\%. Esto significa que 4.900 millones de personas en todo el mundo estaban utilizando mejoras en las instalaciones de saneamiento en 2015. Sin embargo, 2.400 millones no contaban con estas mejoras; entre ellas 946 millones de personas no disponían de instalación alguna y continuaban practicando la defecación al aire libre. La gestión poco segura de los desechos fecales y las aguas residuales continúa significando un importante riesgo a la salud pública y al medio ambiente.
Proporción de la población que cuenta con mejoras en las instalaciones de saneamiento, 2000 y 2015 (porcentaje)

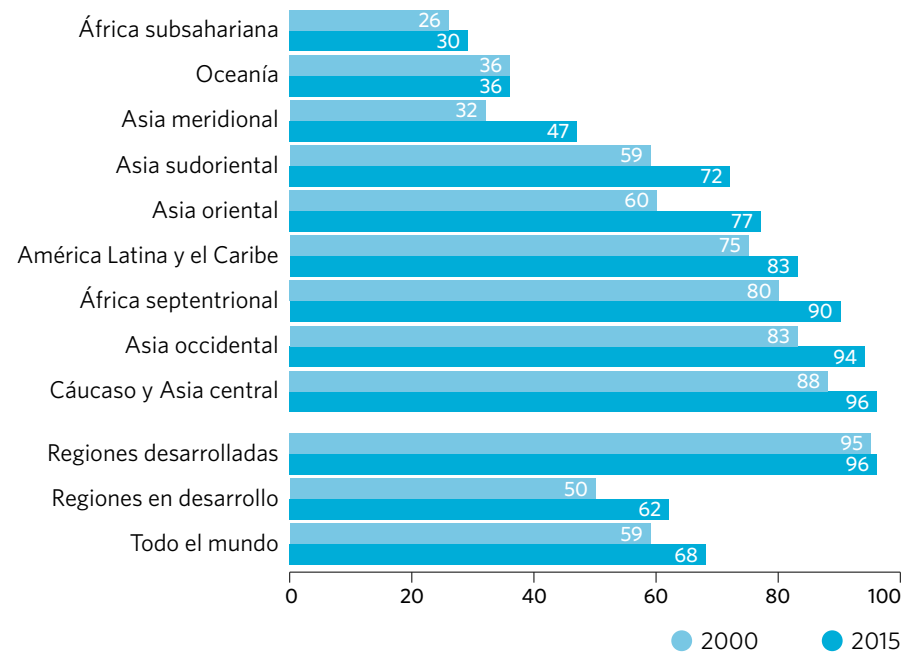

\section{Los planes para la gestión integrada de los recursos hídricos están en marcha en países de todas las regiones, con diverso progreso en la implementación}

Un aspecto clave para una gestión sostenible del agua es la implementación de la Gestión Integrada de Recursos Hídricos (GIRH), un seguimiento al Plan de Implementación de Johannesburgo de 2002. En 2012, $65 \%$ de los 130 países que respondieron a una pregunta en la encuesta de la GIRH informaron que los planes de gestión estaban implementados a nivel nacional, aunque la implementación completa varía según las regiones.
Proporción de países en diversas etapas de implementación nacional de los planes de Gestión Integrada de Recursos Hídricos o equivalentes, 2012 (porcentaje)

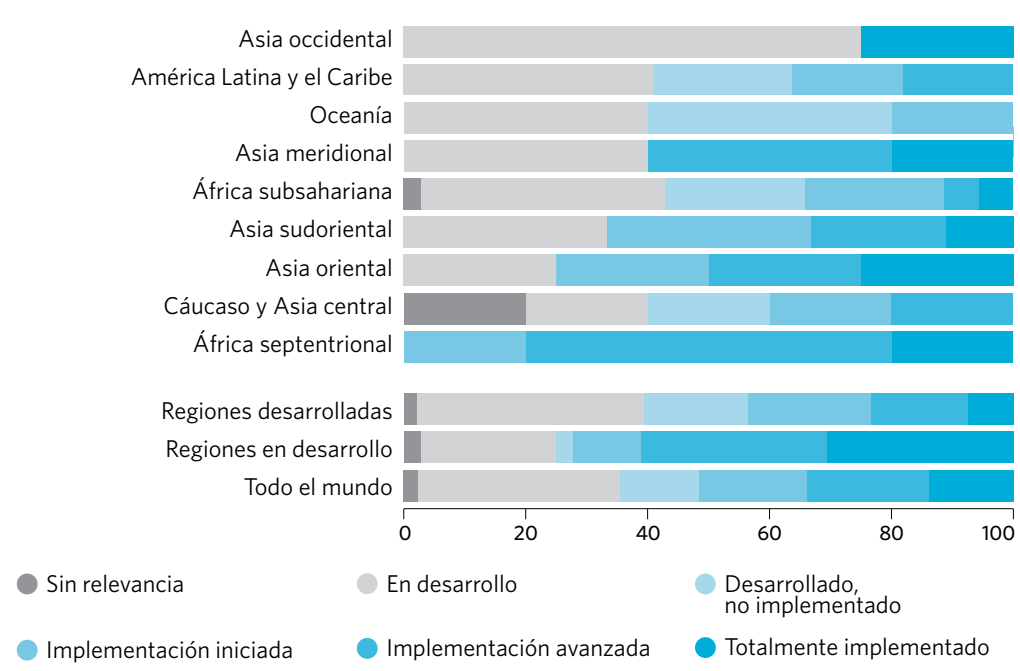




\section{Objetivo 7: Garantizar el acceso a una energía asequible, fiable, sostenible y moderna para todos}

El acceso a una energía asequible, fiable, sostenible y moderna es crucial para alcanzar muchos de los Objetivos de Desarrollo Sostenible; desde la erradicación de la pobreza a través de avances en la salud, la educación, el abastecimiento de agua y la industrialización, hasta la mitigación del cambio climático. Sin embargo, el acceso a la energía varía en gran medida entre los distintos países, y la tasa de progreso actual no es suficiente para alcanzar el Objetivo. Se deberán redoblar los esfuerzos, en particular en países con grandes deficiencias de acceso a la energía y alto consumo.

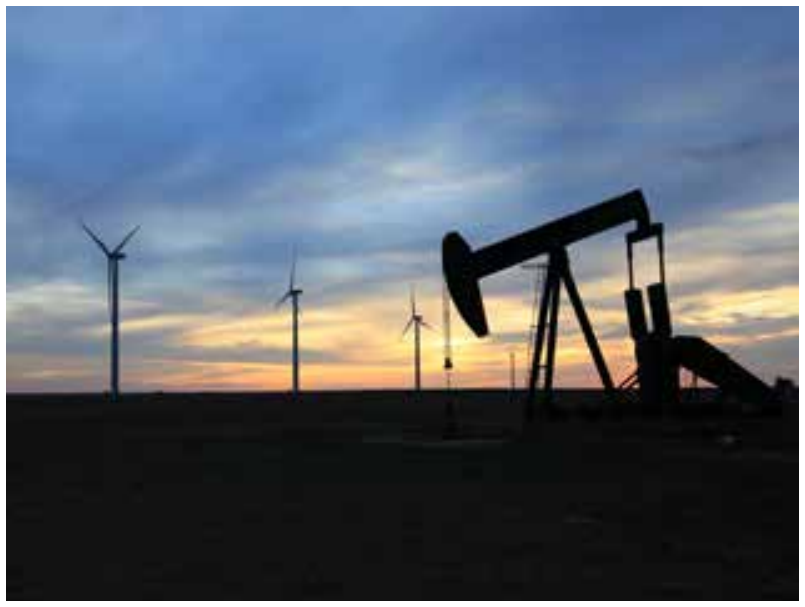

Una creciente proporción de la población obtuvo acceso a energía eléctrica, pero 1.100 millones de personas todavía viven sin ella

La proporción de la población mundial con acceso a energía eléctrica ha aumentado de manera sostenida de un $79 \%$ en el año 2000 a un $85 \%$ en 2012 . El progreso reciente fue impulsado por avances en Asia meridional, Asia sudoriental y África subsahariana. A pesar de estas mejoras, 1.100 millones de personas continúan sin este servicio esencial, incluyendo más del $65 \%$ de la población de África subsahariana y el 70\% en Oceanía. De aquellos con acceso a energía eléctrica a nivel mundial desde 2010, la vasta mayoría (el $80 \%$ ) vive en zonas urbanas. 


\section{Más del $\mathbf{4 0} \%$ de la población mundial todavía depende de combustibles contaminantes e insalubres para cocinar}

Desde el año 2005 al 2014, la proporción de la población global con acceso a combustibles y tecnologías limpios para cocinar, como el gas y la electricidad, aumentó de un 54\% a un 58\%. Los avances han sido lentos en algunas regiones, como en África subsahariana, donde el acceso sigue siendo muy bajo. El limitado progreso desde el 2010 está lejos de alcanzar el crecimiento de la población mundial y está restringido casi exclusivamente a zonas urbanas. Como resultado, la cantidad absoluta de personas que depende de combustibles y tecnologías contaminantes para cocinar parece haber aumentado, habiendo alcanzado un estimado de tres mil millones de personas.
Proporción de la población cuya fuente primaria de energía para cocinar consiste en combustibles y tecnología limpios, 2005 y 2014 (porcentaje)

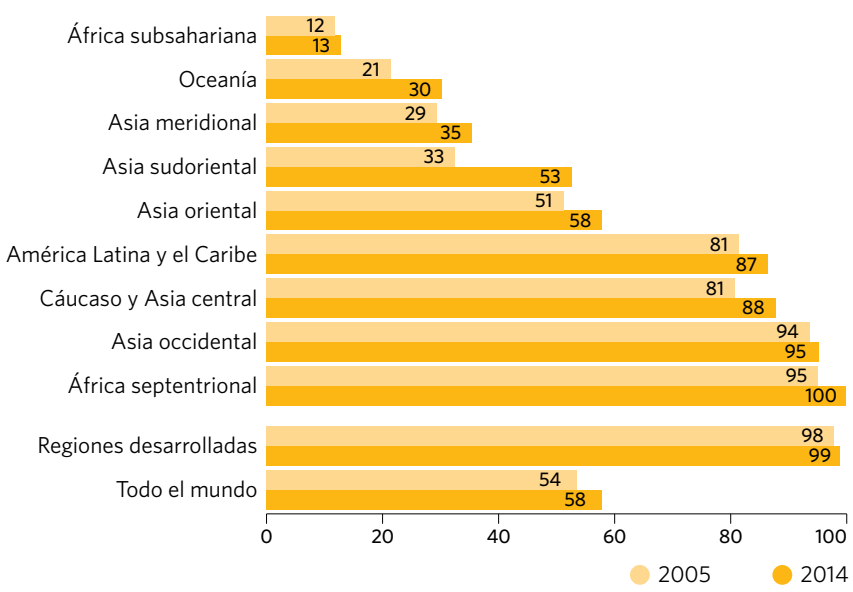

\section{El uso de energía renovable está} aumentando de forma modesta, pero una gran y creciente porción está compuesta de fuentes renovables modernas

La proporción de la energía renovable (derivada de fuentes hidroeléctricas, biocombustibles sólidos y líquidos, fuentes eólicas, solares, de biogás, geotérmicas, marinas y de desechos) en el consumo energético final total aumentó solamente de manera marginal, de un 17,4\% en el año 2000 a un $18,1 \%$ en 2012. No obstante, las fuentes renovables modernas (que excluyen biocombustibles sólidos) aumentaron a una tasa de 4\% al año entre 2010 y 2012. La energía eléctrica presentó un progreso particularmente importante, ya que el $60 \%$ de todas las nuevas capacidades de generación de energía en 2014 fueron de fuentes renovables modernas. En términos absolutos, alrededor del $72 \%$ del aumento en el consumo de energía de fuentes renovables modernas entre 2010 y 2012 provino de regiones en desarrollo, en particular de Asia oriental.
Proporción de la energía renovable en el consumo final total de energía, 2000, 2005, 2010 y 2012 (porcentaje)
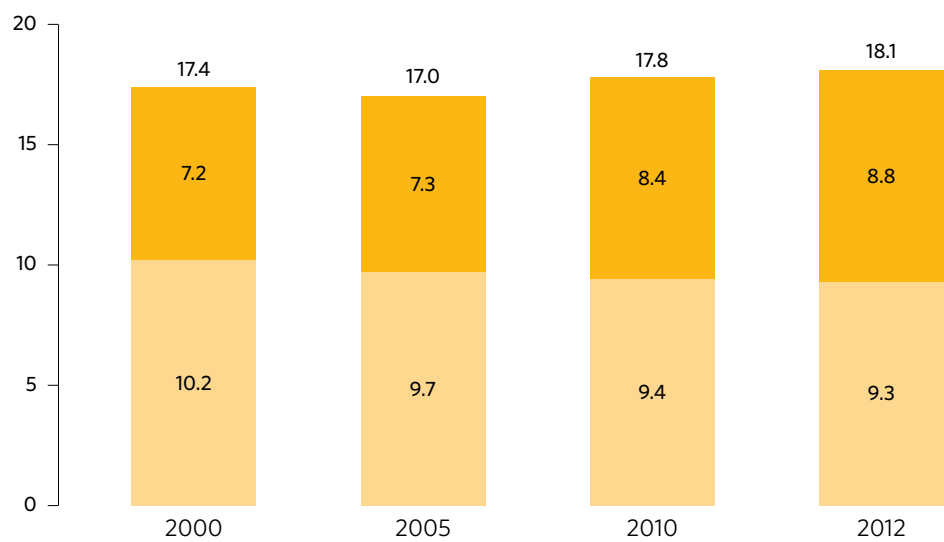

Otras fuentes renovables Fuentes renovables modernas

\section{El crecimiento económico global está siendo disociado del uso de energía, pero no lo suficientemente rápido}

La intensidad energética (calculada de dividir el suministro energético primario total por el PIB) revela cuanta energía es utilizada para producir una unidad de producción económica. La intensidad energética global mejoró en un 1,3\% por año entre los años 2000 y 2012 al caer de 6,7 megajulios por unidad del PIB (dólares de Estados Unidos PPA del 2011) en el año 2000 a 5,7 en 2012. Un factor importante fue la proporción del uso de energía cubierta por una reglamentación de eficiencia energética obligatoria que casi se duplicó en el curso de la última década (pasando de 14\% en 2005 a 27\% en 2014). Aun así, el progreso continúa solamente a dos tercios del ritmo requerido para duplicar la tasa mundial de aumento de eficiencia energética para el 2030. Para los sectores de usuarios finales, la industria fue el mayor contribuyente en la reducción de la intensidad energética, seguida de cerca por el transporte. Alrededor de $68 \%$ del ahorro en intensidad energética entre 2010 y 2012 provino de regiones en desarrollo, siendo Asia oriental su mayor contribuyente.
Intensidad energética medida en función de los energía primaria y el producto interno bruto, 2000 y 2012 (megajulios por dólares de los Estados Unidos PPA de 2011)

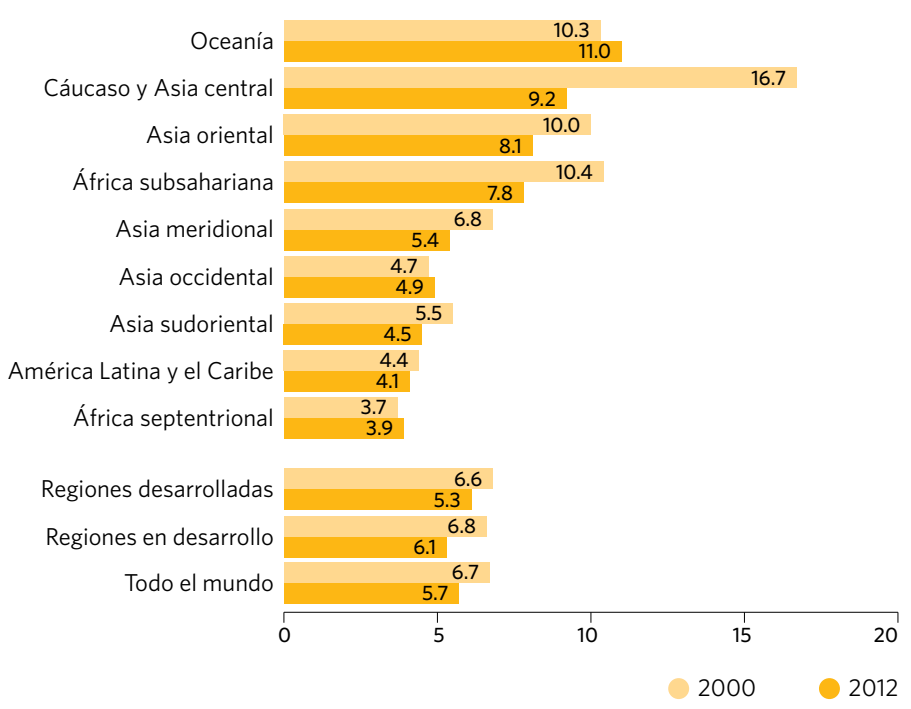

Objetivo 7 | Energía asequible y no contaminante 


\section{Objetivo 8: Promover el crecimiento económico sostenido inclusivo y sostenible, el empleo pleno y productivo y el trabajo decente para todos}

El crecimiento sostenido e inclusivo es un requisito previo para un desarrollo sostenible, lo que puede contribuir a mejorar los medios de subsistencia para las personas en todo el mundo. El crecimiento económico puede llevar a nuevas y mejores oportunidades de empleo y proporcionar un mayor crecimiento económico para todos. Más aun, el crecimiento rápido, en particular en los países menos adelantados y otros países en desarrollo, puede ayudarlos a disminuir la desigualdad salarial con respecto a los países desarrollados, atenuando así la evidente disparidad entre ricos y pobres.

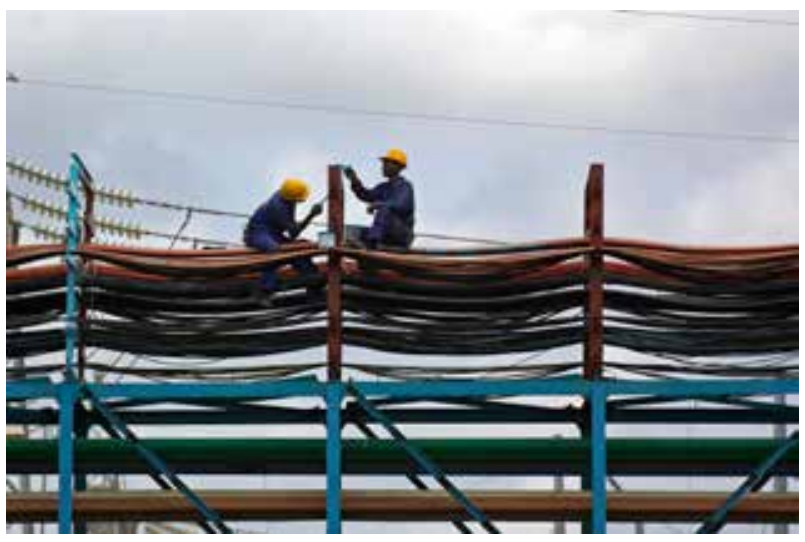

Un mayor crecimiento económico es necesario para cumplir con el objetivo de $7 \%$ de crecimiento del PIB en los países menos adelantados

En el período 2010 a 2014, la tasa media de crecimiento anual del PIB real per cápita a nivel mundial fue de 1,6\%, levemente por debajo de la tasa alcanzada en el período 2000 a 2004. La tasa de crecimiento de los países en regiones en desarrollo fue más del triple de la tasa de las regiones desarrolladas (4,1\% en comparación con el 1,3\%, respectivamente); sin embargo, las tasas de ambas regiones fueron inferiores a sus promedios históricos. Esto sugiere que queda mucho por hacer para poder alcanzar el objetivo de un crecimiento económico sostenido e inclusivo. El desafío es particularmente difícil para los países menos adelantados, cuyo crecimiento per cápita se aceleró durante un tiempo pero que desde entonces se ha lentificado a solo un $2,6 \%$ en promedio durante 2010 a 2014: menos de la mitad de la tasa objetivo de al menos $7 \%$ anual. 
La productividad en regiones en desarrollo, a pesar de las mejoras, continúa muy por debajo de la de las regiones desarrolladas

El crecimiento de la productividad laboral en las regiones en desarrollo superó al de las regiones desarrolladas, sobre todo en Asia. Dicho esto, la productividad de los trabajadores en las regiones más pobres todavía continúa siendo una pequeña fracción de la de los trabajadores en el mundo desarrollado. Los trabajadores en Asia meridional y África subsahariana, por ejemplo, tienen una productividad de solo un $5 \%$ de la de las regiones desarrolladas, cuando se mide como porcentaje del PIB. Incluso la región en desarrollo con la productividad laboral más alta, Asia occidental, presenta solo un $40 \%$ de la productividad laboral de las regiones desarrolladas y esta tasa ha disminuido levemente desde el año 2000.
Productividad laboral (PIB por trabajador) de 2005, 2005 y 2015 (en miles de dólares de los Estados Unidos constantes en 2005)

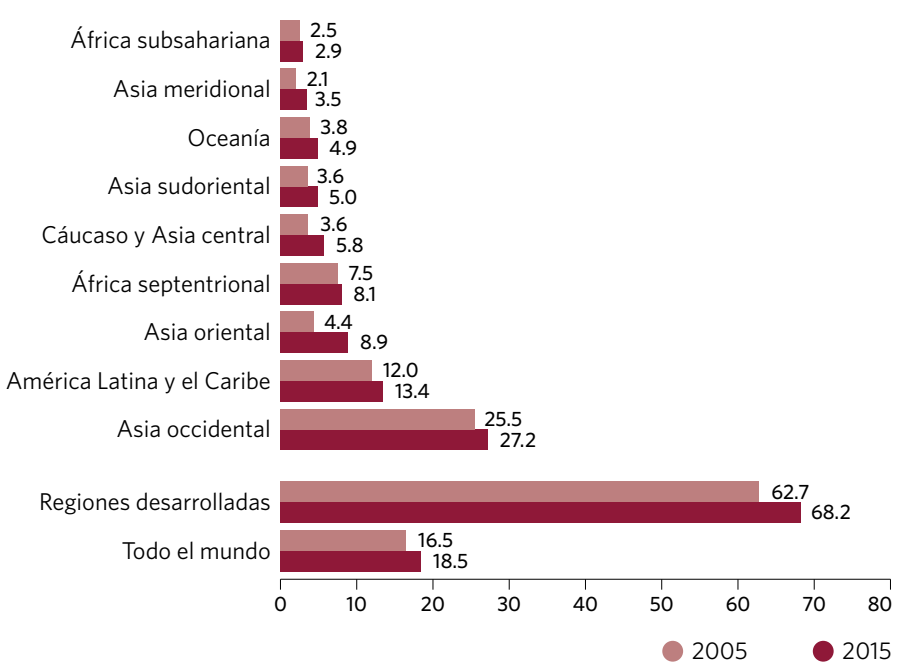

\section{Las mujeres tienen $15 \%$ más probabilidades de estar desempleadas que los hombres en todo el mundo, pero la disparidad entre los géneros es mucho mayor en África septentrional y en Asia occidental}

El desempleo a nivel mundial se colocó en 6,1\% en 2015 , una disminución del pico de $6,6 \%$ en 2009. Los niveles de desempleo más bajos son los de Asia meridional, oriental y sudoriental: por debajo del $5 \%$ en comparación con otras regiones del mundo en que el promedio fue alrededor de $7 \%$ o más. En todo el mundo, es más probable que las mujeres estén desempleadas que los hombres. Las diferencias son más pronunciadas en Asia occidental y África septentrional, donde la tasa de desempleo de las mujeres es más del doble que la de los hombres.
Tasas de desempleo por sexo, 2015 (porcentaje)

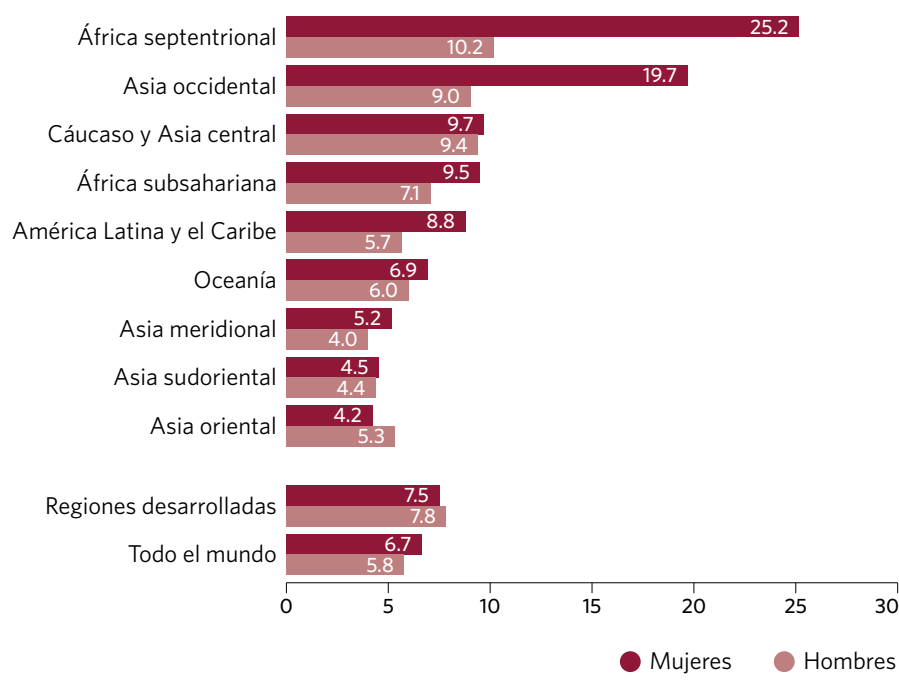

\section{Aunque la proporción de adultos con cuentas bancarias aumentó en $\mathbf{2 0 \%}$ en cuatro años, unas dos mil millones de personas todavía no cuentan con este importante servicio financiero}

Entre 2011 y 2014, la proporción de personas de la población mundial adulta con una cuenta en una institución financiera o un servicio de dinero móvil aumentó de $51 \%$ a $62 \%$, lo que significa que 700 millones de adultos se convirtieron en titulares de una cuenta durante este período.

Sin embargo, dos mil millones de personas en todo el mundo todavía no tienen una cuenta en una institución financiera. La exclusión financiera afectó desproporcionalmente a las mujeres y los pobres. La proporción de mujeres titulares de una cuenta es de 9 puntos porcentuales inferior que la proporción de hombres. Además, la proporción de titulares de cuentas entre el $40 \%$ más pobre de los hogares es de 14 puntos porcentuales inferior que entre aquellos que viven en el $60 \%$ de los hogares más ricos.
Porcentaje de la población mundial adulta que tiene una cuenta en una institución financiera, 2011 y 2014 (porcentaje)
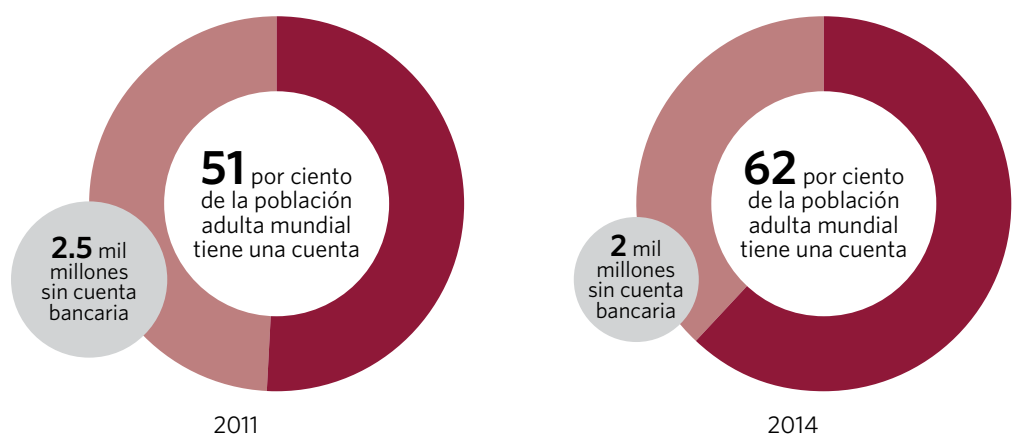


\section{Objetivo 9. Construir infraestructuras resilientes promover la industrialización inclusiva y sostenible y fomentar la innovación}

El Objetivo 9 de Desarrollo Sostenible aborda tres aspectos importantes del desarrollo sostenible: infraestructura, industrialización e innovación. La infraestructura provee las instalaciones físicas básicas que son esenciales para el comercio y la sociedad; la industrialización impulsa el crecimiento económico y la creación de empleo, lo que disminuye la desigualdad de ingresos; y la innovación amplía las capacidades tecnológicas de los sectores industriales y conduce al desarrollo de nuevas habilidades.

Valor agregado por manufactura per cápita, 2005 y 2015 (dólares de los Estados Unidos constantes de 2010)
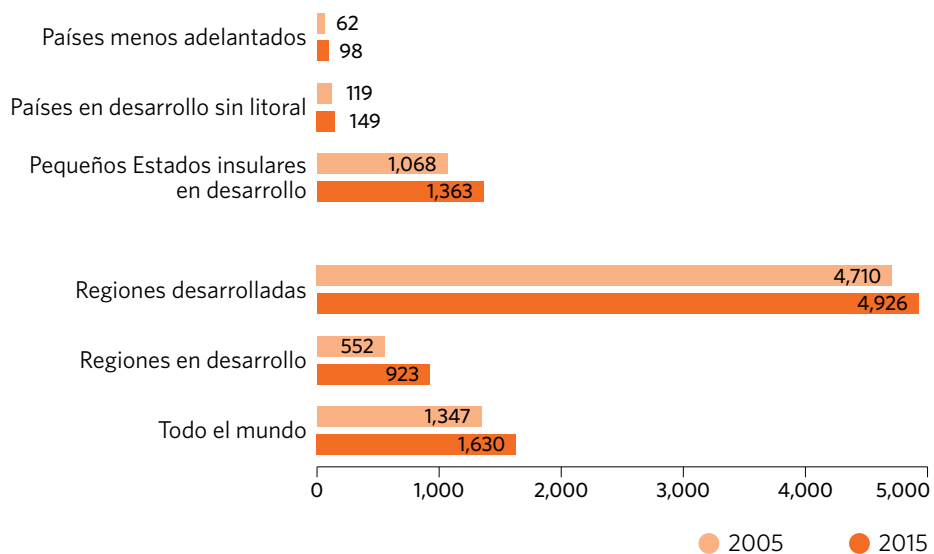

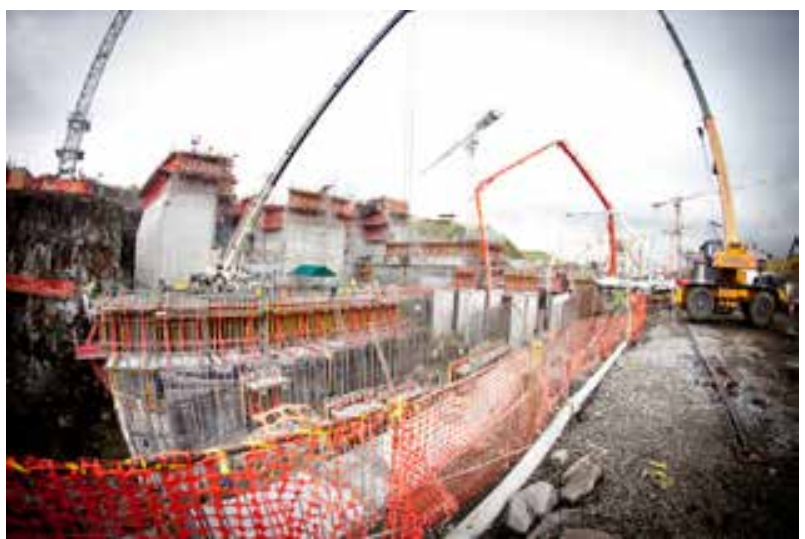

El potencial de manufactura no explotado de los países menos adelantados sugiere importantes oportunidades de crecimiento

La manufactura es uno de los principales motores del crecimiento económico. Sin embargo, las desigualdades en el valor agregado del sector manufacturero señalan importantes desafíos que enfrentan los países más desfavorecidos, así como su potencial para el crecimiento. Por ejemplo, en 2015, el valor agregado por manufactura (VAM) per cápita fue inferior a 100 dólares por año en los países menos adelantados (PMA), en comparación con 4.926 dólares en las regiones desarrolladas. Los PMA necesitan importantes inversiones para impulsar el progreso tecnológico y el crecimiento económico, y para alcanzar la meta de duplicar la contribución de la industria en el producto interno bruto de estos países. Las tendencias del VMA muestran aumentos constantes en las regiones en desarrollo y un leve descenso en las regiones desarrolladas, lo que es similar a las tendencias del empleo en la manufactura. El potencial de crecimiento del empleo en la manufactura es particularmente alto en los PMA ya que grandes segmentos de la población continúan trabajando en los sectores agrícolas y tradicionales. 


\section{La eficiencia energética y los combustibles y tecnologías más limpios han disminuido las emisiones de dióxido de carbono por unidad de valor agregado}

A medida que los países cambian a industrias de menor intensidad energética, combustibles y tecnologías más limpios y políticas de eficiencia energética más firmes, casi todas las regiones han presentado una disminución de la intensidad de carbono en su PIB. La proporción del uso de energía en el mundo regulada por una reglamentación de eficiencia energética obligatoria casi se ha duplicado durante la última década, pasando de 14\% en 2005 a 27\% en 2014.

El despliegue más extenso de tecnologías limpias aumentará la probabilidad de alcanzar el objetivo propuesto de actualizar la infraestructura y acondicionar las industrias para volverlas sostenibles, con un aumento en la eficiencia del uso de recursos y una mayor adopción de tecnologías y procesos industriales limpios idóneos para el medio ambiente.

\section{Aunque los gastos en investigación y desarrollo han aumentado, los países más pobres han quedado rezagados}

En 2013, la inversión mundial en investigación y desarrollo (I+D) se ubicaba en 1700 mil millones de dólares (PPA), ascendiendo de 732 mil millones en el año 2000. Esto representó una tasa de crecimiento anual de 4,6\% y sugiere que $1,7 \%$ del PIB mundial estaba dedicado a I+D en 2013. Aunque es sustancial, este promedio mundial enmascara amplias disparidades entre las regiones: las regiones desarrolladas dedicaron casi 2,4 por ciento de su PIB a I+D en 2013, mientras que el promedio para los PMA y los países en desarrollo sin litoral se ubicó en menos de $0,3 \%$. Se requieren esfuerzos más concertados para mejorar las capacidades de investigación en estos países.

Emisiones de dióxido de carbono (CO2) por unidad de valor agregado, 2000 y 2013 (kilogramos por dólares de los Estados Unidos constantes de 2010)

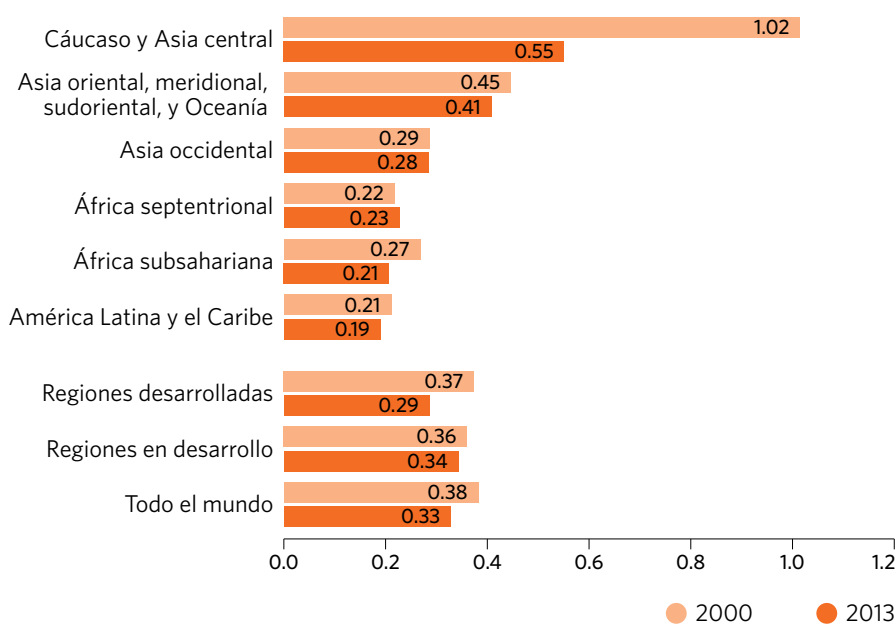

Gastos en investigación y desarrollo como proporción del PIB, 2005 y 2013 (porcentaje)
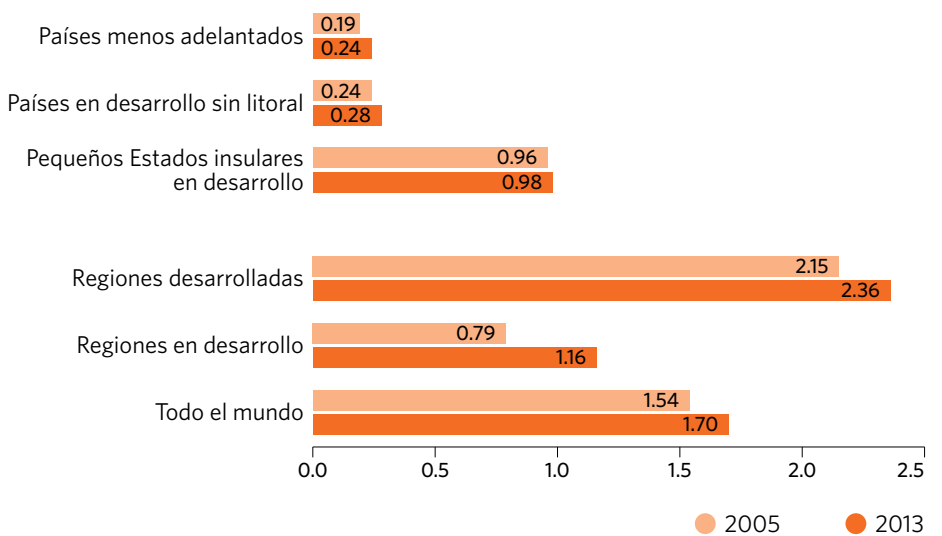

\section{Las redes de banda ancha móvil alcanzan casi el $\mathbf{9 0 \%}$ de la población urbana pero menos del $30 \%$ de la población rural}

Los avances tecnológicos en el sector de comunicaciones, la ampliación de redes y la caída de los precios han impulsado la propagación de los servicios de telefonía móvil en todo el mundo. Las personas que antes se encontraban en áreas desconectadas se han unido a la sociedad de la información global y, en 2015, 95\% de las personas que vivían en los PMA estaban cubiertos por una señal de telefonía móvil celular. Sin embargo, el acceso a Internet de mayor velocidad a través de tecnología de tercera generación (3G) está menos extendida: solo el $29 \%$ de la población rural cuenta con cobertura. El acceso a Internet es cada vez más necesario para que los productores y empresarios sean competitivos y se requieren más esfuerzos para ampliar este tipo de cobertura a regiones rurales y remotas del mundo.
Proporción de la población cubierta por una red móvil de tercera generación, por ubicación y tecnología, 2015 (porcentaje)

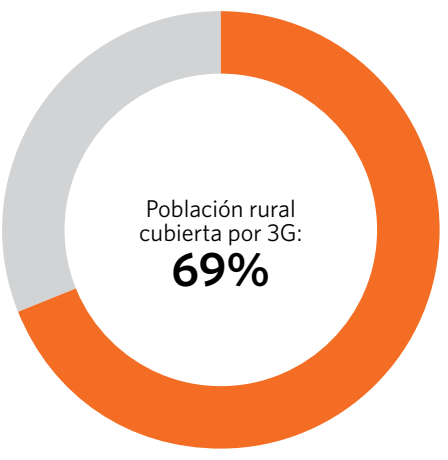

Población mundial: 7.400 millones

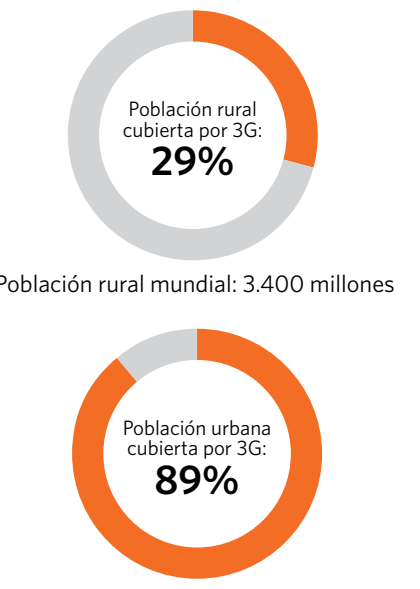

Población urbana mundial: 4.000 millones 


\section{REDUGCIŌN DE LAS DESIGUALDADES}

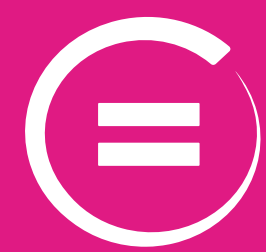

\section{Objetivo 10: Reducir la desigualdad en los países $y$ entre ellos}

El Objetivo 10 aboga por reducir la desigualdad de ingresos, así como aquellas basadas en sexo, edad, discapacidad, raza, clase, etnia, religión y oportunidad, tanto dentro de los países como entre ellos. Los líderes del mundo han reconocido la contribución positiva de la migración internacional al crecimiento inclusivo y al desarrollo sostenible, al tiempo que reconocen que requiere respuestas coherentes e integrales. Por lo tanto, se han comprometido a cooperar internacionalmente para garantizar una migración segura, ordenada y regular. El Objetivo también aborda problemas relacionados con las representaciones de los países en desarrollo en las decisiones tomadas a nivel mundial y la asistencia al desarrollo.

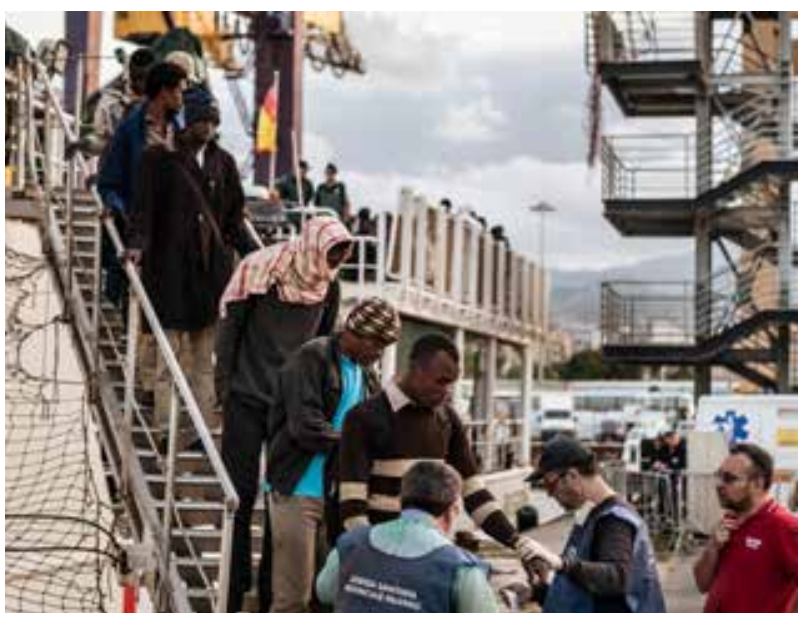

\section{Muchos países en América Latina y el Caribe y en Asia percibieron una reducción en la desigualdad de ingresos}

Cuando el crecimiento de los ingresos entre la población más pobre de un país es superior al promedio nacional, se reduce la desigualdad de ingresos. En 56 de 94 países de que se dispone de datos para el período entre los años 2007 y 2012, los ingresos per cápita del 40\% más pobre de los hogares creció más rápidamente que el promedio nacional. Esto se presenta particularmente en América Latina y el Caribe y en Asia, donde el $88 \%$ y el $67 \%$ de los países, respectivamente, vieron mejoras para el $40 \%$ más pobre de los hogares. Dicho esto, un crecimiento más acelerado de la franja más pobre no implica necesariamente una mayor prosperidad, ya que nueve de los 56 países experimentaron tasas negativas de crecimiento de los ingresos durante este período. 


\section{La contribución laboral al PIB se redujo en la mayoría de las regiones}

La proporción del PIB que se atribuye al trabajo ha tenido una tendencia descendente en los últimos 15 años, a medida que los procesos se vuelven más mecanizados y el capital asume una mayor proporción del PIB. Durante este período, la proporción laboral del PIB solo aumentó en Oceanía y en América Latina y el Caribe, siendo de un 48\% y 52\% respectivamente en 2015. Asia oriental experimentó un crecimiento plano de su proporción laboral del PIB y continúa manteniendo la proporción más alta a nivel mundial con un 61,4\% de su PIB. Aunque la proporción laboral del PIB cayó de casi un $58 \%$ en el año 2000 a poco más de $55 \%$ en 2015 para las regiones desarrolladas, las regiones en desarrollo experimentaron una leve mejora del $54 \%$ al $55 \%$. El estancamiento de los salarios en todas las regiones contribuye de forma significativa a estos resultados.
Proporción laboral del PIB (PPA) que comprende los salarios y las transferencias de protección social, 2000 y 2015 (porcentaje)

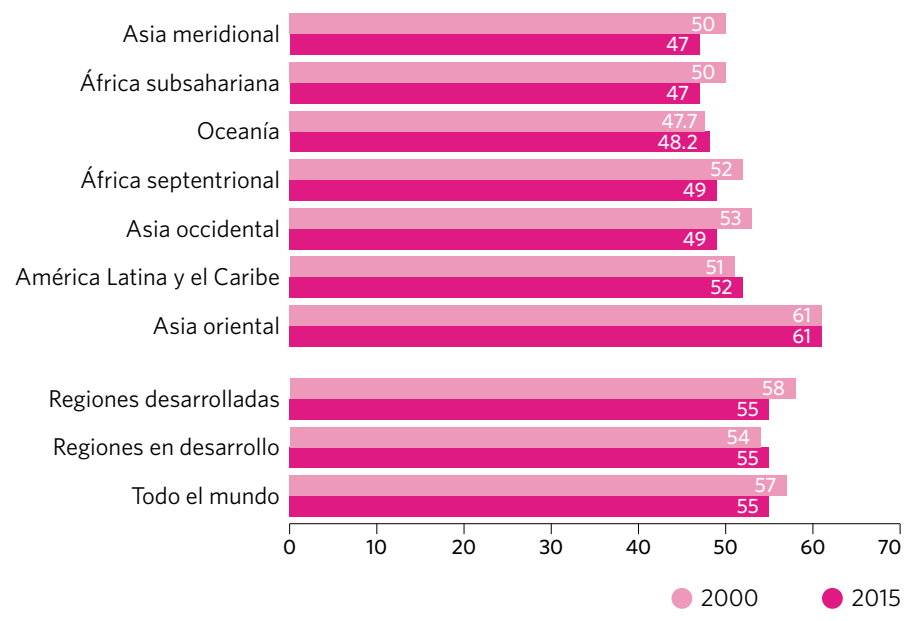

La proporción de importaciones desde los PMA y los países en desarrollo que ingresa a los países desarrollados con franquicias aduaneras ha crecido consistentemente

La proporción de exportaciones de los países menos adelantados y en desarrollo que se beneficiaron de las franquicias aduaneras aumentó entre 2000 y 2014, alcanzando un $84 \%$ y un $79 \%$ respectivamente, aunque el ritmo de este cambio fue más acelerado en los países en desarrollo. La ventaja comparativa para los PMA de las franquicias aduaneras fue variable según los grupos de productos: casi todos los productos agrícolas de los PMA (98\%) fueron exonerados de aranceles por los países desarrollados, en comparación con el 74\% de los productos de los países en desarrollo. La ventaja relativa para los PMA fue incluso mayor en textiles y vestimenta: las tasas para ambos grupos de producto fueron alrededor de $70 \%$ para los PMA; para los países en desarrollo, las tasas fueron de un $41 \%$ para los textiles y un $34 \%$ para vestimenta.
Proporción de importaciones (excluye armas y petróleo) desde los países menos adelantados y países en desarrollo que ingresan con franquicias aduaneras, 2000-2014 (porcentaje)

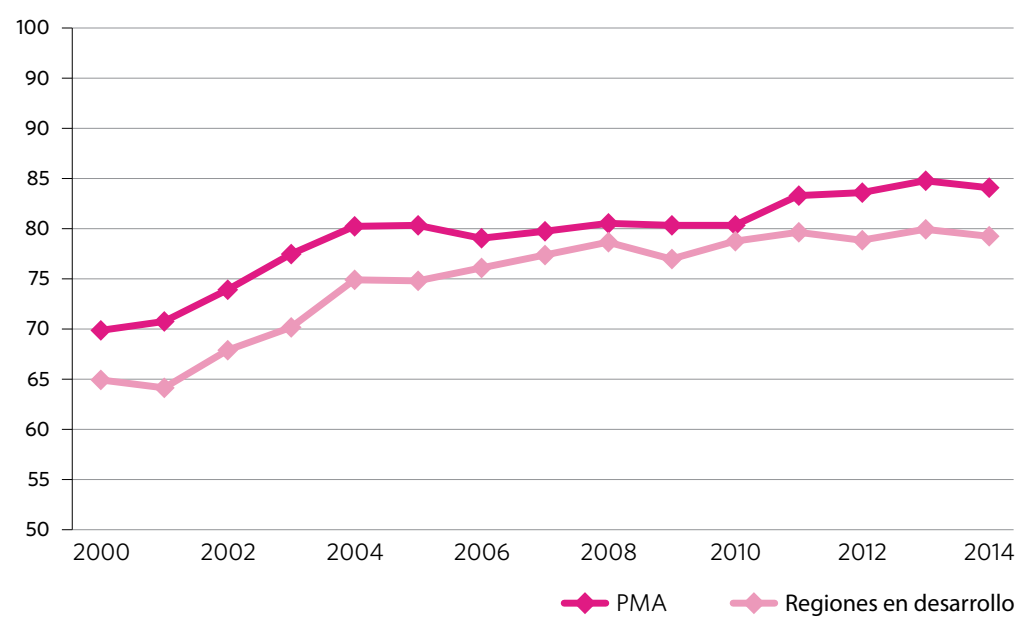

\section{El costo de enviar dinero a través de fronteras internacionales disminuyó}

Los migrantes contribuyen positivamente al crecimiento inclusivo y al desarrollo sostenible. También contribuyen al desarrollo de sus países de origen y de destino a través de su trabajo y de las remesas que envían a sus hogares. El total de las remesas a países en desarrollo aumentó levemente en 2015 a 431,6 mil millones de dólares (hasta un 0,4\% del de 2014), pero el costo de enviar el dinero entre fronteras internacionales sigue siendo alto. Aunque los costos disminuyeron entre 2012 y 2015 , todavía promediaba un $7,5 \%$ del monto remitido en 2015 , más del doble de la cifra objetivo de $3 \%$.
Costo medio mundial del envío de remesas equivalentes a 200 dólares de los Estados Unidos como proporción del monto remitido, 2008-2015 (porcentaje)

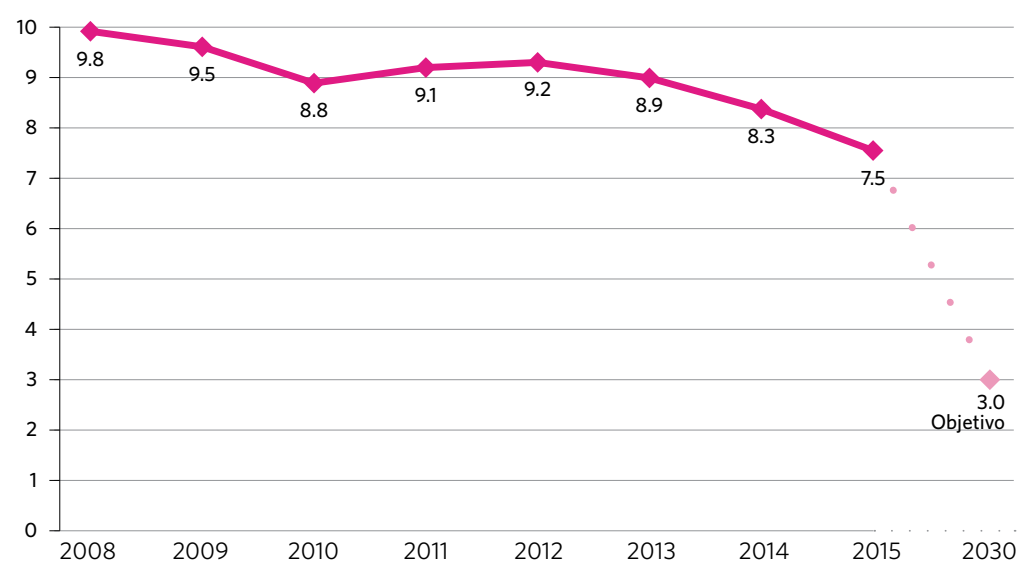




\section{Objetivo 11: Lograr que las ciudades y los asentamientos humanos sean inclusivos, seguros, resilientes y sostenibles}

En la actualidad, más de la mitad de la población mundial vive en ciudades. Para el año 2030, se proyecta que 6 de cada 10 personas serán habitantes urbanos. A pesar de los numerosos desafíos de planificación, las ciudades ofrecen economías de escala más eficientes en muchos niveles, incluyendo la provisión de bienes, servicios y transporte. Con una planificación y gestión acertadas e informadas de los riesgos, las ciudades pueden volverse incubadoras de innovación y crecimiento, así como motores de desarrollo sostenible.

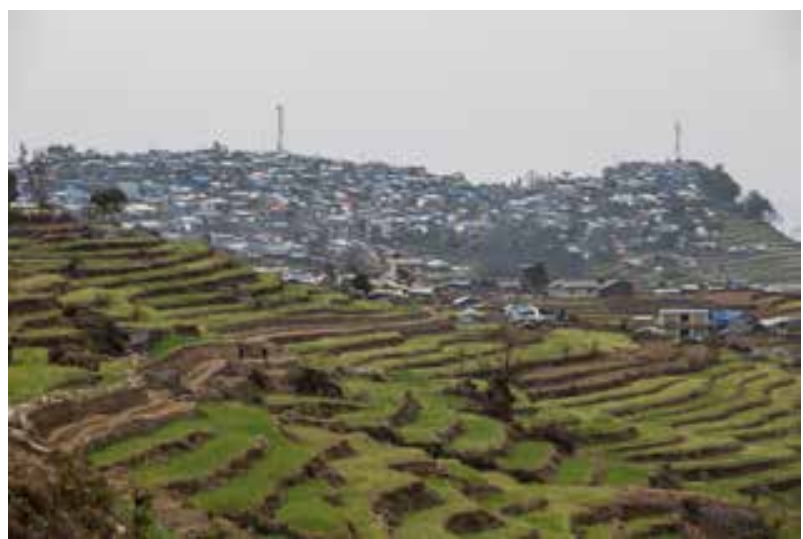

Proporción de la población urbana que vive en barrios marginales, 2000 y 2014 (porcentaje)

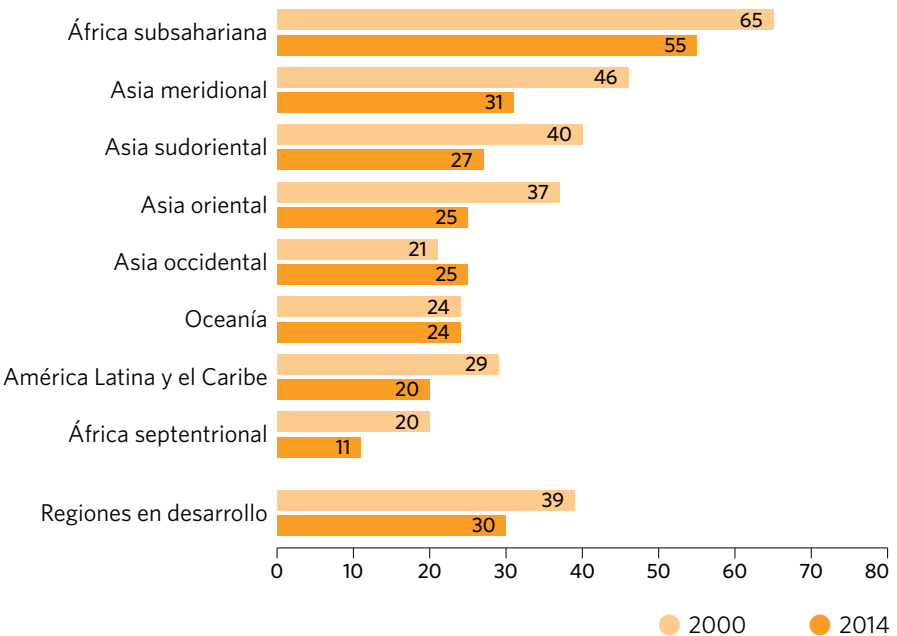

Casi la tercera parte de la población urbana en regiones en desarrollo todavía vive en barrios marginales

En 2014, el 30\% de la población urbana en regiones en desarrollo vivía en condiciones categorizadas como barrios marginales. En África subsahariana, la proporción era del $55 \%$, la más alta de cualquier región. A pesar de que el porcentaje de los habitantes urbanos que viven en tales condiciones se redujo en la última década, más de 880 millones de personas alrededor del mundo todavía vivían en barrios marginales en el año 2014. Se requiere una acción coordinada para abordar este desafío y aumentar la resiliencia, dado que muchas ciudades continúan siendo imanes para las personas que buscan mejores oportunidades y una vida mejor. 


\section{El crecimiento urbano descontrolado se encuentra en muchas ciudades en todo el mundo}

En muchas ciudades de rápido crecimiento en todo el mundo, la población en expansión se mueve hacia afuera, mucho más allá de las barreras burocráticas. El crecimiento urbano descontrolado se puede encontrar en muchas regiones: Asia oriental y Oceanía tuvieron la mayor proporción entre el consumo de tierra y el crecimiento de población en el mundo, entre los años 2000 y 2015. Las regiones desarrolladas ocuparon el segundo lugar. Solo América Latina y el Caribe y Asia meridional y central presentaron una tasa inferior a 1.0, lo que significa que las ciudades en estas regiones aumentaron en densidad de población. Desafortunadamente, un valor bajo en esta proporción no señala necesariamente que los habitantes urbanos estén pasando por una buena situación, ya que también puede indicar una prevalencia de barrios marginales superpoblados. El alto crecimiento urbano no planificado está vinculado a mayores emisiones per cápita de dióxido de carbono y contaminación peligrosa, y muchas veces eleva los precios de las viviendas, lo que obstaculiza el desarrollo sostenible.
Cociente promedio entre la tasa de consumo de tierras y la tasa de crecimiento de la población, 1990-2000 y 2000-2015, en base a una muestra estratificada de 194 ciudades

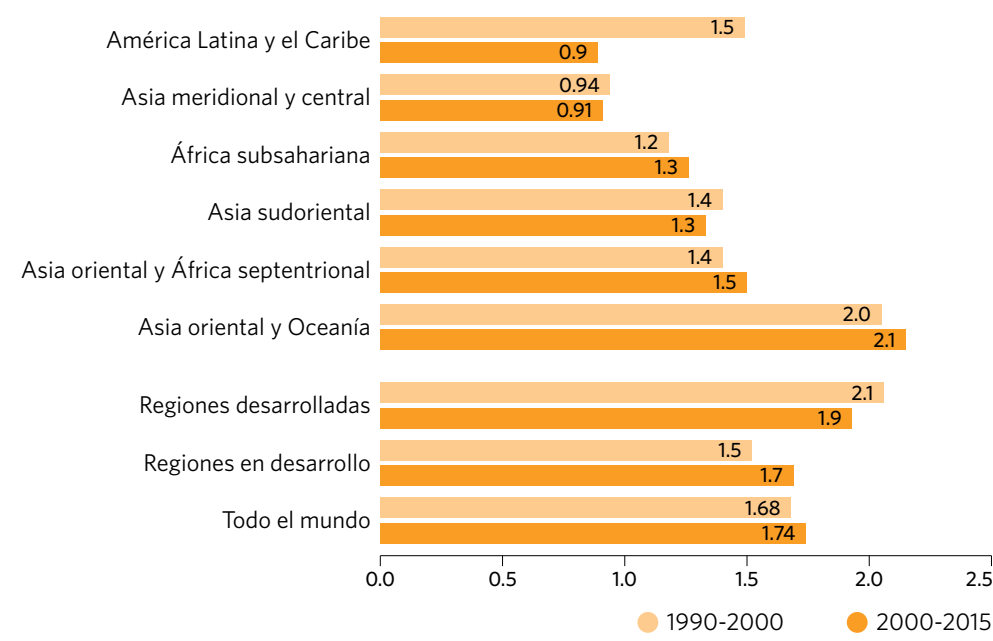

\section{Las ciudades en todas las regiones del planeta tienen niveles de contaminación del aire peligrosamente altos}

La contaminación del aire es un importante riesgo ambiental para la salud. Se estima que, a nivel mundial, la contaminación ambiental del aire (en exteriores) tanto en ciudades como en zonas rurales fue la causa de 3,7 millones de muertes prematuras en 2012. En 2014, alrededor de la mitad de la población urbana en todo el mundo estaba expuesta a niveles de contaminación del aire al menos 2,5 veces mayores a las normas de seguridad establecidas por la Organización Mundial de la Salud (OMS). Ninguna región presentó un promedio anual de concentraciones de material particulado inferior al máximo establecido por la OMS de 10 microgramos por metro cúbico $\left(\mu \mathrm{g} / \mathrm{m}^{3}\right)$.
Promedio anual neto de niveles de concentración en áreas urbanas $\left(\mu \mathrm{g} / \mathrm{m}^{3}\right)$ de material particulado de 2.5 micrones de diámetro o menores (PM2.5), 2014

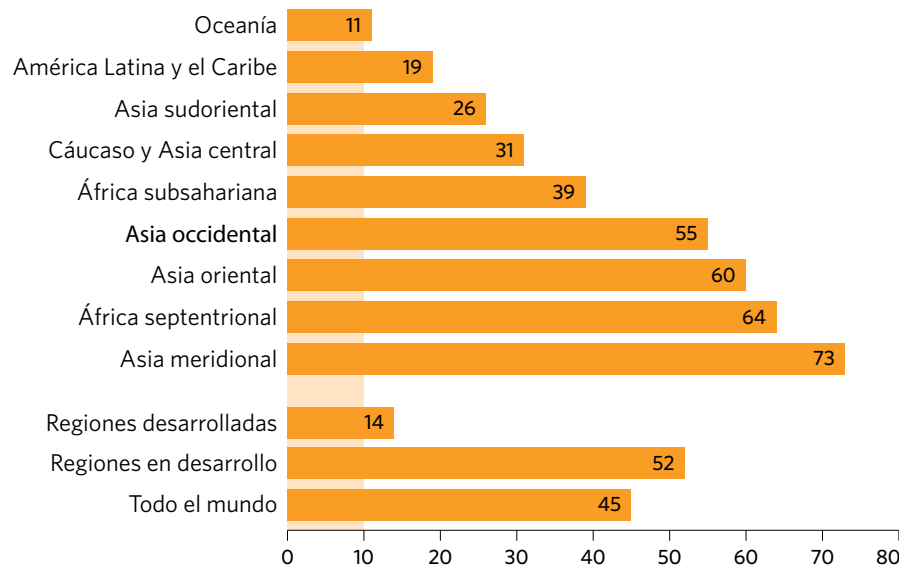

Máximo nivel de contaminación ambiental recomendado por la OMS: $10 \mu \mathrm{g} / \mathrm{m}^{3}$ Nota: Datos reportados solamente para Estados Miembro de la OMS.

\section{Casi tres cuartas partes de los países han implementado o están trabajando para implementar políticas urbanas a nivel nacional}

Las políticas nacionales y los planes de desarrollo regional que toman en cuenta las necesidades y características de las zonas urbanas son esenciales para el desarrollo sostenible. Al 2015, 142 países estaban desarrollando políticas urbanas a nivel nacional; de estos, 82 países ya se encontraban en proceso de implementación y 23 alcanzaron la etapa de supervisión y evaluación. La vasta mayoría de estas políticas urbanas puede alinearse fácilmente con los ODS y pueden desglosarse de acuerdo a los temas clave de la agenda de sostenibilidad, siendo una manera de conectar la política nacional con la acción local.
Proporción y cantidad de países que están implementando políticas urbanas nacionales, por etapa de implementación, 2015 (porcentaje)

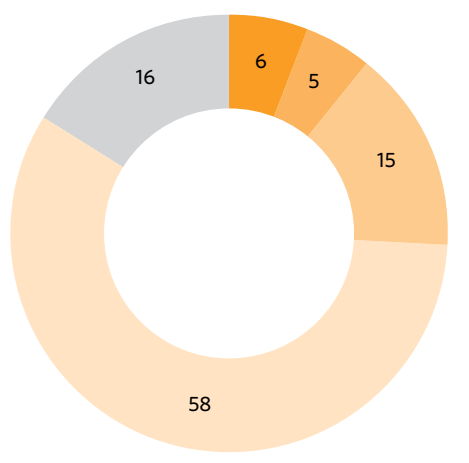




\section{Objetivo 12: Garantizar modalidades de consumo y producción sostenibles}

El crecimiento y desarrollo sostenibles requieren minimizar los recursos naturales y materiales tóxicos utilizados,

y la generación de desechos y contaminantes en todo el proceso de producción y consumo. El Objetivo de Desarrollo Sostenible 12 alienta a regímenes de consumo y producción más sostenibles a través de diversas medidas que incluyen políticas específicas y acuerdos internacionales sobre la gestión de materiales que son tóxicos para el medio ambiente.

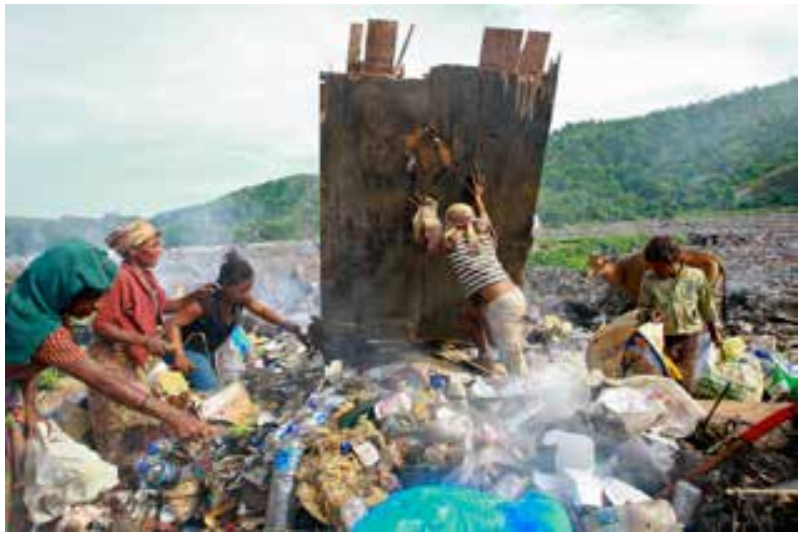

Huella material por PIB, 2000 y 2010, por tipo de materia prima

(kilogramo por unidad de PIB a dólares de los Estados Unidos constantes de 2005)

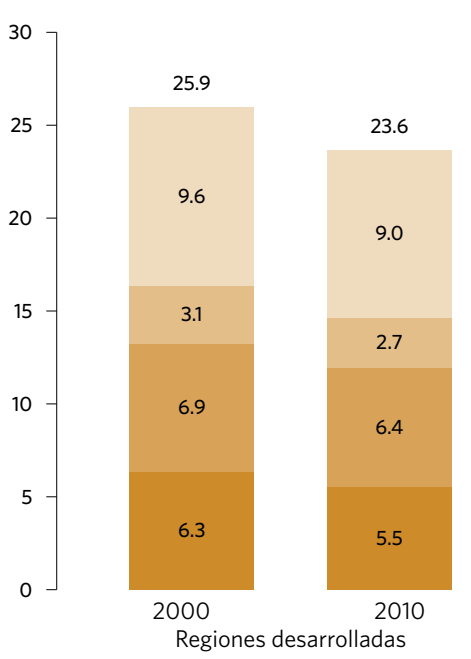

Huella material (minerales no metálicos)

- Huella material (minerales metálicos)

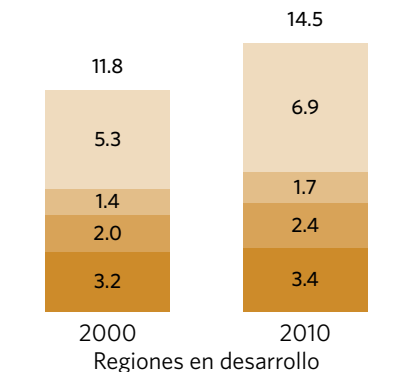

- Huella material (combustibles fósiles)

- Huella material (biomasa)

Nota: La suma de categorías de materia prima puede no alcanzar el total debido al redondeo.

\section{A medida que las regiones en desarrollo se industrializan, su uso de materia prima ha aumentado}

La huella material es una contabilización de combustibles fósiles y otra materia prima que se extrae en todo el mundo y que se utiliza en un país en particular. Refleja la cantidad de materia prima requerida para satisfacer las necesidades de un país y que puede interpretarse como un indicador del nivel de vida material o el nivel de capitalización de una economía. De 2000 a 2010, la huella material por unidad de PIB de las regiones desarrolladas disminuyó como resultado de una mayor eficiencia en los procesos industriales. Sin embargo, a 23,6 kilogramos por unidad de PIB en 2010, todavía continuaba sustancialmente más alta que el total de las regiones en desarrollo, a 14,5 kilogramos por unidad de PIB. A medida que los países en desarrollo se industrializan, la huella material de las regiones en su totalidad ha aumentado en el curso de este período de diez años. Los minerales no metálicos mostraron el mayor aumento, con un crecimiento de 5,3 a 6,9 kilogramos por unidad de PIB. Este componente representa casi la mitad de la huella material de las regiones en desarrollo. 


\section{El consumo per cápita de recursos naturales disminuyó en las regiones desarrolladas, mientras que aumentó en la mayoría de las regiones en desarrollo}

Otra medida del flujo o uso de materiales en países individuales es el consumo nacional de materiales que mide la cantidad de recursos naturales utilizados en procesos económicos. El consumo nacional de materiales per cápita disminuyó levemente en las regiones desarrolladas, de 17,5 toneladas per cápita en el año 2000, a 15,3 toneladas per cápita en 2010. Sin embargo, se mantuvo un $72 \%$ más alto que el valor para las regiones en desarrollo que se ubicó en 8,9 toneladas per cápita en 2010. El consumo nacional de materiales per cápita aumentó en casi todas las regiones en desarrollo en el curso de ese período, salvo en África subsahariana donde permaneció relativamente estable, y en Oceanía donde disminuyó de 10,7 a 7,7 toneladas per cápita. El dramático aumento en el consumo de materia prima per cápita en Asia durante este período, en particular en Asia occidental, se debe principalmente a la rápida industrialización.
Consumo nacional de materiales per cápita, 2000 y 2010 (toneladas per cápita)

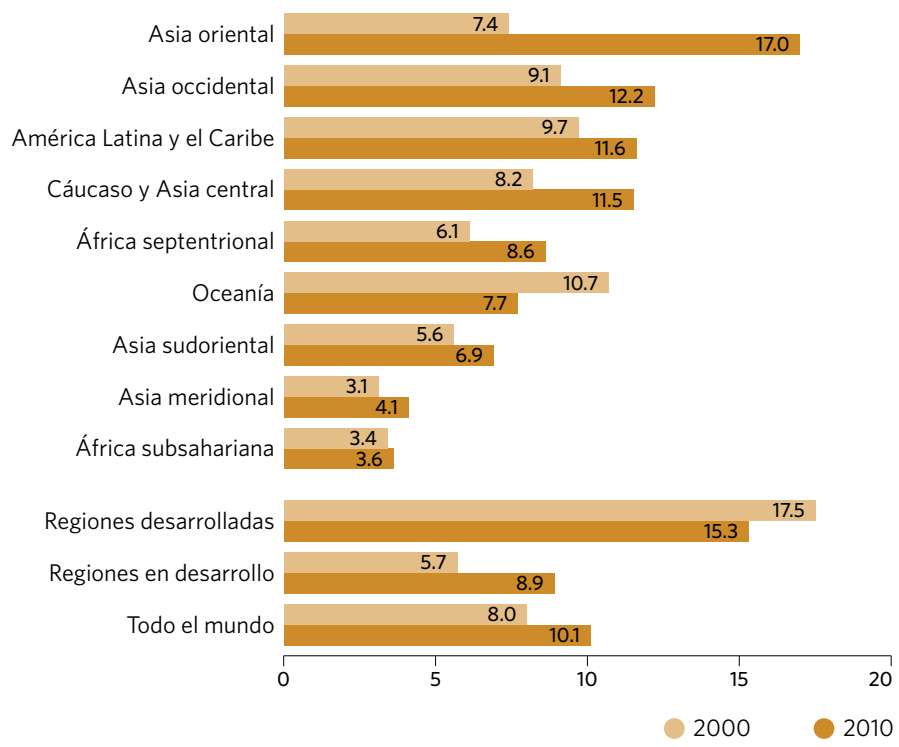

Nota: El comsumo material interior mide la cantidad total de recursos utilizados por una economía. Se define como la cantidad anual de materiales en bruto extraídos del territorio nacional, más todas las importaciones físicas, menos todas las exportaciones físicas. Esto incluye el consumo intermedio y final hasta ser liberado en el ambiente.

\section{Casi todos los países se adhirieron al menos a un acuerdo internacional sobre el medio ambiente vinculado a desechos peligrosos y otros químicos}

Los convenios de Basilea, Rotterdam y Estocolmo han establecido marcos de trabajo internacionales para alcanzar una gestión idónea desde el punto de vista ambiental de desechos peligrosos, químicos y contaminantes orgánicos persistentes. Salvo por seis excepciones, todos los Estados Miembros de las Naciones Unidas son partes en al menos uno de estos convenios. El número de partes en estos convenios aumentó significativamente entre 2005 y 2015, en particular en África y Oceanía. En la actualidad, existen 183 partes en el convenio de Basilea, 180 en el convenio de Estocolmo y 155 en el convenio de Rotterdam (lo que incluye a la Unión Europea como parte en las tres convenciones). Ser parte en estos acuerdos internacionales conlleva determinadas obligaciones, entre ellas el establecimiento de una persona de contacto para transmitir comunicaciones pertinentes. Salvo por uno, todas las partes en el convenio de Basilea y la mayoría de las partes en los convenios de Rotterdam y Estocolmo han designado a dichos contactos. No obstante, la cantidad de países que presenta informes nacionales de progreso, que además son obligatorios de acuerdo a los convenios de Basilea y Estocolmo, ha disminuido a partir de 2009-2010.
Proporción de partes de acuerdos internacionales multilaterales sobre el medio ambiente y otros químicos (Convenios de Basilea, Rotterdam y Estocolmo), 2000 y 2015 (porcentaje)
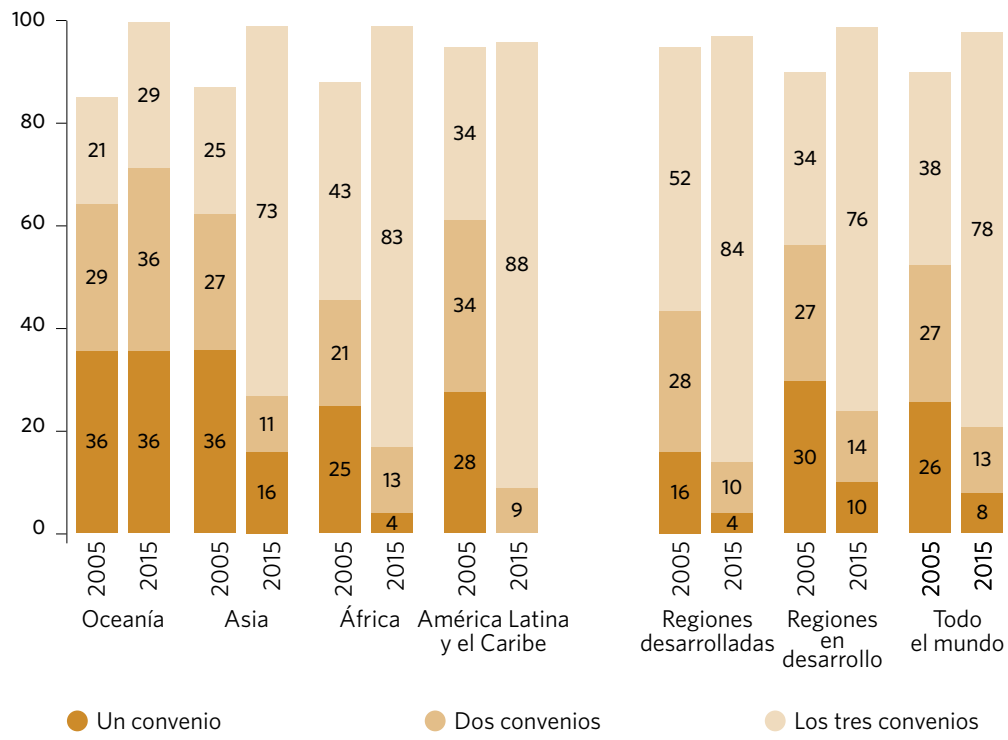

Nota: Los datos para Asia incluyen el Cáucaso y Asia central, Asia occidental, meridional, sudoriental y oriental. Los datos para África incluyen África septentrional y África subsahariana. Los porcentajes en los gráficos no siempre suman 100 debido al redondeo. 


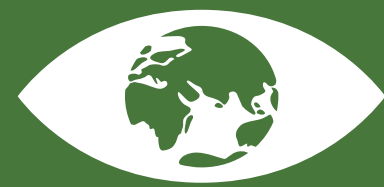

\section{Objetivo 13: Adoptar medidas urgentes para combatir el cambio climático y sus efectos}

El cambio climático representa la principal amenaza al desarrollo y sus efectos masivos y sin precedentes afectan desproporcionadamente a los más pobres y vulnerables. El Objetivo 13 convoca a tomar medidas urgentes no solo para combatir el cambio climático y sus efectos, sino también para fortalecer la resiliencia para responder a los peligros relacionados con el clima y los desastres naturales.

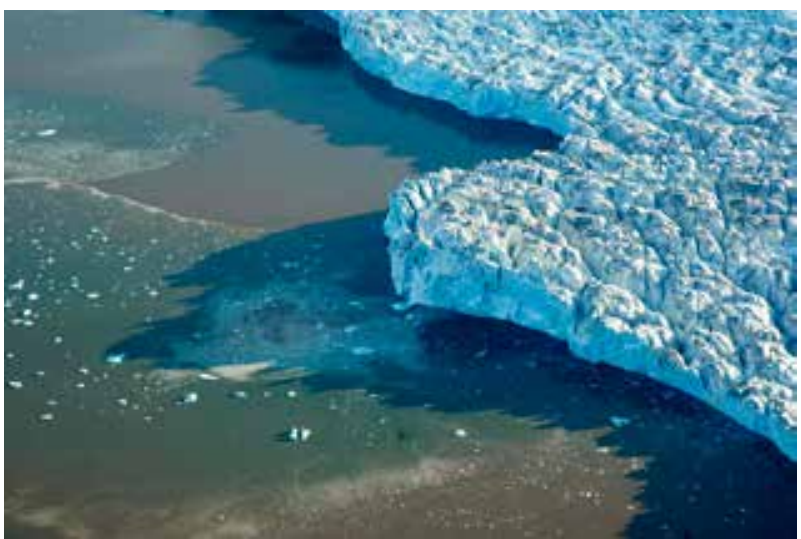

Comparación de los niveles de emisiones de gases de efecto invernadero a nivel mundial en 2025 y 2030, resultantes de la implementación de la contribución prevista determinada a nivel nacional (CPDN) y bajo otros escenarios ( $\mathrm{GtCO} 2$ eq/año)

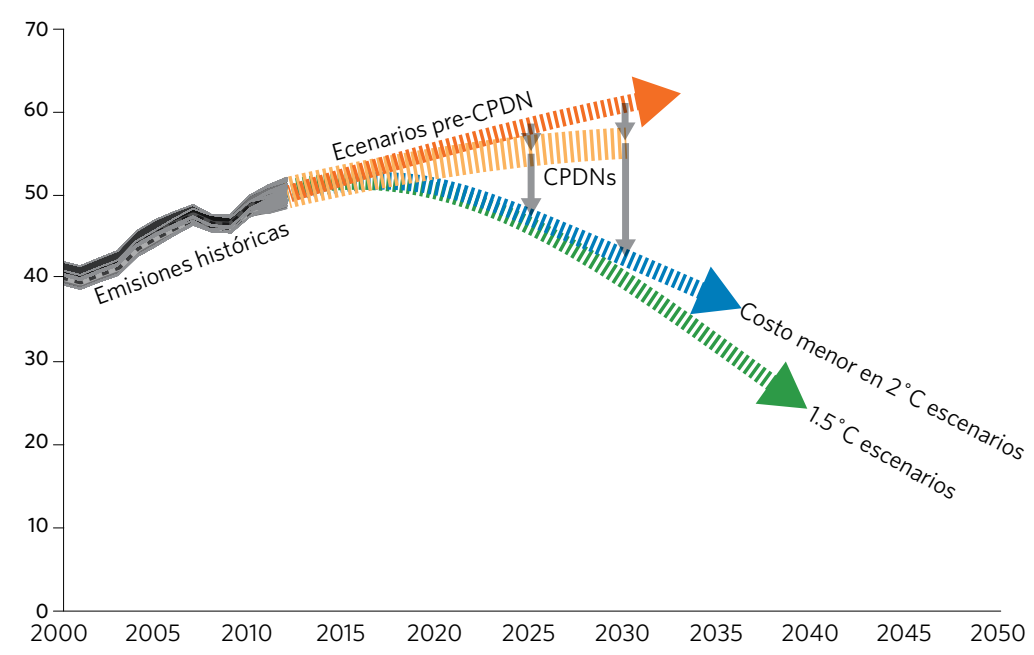

Nota: Para un gráfico más detallado ver el gráfico 2 del informe de síntesis actualizado de la Convención Marco de las Naciones Unidas sobre el Cambio Climático sobre el effecto total de las contribuciones previstas determinadas a nivel nacional, 2 de mayo de 2016 (http://unfccc.int/focus/indc_portal/items/9240.php).
El Acuerdo de París prepara el terreno para una ambiciosa acción por el clima por todos para un desarrollo sostenible

Las emisiones de carbono han aumentado sostenidamente en el curso de las últimas décadas, lo que lleva al aumento de las temperaturas mundiales. El período de 2011 a 2015 fue el más caluroso registrado; como consecuencia, el hielo marino alcanzó su nivel más bajo en la historia, y la decoloración del coral (que resulta del aumento de las temperaturas de la superficie marina) amenaza los arrecifes de coral del mundo. El documento histórico del Acuerdo de París, firmado en abril de 2016 por 175 Estados Miembros, pretende mitigar el cambio climático y acelerar e intensificar las acciones y las inversiones necesarias para un futuro sostenible y bajo en carbono. De importancia central para el acuerdo es la necesidad de fortalecer la respuesta global para evitar que las temperaturas mundiales no aumenten en más de 2 grados Celsius por encima de los niveles preindustriales y empeñarse en realizar esfuerzos adicionales para limitar el aumento a 1,5 grados Celsius. El Acuerdo de París requiere que las partes identifiquen sus "contribuciones previstas determinadas a nivel nacional" (CPDN). Se hará un seguimiento del progreso del Acuerdo de París cada cinco años a través de un ejercicio de inventario global. 
Más de $70 \%$ de las Partes de la Convención Marco de las Naciones Unidas sobre el Cambio Climático incluyeron un componente de adaptación en sus planes para la acción por el clima

Al 4 de abril de 2016, 189 de las 197 Partes de la Convención Marco de las Naciones Unidas sobre el Cambio Climático presentaron 161 CPDN (la Comisión Europea presentó una CPDN conjunta). De éstas, 137 incluyeron un componente de adaptación. Algunos hicieron énfasis en que la adaptación era su prioridad principal, ya que ven los posibles efectos del cambio climático como fuertemente vinculados al desarrollo, la sostenibilidad y la seguridad nacionales. En el componente de adaptación de sus CPDN, las Partes se refirieron virtualmente a cada sector y área de la economía. Las tres principales áreas de prioridad fueron el agua, la agricultura y la salud, lo que coincide con los principales peligros climáticos identificados por las Partes: inundaciones, sequías y temperaturas más altas. Muchas de las Partes también se refirieron a las enfermedades transmitidas por vectores o agua como un peligro que requiere adaptación.
Cantidad de partes que refirieron a un área o sector como prioridad en las acciones de adaptación comunicadas en el componente de adaptación de las CPDN

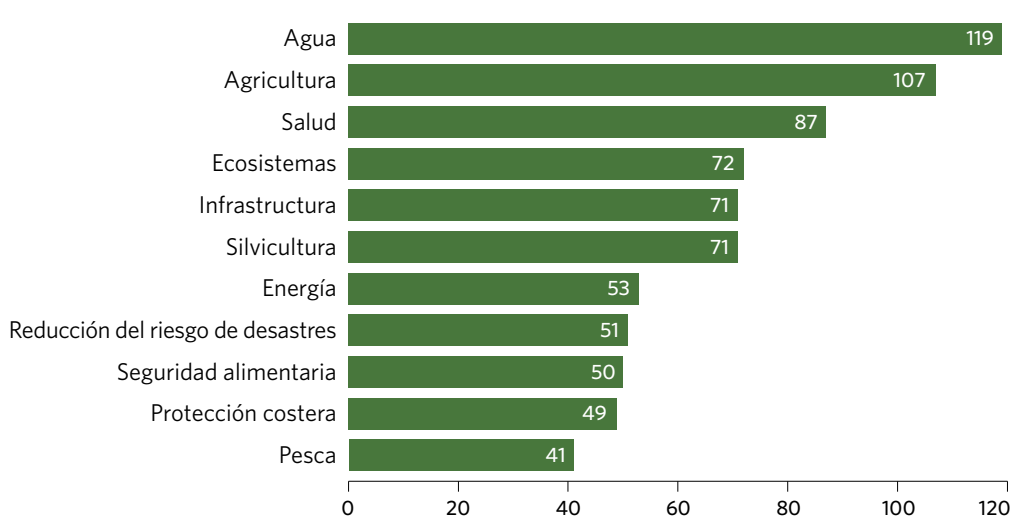

\section{A medida que los desastres naturales han aumentado en frecuencia e intensidad, más personas se han visto afectadas por éstos}

Los desastres, muchos de los cuales se ven exacerbados por el cambio climático y que están aumentando en frecuencia e intensidad, impiden el progreso hacia un desarrollo sostenible. Aunque la cantidad de personas afectadas varía en gran medida año con año, en promedio murieron 83.000 personas y 211 millones se vieron afectadas cada año como resultado de algún desastre natural ocurrido entre los años 2000 y 2013.
Número de muertes y personas afectadas resultantes de desastres naturales en todo el mundo, 2000-2013 (miles)

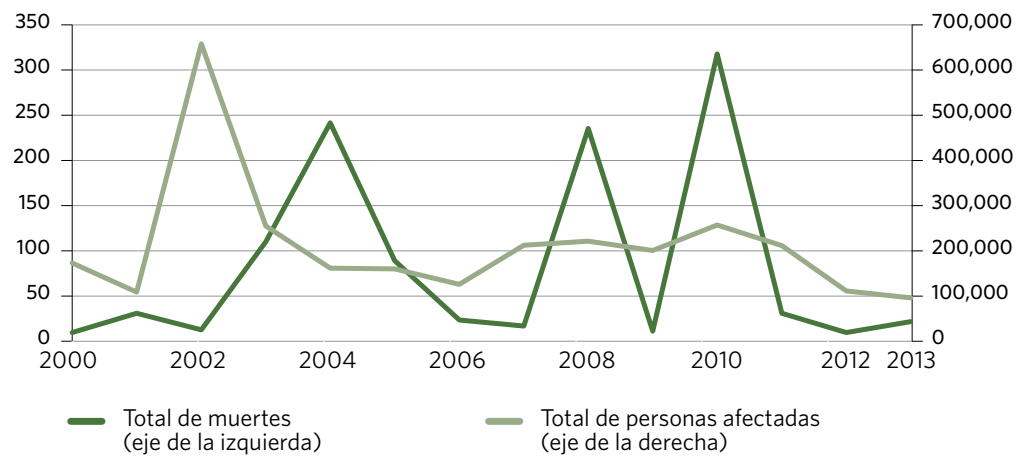

\section{3 países en todo el mundo cuentan con disposiciones establecidas para manejar el riesgo de desastres}

Con el aumento de los desastres naturales, los países han comenzado a implementar estrategias de reducción de riesgos de desastre a nivel local y nacional. En 2015, 95 países acordaron voluntariamente realizar una autoevaluación de la inclusión de disposiciones legislativas y/o normativas para manejar el riesgo de desastres. Entre éstos, 83 países tenían dichas disposiciones establecidas. Con el fin de reducir los factores de riesgo de desastre subyacentes, los países han comenzado a considerar e implementar diversos mecanismos que incluyen proyectos y programas de adaptación al cambio climático, evaluaciones de impacto ambiental, planificación integrada, pagos para servicios derivados de los ecosistemas y legislación para la protección de áreas ambientalmente sensibles.
Número de países que cuentan con disposiciones legislativas y/o normativas para manejar el riesgo de desastres, 2015

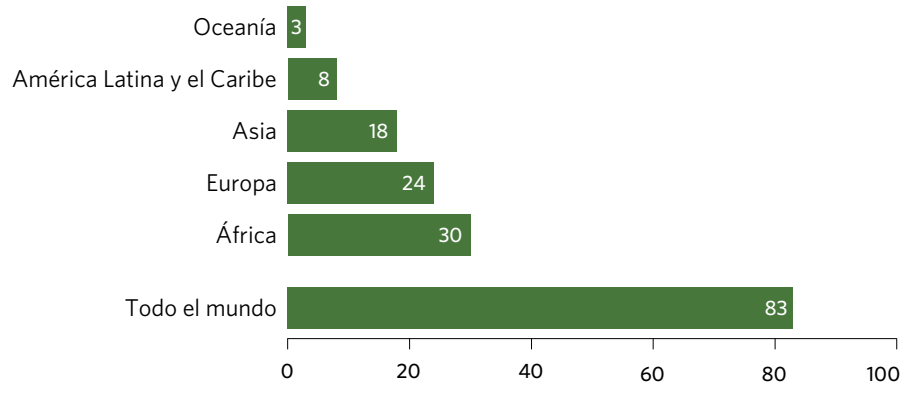




\section{Objetivo 14: Conservar y utilizar sosteniblemente los océanos, los mares y los recursos marinos para el desarrollo sostenible}

Los océanos, mares y otros recursos marinos son esenciales para el bienestar humano y para el desarrollo social y económico a nivel mundial. Su conservación y uso sostenible son temas centrales para cumplir con la Agenda 2030, especialmente para pequeños Estados insulares en desarrollo. Los recursos marinos son particularmente importantes para quienes habitan en comunidades costeras, que en 2010 representaban el 37\% de la población mundial. Los océanos proveen medios de vida, subsistencia y beneficios para la pesca, el turismo y otros sectores. También ayudan a regular el ecosistema global al absorber calor y dióxido de carbono (CO2) de la atmósfera. Sin embargo, los océanos y las áreas costeras son extremadamente vulnerables a la degradación del medio ambiente, la pesca excesiva, el cambio climático y la contaminación.

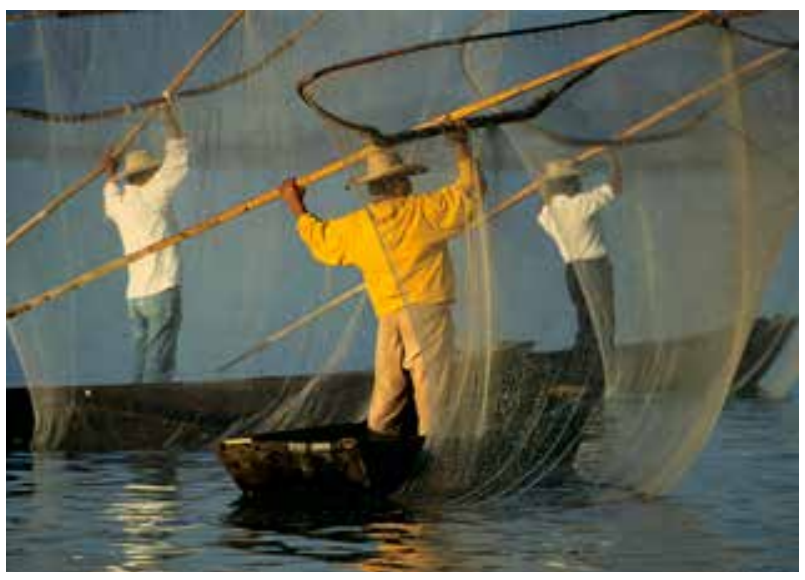

La reducción progresiva de la población sostenible de peces se ha lentificado y parece haberse estabilizado

La pesca contribuye de manera significativa a la seguridad alimentaria mundial, a los medios de subsistencia y a la economía. Sin embargo, si no se gestiona de forma sostenible, la pesca puede dañar los hábitats de los peces, reducir la biodiversidad y dañar el funcionamiento de ecosistemas, lo que causaría repercusiones negativas para el desarrollo económico y social sostenibles. Para alcanzar un equilibrio saludable, las poblaciones de peces deben mantenerse dentro de límites biológicamente sostenibles: en o por encima del nivel de abundancia que genere el máximo rendimiento sostenible. En base al análisis de las poblaciones evaluadas, la proporción de poblaciones marinas de peces a nivel mundial dentro de niveles biológicamente sostenibles disminuyó del $90 \%$ en 1974 al 69\% en 2013 y parece haberse estabilizado en los últimos años. 


\section{La cobertura de áreas costeras y marinas protegidas se cuadriplicó desde el año 2000}

La protección de lugares de biodiversidad marina es vital para asegurar la sostenibilidad de la biodiversidad marina y los servicios derivados de los ecosistemas. En 2014, el 8,4\% del ambiente marino bajo jurisdicción nacional (hasta 200 millas náuticas desde la costa), y un $0,25 \%$ del ambiente marino no comprendido bajo jurisdicción nacional, estaban protegidos. Tanto las regiones desarrolladas como las regiones en desarrollo aumentaron su protección a áreas marítimas entre los años 2000 y 2014. Sin embargo, gran parte de este aumento fue causado por el establecimiento de grandes áreas protegidas alrededor de algunos países y en áreas que no fueron necesariamente elegidas por su biodiversidad. En consecuencias, las áreas de protección marina no están distribuidas de manera uniforme y las diferencias entre las distintas regiones es significativa. En Oceanía, la porción de áreas marinas y costeras protegidas creció de menos del $0.1 \%$ en el año 2000 a un 7,4\% en 2014: el mayor porcentaje entre regiones en desarrollo. Para asegurar que no se pierdan especies y habitantes marinos, estas áreas deben gestionarse de manera eficaz y cubrir áreas que son importantes para la biodiversidad, tales como áreas de biodiversidad clave, que son sitios importantes para la persistencia de la biodiversidad en el mundo. Entre 2000 y 2016, el porcentaje de áreas de biodiversidad marina clave que estaban completamente cubiertas por áreas de protección aumentó de 15\% a 19\%.
Proporción de áreas costeras y marinas protegidas, 2000 y 2014 (porcentaje)

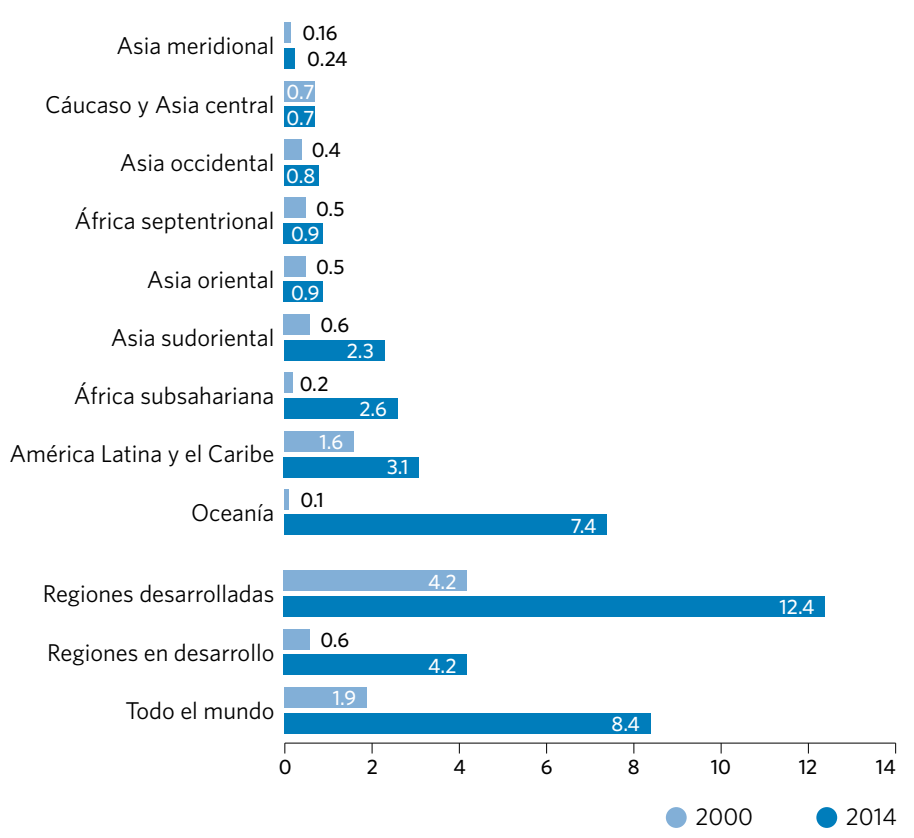

\section{Importantes ecosistemas marinos que albergan a más de 780 millones de personas están en grave riesgo de eutrofización costera}

Las regiones costeras son particularmente vulnerables a la contaminación. Ya que las cuencas de los ríos, los ecosistemas marinos y la atmósfera son todos parte del sistema hidrológico, los efectos de la contaminación pueden sentirse lejos de su punto de origen. En muchas comunidades costeras, la contaminación y la eutrofización (exceso de nutrientes en el agua, frecuentemente debido a los drenajes de la tierra, causan un denso crecimiento de plantas y algas y la muerte de la vida animal por falta de oxígeno) han sido factores clave en el avance de cambios perjudiciales. De acuerdo con la evaluación comparativa mundial del Programa de Evaluación de las Aguas Transfronterizas realizada en 2016, los cinco grandes ecosistemas marinos en mayor riesgo de eutrofización costera son la Bahía de Bengala, el Mar de la China oriental, el Golfo de México, la plataforma del norte de Brasil y el Mar de la China meridional; áreas que proporcionaban servicios derivados de los ecosistemas para una población costera de 781 millones de personas en 2010.
Categorías de indicadores de riesgo de nutrientes para grandes ecosistemas marinos

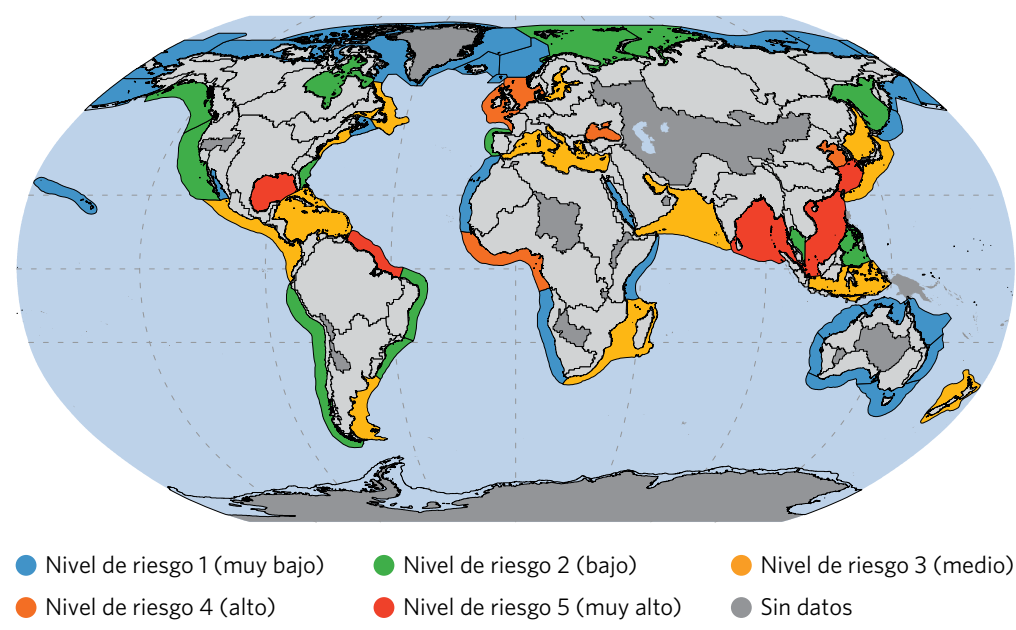

Nota: El mapa mundial sólo tiene fines ilustrativos y no implica la expresión de ninguna opinión respecto al estado legal de cualquier país o territorio, o en cuanto a la delimitación de sus límites o fronteras. 


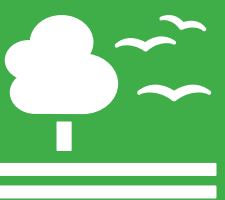

\section{Objetivo 15: Proteger, restablecer y promover el uso sostenible de los ecosistemas terrestres, gestionar sosteniblemente los bosques, luchar contra la desertificación, detener e invertir la degradación de las tierras y detener la pérdida de biodiversidad}

Preservar las diversas formas de vida en la tierra requiere esfuerzos dirigidos para proteger, restaurar y promover la conservación y el uso sostenible de los ecosistemas terrestres y de otros tipos. El Objetivo 15 se enfoca específicamente en gestionar bosques de forma sostenible, detener y revertir la degradación del terreno y los hábitats naturales, combatir exitosamente la desertificación y detener la pérdida de biodiversidad. Todos estos esfuerzos combinados buscan asegurar que las generaciones futuras puedan disfrutar de todos los beneficios de los ecosistemas terrestres, así como medios de vida sostenibles.

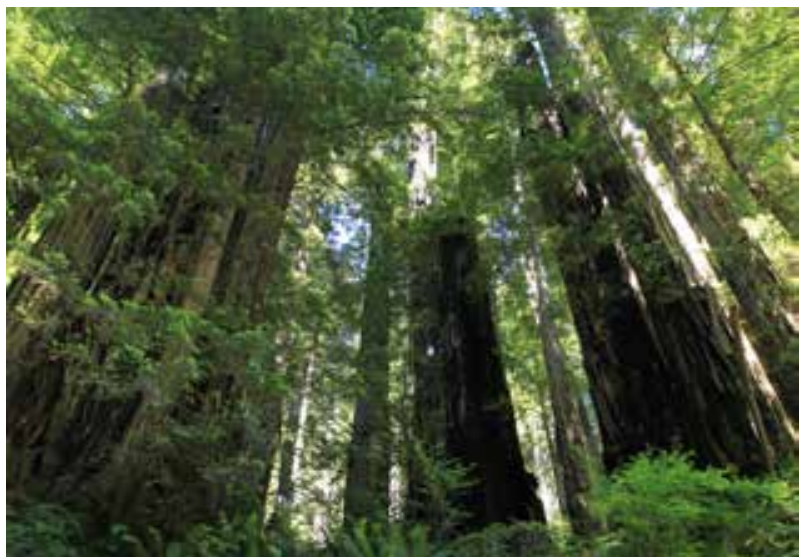

La pérdida neta de bosques se redujo en más de la mitad desde la década de 1990, pero todavía continúa

Entre 1990 y 2015, la superficie forestal del mundo disminuyo de $31,7 \%$ del total de la masa continental a un $30,7 \%$. Esta pérdida fue causada principalmente por la conversión de bosques para otros usos, como la agricultura y el desarrollo de infraestructura. Al mismo tiempo, se recuperaron otras áreas forestales a través de la plantación, la restauración de terreno o la expansión natural. Como resultado de estos procesos y los esfuerzos para desacelerar la deforestación, la pérdida neta de la superficie forestal se redujo de 7,3 millones de hectáreas anuales en la década de 1990 a 3,3 millones de hectáreas anuales durante el período comprendido entre 2010 y 2015. El progreso es desigual entre las regiones: América Latina y el Caribe, África subsahariana, y Asia sudoriental sufrieron las mayores pérdidas de superficie forestal, mientras que Asia oriental experimentó mayores recuperaciones. 


\section{Cada vez más áreas clave de biodiversidad forman parte de zonas protegidas}

En el año 2014, 15,2\% de los ambientes terrestres y de agua dulce del mundo formaban parte de zonas protegidas reconocidas, dedicadas y administradas para alcanzar la conservación de la naturaleza a largo plazo. Una muestra fundamental de su eficacia es la medida en que se incluyen lugares que contribuyen de forma significativa a mantener la biodiversidad mundial, tales como las áreas clave de biodiversidad (ACB). A nivel mundial, el porcentaje de $A C B$ terrestres, interiores de agua dulce y de montañas que forman parte de zonas protegidas aumentó de un $16,5 \%$ a un $19,3 \%$, de un $13,8 \%$ a un $16,6 \%$, y de un $18,1 \%$ a un $20,1 \%$ respectivamente, entre los años 2000 y 2016 . Salvaguardar las áreas clave de biodiversidad en todo el mundo para los tres ecosistemas es fundamental para mantener la diversidad genética, de especies y de ecosistemas, y por lo tanto, los beneficios que estos ofrecen a las personas.

\section{En cada región, la supervivencia de las especies se ve cada vez más amenazada}

Al 2015, se tenía conocimiento de que más de 23.000 especies de plantas, hongos y animales enfrentaban una alta probabilidad de extinción. De acuerdo al Índice de la Lista Roja compilada por la Unión Internacional para la Conservación Natural, los anfibios disminuyen más rápidamente en América Latina y el Caribe, principalmente debido a la quitridiomicosis, una de las numerosas y crecientes enfermedades que afectan la vida salvaje a nivel mundial. Las aves y mamíferos con mayores riesgos de extinción se encuentran en Asia sudoriental, impulsados sobre todo por la conversión de bosques en tierras bajas. En promedio, el riesgo de extinción de las especies de coral aumenta con mayor rapidez, mientras que las especies de cícadas (un grupo antiguo de plantas productoras de conos) son el grupo de especies más amenazado. Sin embargo, la pérdida de especies no es inevitable: en cinco pequeños estados insulares en desarrollo (Islas Cook, Fiji, Mauricio, Seychelles y Tonga), el riesgo de extinción de las especies vertebradas pudo revertirse como resultado de las acciones de conservación llevadas a cabo en el curso de las últimas décadas.
Proporción de áreas clave de biodiversidad que forman parte de zonas protegidas, por tipo de ecosistema (terrestre, agua dulce y montañoso), 2000-2016 (porcentaje)

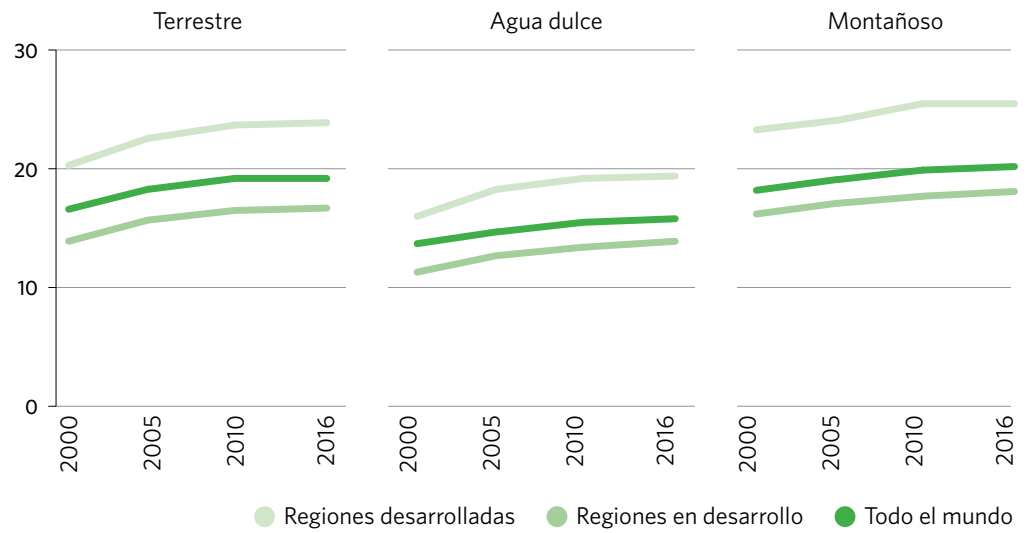

Nota: Los tipos de ecosistemas no son mutuamente excluyentes.

Índice de la Lista Roja* de la supervivencia de las especies, 1993-2016

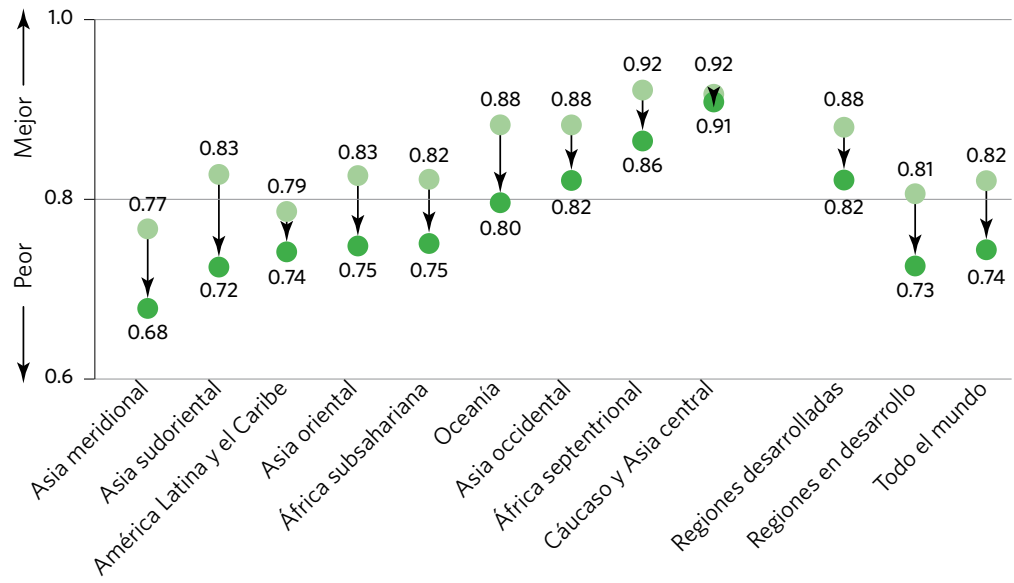

1993

2016

El Índice de la Lista Roja para cada región está basado en la probabilidad de supervivencia agregada (el opuesto al riesgo de extinción) para todas las aves, mamíferos, anfibios, corales y cícadas que habitan en la región, ponderadas a partir de la fracción de la distribución de cada especie en la región. Los valores varían desde 1,0, que indica una contribución mínima al índice mundial (es decir, todas las especies de la región se clasifican como "de menor preocupación") a cero, que indica la máxima contribución posible al índice global (es decir, todas las especies en la región se clasifican como Extintas).

\section{El tráfico ilegal de vida silvestre es un fenómeno mundial con variaciones regionales distintivas}

La lista de especies bajo protección internacional continúa creciendo. Al mismo tiempo, los esfuerzos de conservación se ven frustrados por la caza furtiva y el tráfico de vida silvestre, delitos que ocurren en todo el mundo. Desde 1999, se han denunciado al menos 7.000 especies de animales y plantas por su tráfico ilegal, lo que afecta a 120 países. El tráfico de vida silvestre afecta a todas las regiones del mundo, ya sea como fuente, zona de tránsito o destino. El tráfico de aves es más común en América Central y del Sur; mamíferos en Asia y África; reptiles en Europa y América del Norte; y corales en Oceanía.
Proporción de incidentes de incautación por región y clase taxonómica, 1999-2015 (porcentaje)

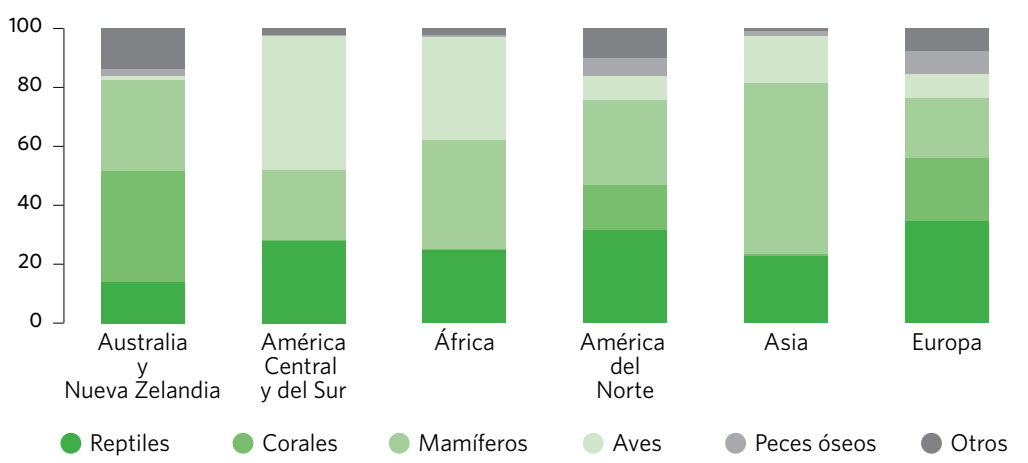

Nota: Porcentaje de todos los incidentes de incautación en la base de datos de World Wildlife Seizures (Incautaciones Mundiales de Vida Silvestre), que contiene más de 164.000
incautaciones en 120 países. Las agrupaciones regionales fueron realizadas de acuerdo a los estándares de las Naciones Unidas para el uso estadístico de regiones geográficas (M49). 


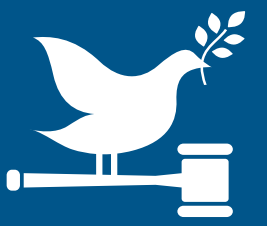

\section{Objetivo 16: Promover sociedades pacíficas e inclusivas para el desarrollo sostenible, facilitar el acceso a la justicia para todos y construir a todos los niveles instituciones eficaces e inclusivas que rindan cuentas}

\begin{abstract}
Un tema central para la Agenda 2030 para el Desarrollo Sostenible es la necesidad de promover sociedades pacíficas e inclusivas basadas en el respeto a los derechos humanos, el estado de derecho e instituciones transparentes, eficaces y responsables. En las últimas décadas, varias regiones disfrutaron de mayores y continuos niveles de paz y seguridad. Sin embargo, muchos países todavía enfrentan violencia y conflictos armados prolongados, demasiadas personas dependen del apoyo limitado de instituciones débiles y no tienen acceso a la justicia, a la información ni a otras libertades fundamentales. Se están realizando esfuerzos para lograr que las instituciones nacionales e internacionales sean más eficaces, inclusivas y transparentes. Hoy en día, más de la mitad del mundo tiene instituciones de derechos humanos internacionalmente reconocidas. No obstante, todavía existen importantes desafíos, como la falta de datos sobre las diversas formas de violencia contra niños y otros grupos vulnerables, así como el acceso a la justicia y el acceso público a la información.
\end{abstract}

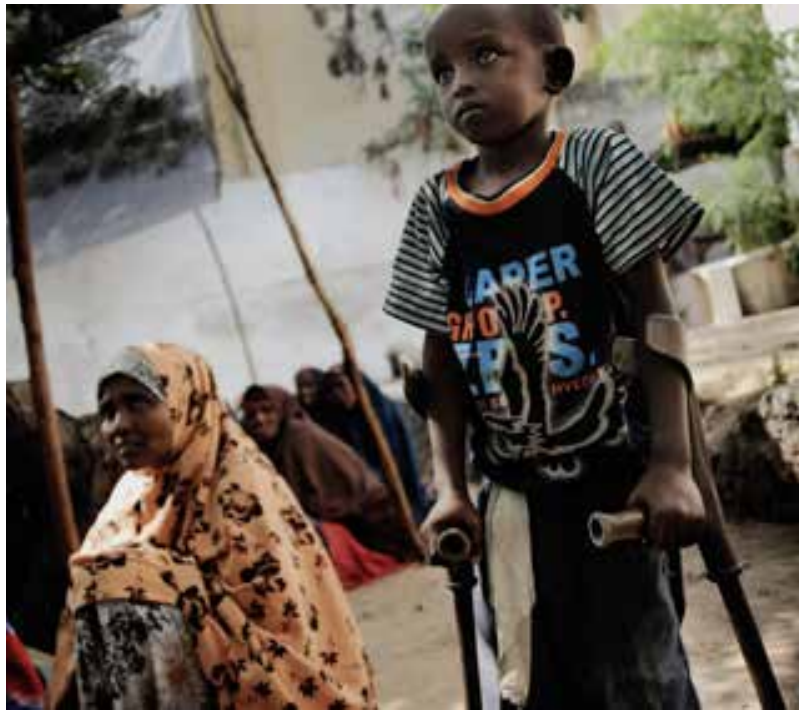

Número de víctimas de homicidios dolosos por cada 100.000 habitantes, desde 2014 en adelante

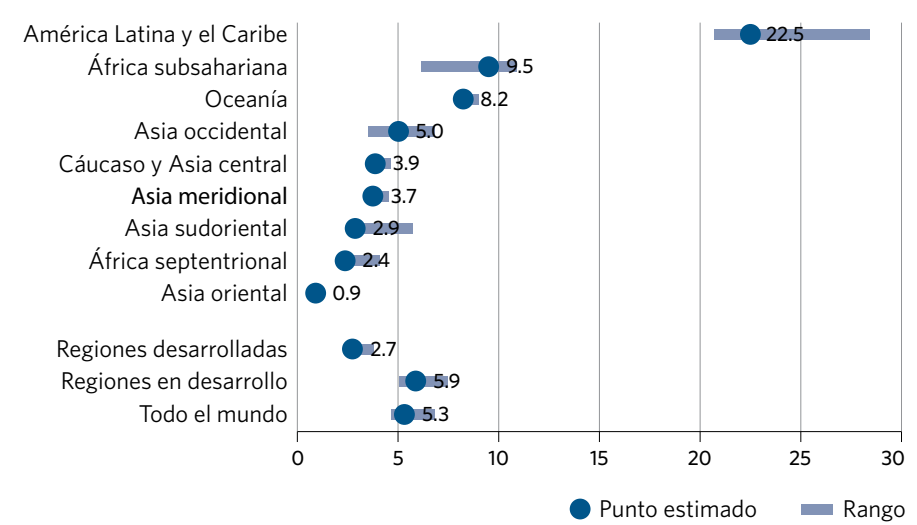

Las tasas de homicidio varían ampliamente entre las regiones

Se ha estimado que el número de víctimas de homicidios dolosos por cada 100.000 habitantes se encontraba entre 4,6 y 6,8 en el año 2014 a nivel mundial. Sin embargo, la tasa de homicidios en regiones en desarrollo fue el doble que la de las regiones desarrolladas; en América Latina y el Caribe la tasa fue cuatro veces mayor que el promedio mundial. 


\section{Los niños, en su mayoría niñas, representan casi el $30 \%$ de las víctimas de la trata de personas a nivel mundial}

Persisten varias formas de violencia contra los niños, incluyendo la trata de personas y la violencia sexual. A nivel mundial, la proporción de niñas y niños entre las víctimas de trata de personas alcanzó un punto máximo en el año 2011 , con $21 \%$ y $13 \%$, respectivamente, de los casos detectados por autoridades ese año. Las niñas víctimas de la trata de personas suelen ser objeto de explotación sexual, forzadas al matrimonio y/o a la servidumbre doméstica. La falta de denuncias y de datos comparativos continúan obstaculizando los esfuerzos para entender el alcance total de la violencia sexual hacia los niños. Los datos de encuestas de 31 países de bajos y medianos ingresos sugieren que la proporción de mujeres entre las edades de 18 y 29 años que sufrieron violencia sexual por primera vez antes de los 18 años podría alcanzar un $16 \%$.
Proporción de niños entre las víctimas de trata de personas detectadas, en cantidad de personas a nivel mundial, por sexo, 2004-2014 (porcentaje)

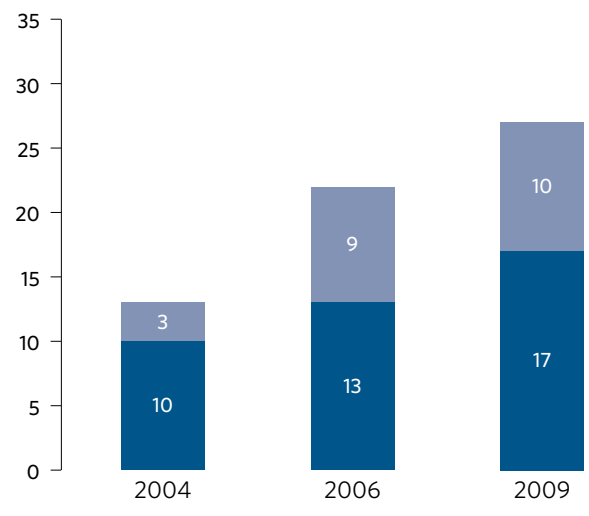

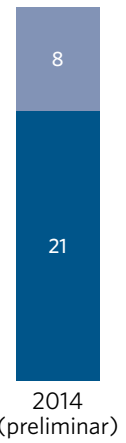

- Niñas Niños

\section{El 30\% de los prisioneros en todo el mundo, de los cuales dos tercios se encuentran en países en desarrollo, están encarcelados sin sentencia}

La proporción de personas detenidas sin sentencia apenas disminuyó levemente a nivel mundial durante la última década: de un 32\% del total de los detenidos entre 2003 y 2005, a 30\% de 2012 a 2014. La cifra para las regiones en desarrollo ha sido en promedio superior a la de las regiones desarrolladas. El mayor índice de detenidos sin sentencia se registró en Asia meridional, donde a pesar de los progresos recientes, más de dos de cada tres prisioneros permanecieron sin sentencia entre 2012 y 2014. En América Latina y el Caribe, la región con el segundo porcentaje más alto, la proporción de personas detenidas sin sentencia permaneció prácticamente sin cambios durante la última década, siendo de un $43 \%$.

\section{El registro de nacimientos es el primer paso} para asegurar el reconocimiento ante la ley, sin embargo, se le sigue negando este derecho fundamental a uno de cada cuatro niños

El registro de niños al momento de su nacimiento es el primer paso para asegurar su reconocimiento ante la ley, la protección de sus derechos individuales y el acceso a la justicia y a servicios sociales. Sin embargo, los nacimientos de uno de cada cuatro niños menores de 5 años todavía siguen sin registrarse. En África subsahariana la proporción corresponde a más de la mitad (54\%). En todo el mundo, los niños que viven en zonas urbanas tienen 1,5 veces más probabilidades de ser registrados que sus contrapartes rurales. En la mayoría de las regiones, las tasas de registro de nacimientos tienden a ser las más altas para el $20 \%$ más rico de la población.
Detenidos que no han sido sentenciados como proporción de la población carcelaria total, 2003-2005 y 2012-2014 (porcentaje)

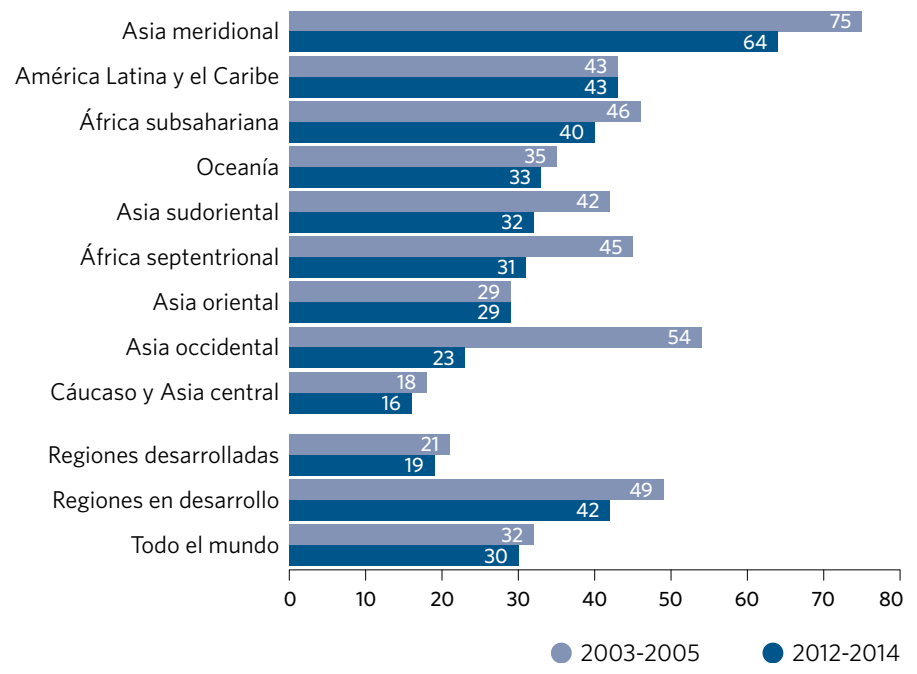

Proporción estimada de niños menores de 5 años cuyos nacimientos fueron registrados, 2010-2015 (porcentaje)

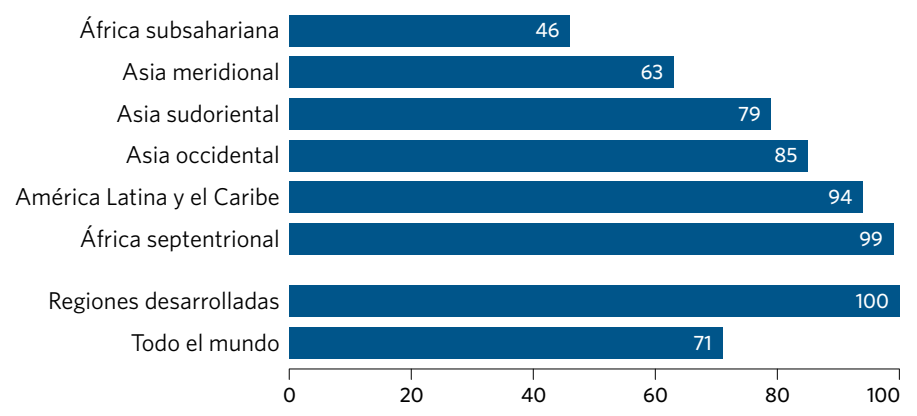

Nota: Las estimaciones se basan en los datos de 144 países que componen el $92 \%$ de la población mundial de niños menores de 5 años. La disponibilidad de datos ha sido insuficiente para calcular las estimaciones regionales para Asia oriental, Oceanía y el Cáucaso y Asia central. 


\section{Objetivo 17: Fortalecer los medios de implementación y revitalizar la Alianza Mundial para el Desarrollo Sostenible}

Alcanzar las ambiciosas metas de la Agenda 2030 requiere alianzas mundiales revitalizadas y mejoradas que unan a los Gobiernos, las sociedades civiles, el sector privado, el sistema de las Naciones Unidas y otros actores, y que movilicen todos los recursos disponibles. Lograr los objetivos de implementación, lo que incluye la recaudación de los fondos necesarios, es crucial para realizar la Agenda, así como lo es la completa implementación de la Agenda de Acción de Addis Abeba. Aumentar el apoyo a los países en desarrollo, en particular a los países menos adelantados, los países en desarrollo sin litoral y los pequeños estados insulares en desarrollo, es fundamental para lograr un progreso equitativo para todos.

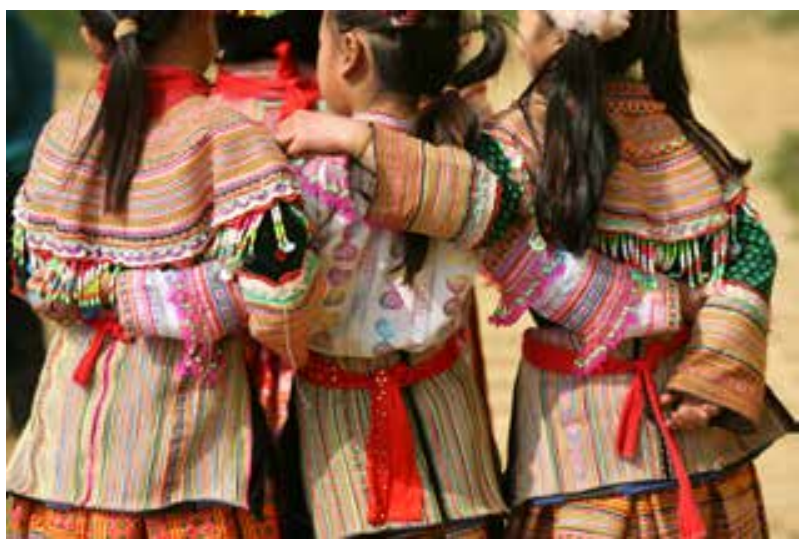

Asistencia oficial para el desarrollo neta de los países del CAD-OCDE (miles de millones de dólares constantes de Estados Unidos de 2014) y como proporción del ingreso nacional bruto de los donantes (porcentaje), 2000-2015

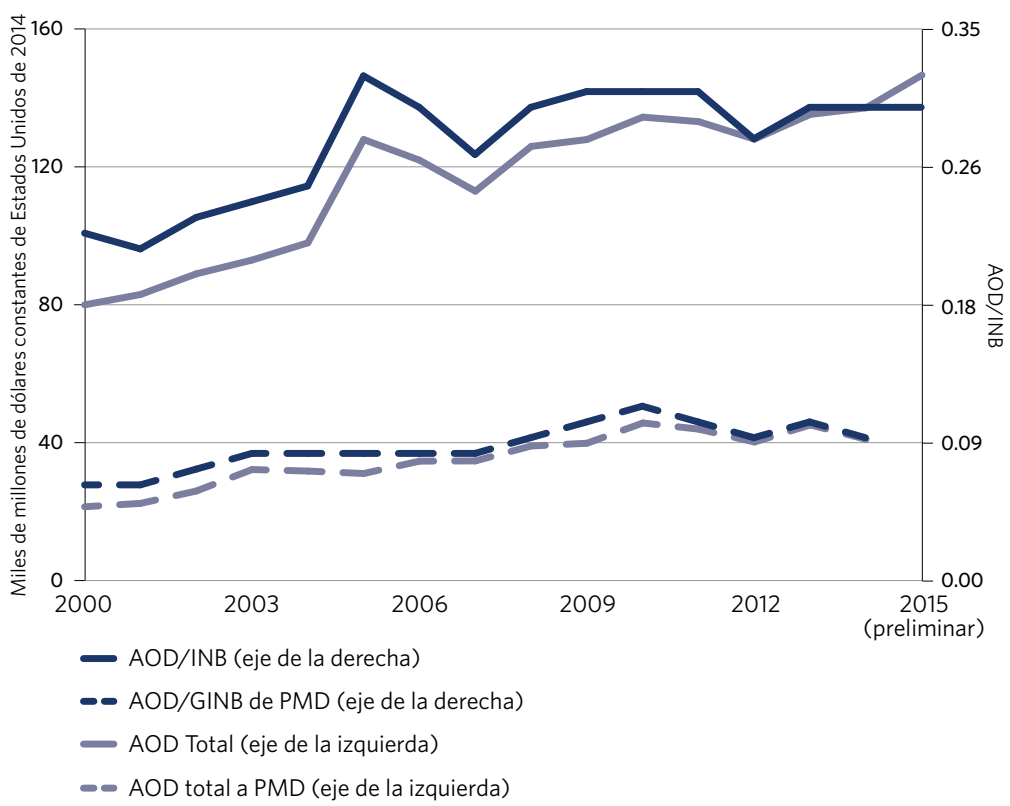

La asistencia oficial para el desarrollo continúa creciendo, a pesar de que la ayuda a los países más pobres se ha estancado

En 2015, la asistencia oficial para el desarrollo (AOD) provista por los países miembros del Comité de Asistencia para el Desarrollo (CAD) de la Organización para la Cooperación y el Desarrollo Económicos (OCDE) alcanzó un total de 131.600 millones de dólares. Teniendo en cuenta la inflación y el aumento del valor del dólar en 2015 , esto significó un aumento de $6,9 \%$ en términos reales con respecto a 2014, y representó el nivel más alto jamás alcanzado. La AOD total de los países del CAD como parte de su ingreso nacional bruto (INB) fue de un 0,30\%, a la par con 2014. La mayor parte de este incremento se debe a un aumento de gastos para los costos de los refugiados. Sin embargo, incluso si se excluyen esos costos, la AOD de todas formas aumentó en un 1,7\%. En el año 2015, siete países alcanzaron el objetivo de las Naciones Unidas de un AOD del 0,7\% del INB: Dinamarca, Luxemburgo, Países Bajos, Noruega, Suecia, los Emiratos Árabes y el Reino Unido. 


\section{La carga del servicio de deuda se redujo sustancialmente entre los años 2000 y 2012}

La proporción entre el servicio de deuda externa y las exportaciones se encontraba por debajo del $6 \%$ para casi todas las regiones en desarrollo en 2012. Esto representa una disminución sustancial de los índices comparables del año 2000. El aumento de las ganancias por exportaciones, una mejora en la gestión de deudas y condiciones de préstamo atractivas en los mercados internacionales contribuyeron a esta mejora. Sin embargo, para los países más pobres, el factor contribuyente más importante fue el inmediato alivio de la deuda: 36 de los 39 países elegibles para la "Iniciativa en favor de los países pobres muy endeudados" completaron el proceso y recibieron un alivio de la deuda de alrededor de 136 mil millones de dólares de acreedores oficiales.
Servicio de la deuda como proporción del total de las exportaciones de bienes y servicios, 2000 y 2012 (porcentaje)

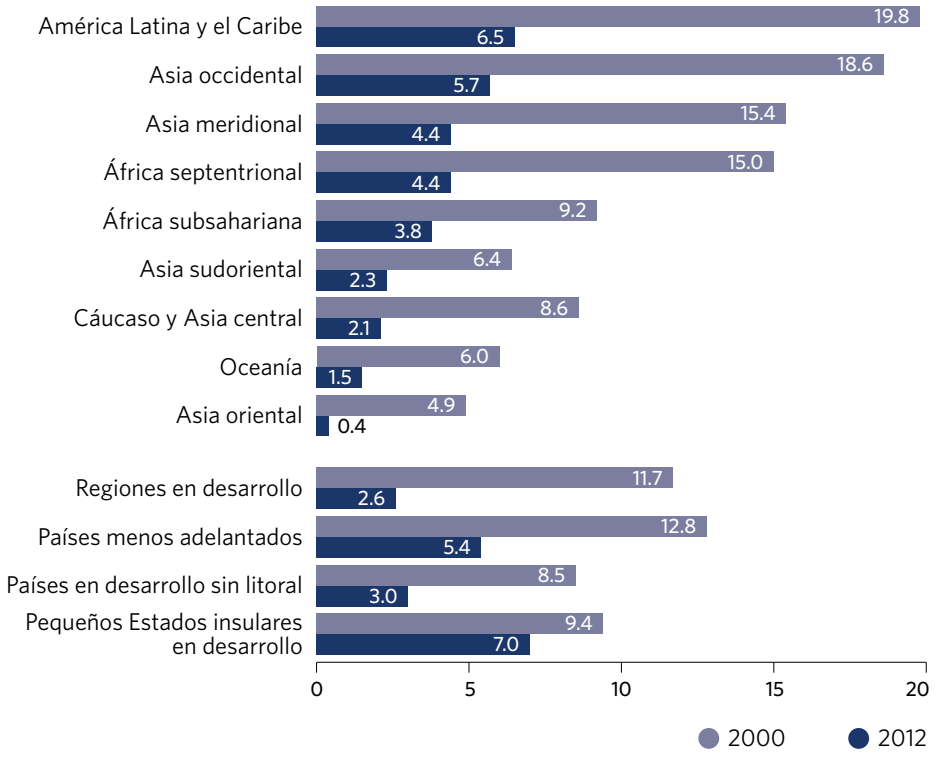

\section{El Internet de alta velocidad permanece fuera del alcance de la vasta mayoría de las personas que viven en los países menos adelantados}

Las conexiones de banda ancha fija siguen siendo demasiado costosas e inaccesibles para grandes franjas de la población en las regiones en desarrollo, lo que resalta la vasta brecha digital en el acceso a servicios de Internet de alta velocidad y alta capacidad. En 2015, la penetración de la banda ancha fija alcanzó un 29\% de la población en las regiones desarrolladas, pero solamente un $7,1 \%$ de las regiones en desarrollo y un 0,5\% en los países menos adelantados. Adicionalmente, mientras que las velocidades superiores a los 10 megabits por segundo son comunes en las regiones desarrolladas, las conexiones en la mayor parte de las regiones en desarrollo no supera los 2 megabits por segundo. De forma similar, mientras que el acceso a Internet aumentó sustancialmente en la última década, solo un tercio de la población de los países en desarrollo y una décima parte en los PMA estuvieron conectados en 2015 , en comparación con el $80 \%$ de la población en los países desarrollados. También existe una importante brecha digital en cuanto al género, ya que el índice de penetración de Internet es 11\% inferior para las mujeres que para los hombres, a nivel mundial.
Suscripciones a Internet de banda ancha fija por cada 100 habitantes, 2010 y 2015

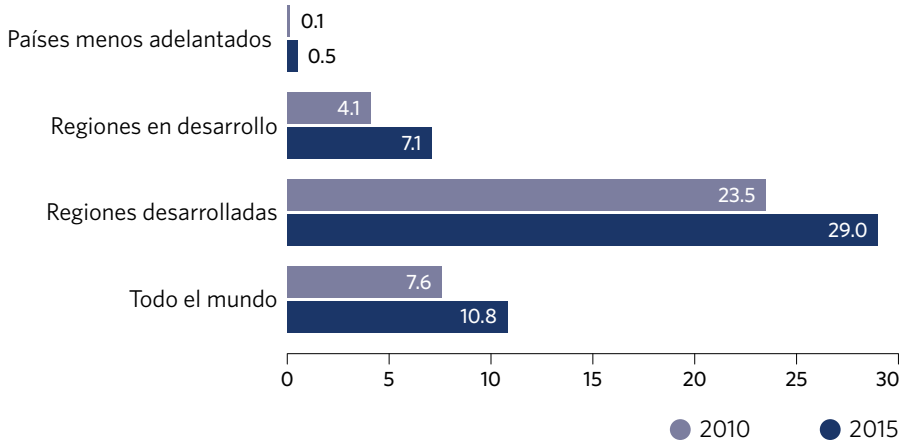


Participación de las regiones en desarrollo y de los países menos adelantados en las exportaciones de mercancías y servicios a nivel mundial, 2000-2014 (porcentaje)

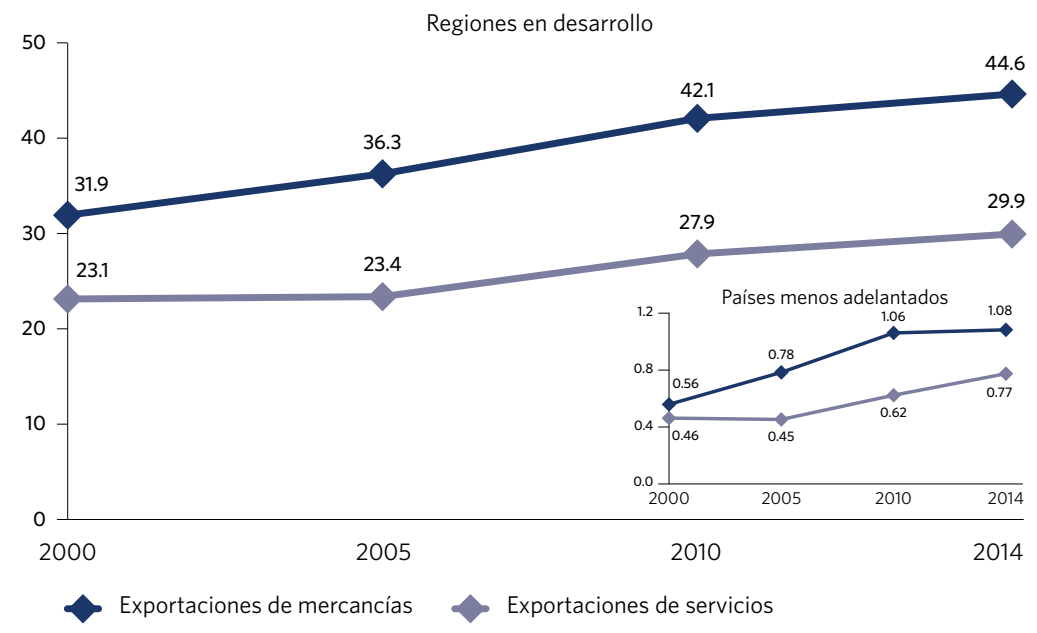

Promedio de aranceles aduaneros impuestos por los países desarrollados sobre productos clave exportados por los países menos adelantados, 2000, 2005, 2010 y 2014 (porcentaje)
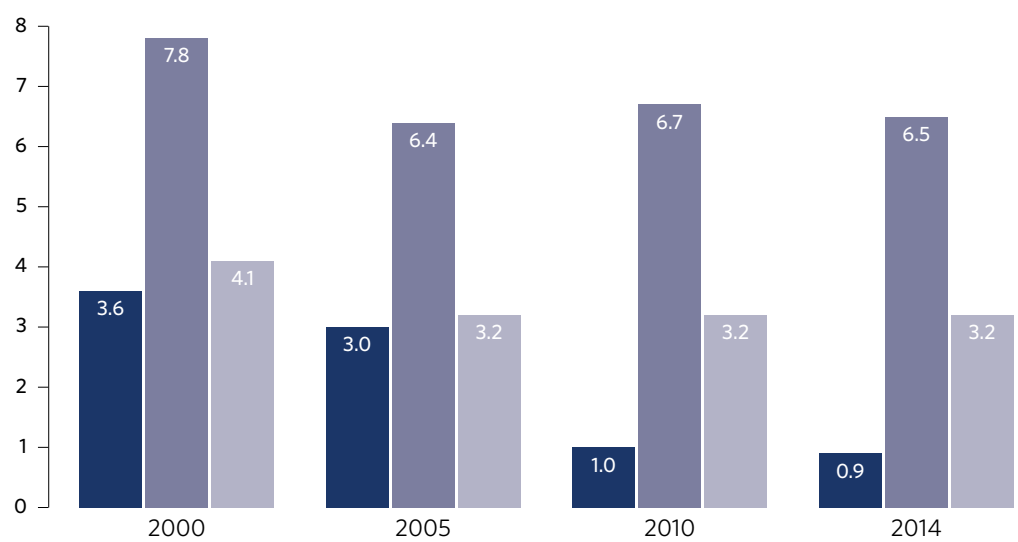

Agricultura

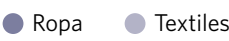

La contribución de los países en desarrollo a las exportaciones mundiales aumentó sustancialmente, pero las exportaciones de los PMA siguen siendo bajas

La contribución a las exportaciones de mercancías de los países menos adelantados en el mercado mundial de exportaciones se duplicó en el período de 2000 a 2014 Aun así, esta representó solo una pequeña fracción de las exportaciones mundiales en 2014, de 1,1\%. De forma más general, para las regiones en desarrollo, las exportaciones de mercancía crecieron en casi un $40 \%$ y representaron casi $45 \%$ de las exportaciones mundiales en 2014 . En comparación, las exportaciones de servicios en las regiones en desarrollo quedaron rezagadas, correspondiendo a aproximadamente un $30 \%$ del total de las exportaciones. El impulsor clave del crecimiento de las exportaciones durante este período fue un aumento masivo del precio de los combustibles, minerales y metales, que reflejaron su alta demanda en los países en desarrollo, particularmente en China.

\section{Aunque los aranceles aduaneros sobre los productos agrícolas de los países menos adelantados se redujeron, los de ropa y textiles continúan siendo altos}

El promedio de aranceles impuestos por los países desarrollados sobre las importaciones desde los países menos adelantados se redujo de manera sostenida para todos los grupos de productos hasta 2005. Después de ese año, el promedio de aranceles para los productos agrícolas continuó disminuyendo, alcanzando menos del 1\% en 2014. Los aranceles todavía son altos para la exportación de ropa y textiles desde los países menos adelantados debido a que se excluyó a algunos grandes exportadores asiáticos de determinados aranceles preferenciales.
Cantidad de países con un plan de estadística nacional, 2010 y 2015
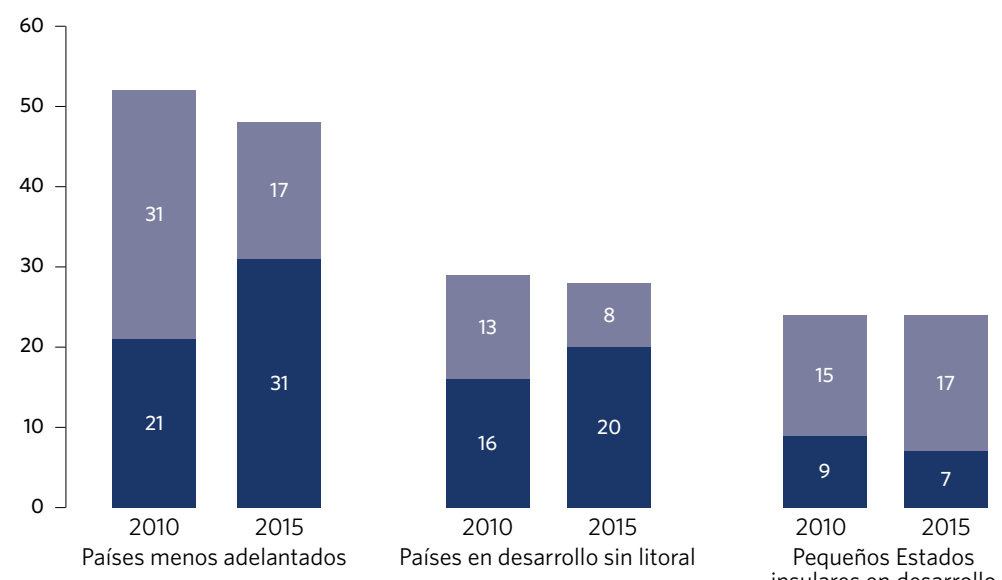

Países sin un plan insulares en desarrollo

Países con un plan activo

\section{Los planes de estadística nacional necesitan actualizarse en muchos países}

Para fortalecer un sistema nacional de estadística es necesario contar con un plan de estadística nacional. Los requisitos de los indicadores de los ODM han logrado mucho para fomentar planes y sistemas nacionales de estadística fiables. El número de países que cuentan con un plan nacional de estadística aumentó en algunas regiones y grupos de países entre 2010 y 2015 ,

lo que incluye países menos adelantados y países en desarrollo sin litoral. Sin embargo, muchos continúan sin tener un plan. La cantidad total de pequeños estados insulares en desarrollo con un plan de estadística disminuyó de 9 a 7 durante este período, a medida que algunos de los planes existentes iban venciendo. 


\section{En 2013, los países menos adelantados recibieron más del $80 \%$ de la AOD dirigida a la creación de capacidades estadísticas}

El apoyo financiero para crear capacidades estadísticas nacionales alcanzó los 325 millones de dólares en el 2013, una disminución del 14\% con respecto a los 379 millones de dólares de 2010. Sin embargo, la asistencia a los países menos adelantados se triplicó durante este período, alcanzando los 265 millones de dólares. Esto significa que el $82 \%$ de todo el apoyo financiero para la creación de capacidades estadísticas se volcó a los países menos adelantados en 2013. Asia sudoriental, Asia occidental y África subsahariana fueron los mayores beneficiarios de este cambio en las prioridades de financiación. A pesar de una creciente concientización de la importancia de las estadísticas para una función normativa empírica, la proporción de la AOD dedicada a la estadística rondó en 0,3\% entre 2010 y 2013.
Total de la asistencia oficial para el desarrollo dedicada a actividades de creación de capacidad estadística en regiones en desarrollo, 2010 y 2013 (millones de dólares de los Estados Unidos)

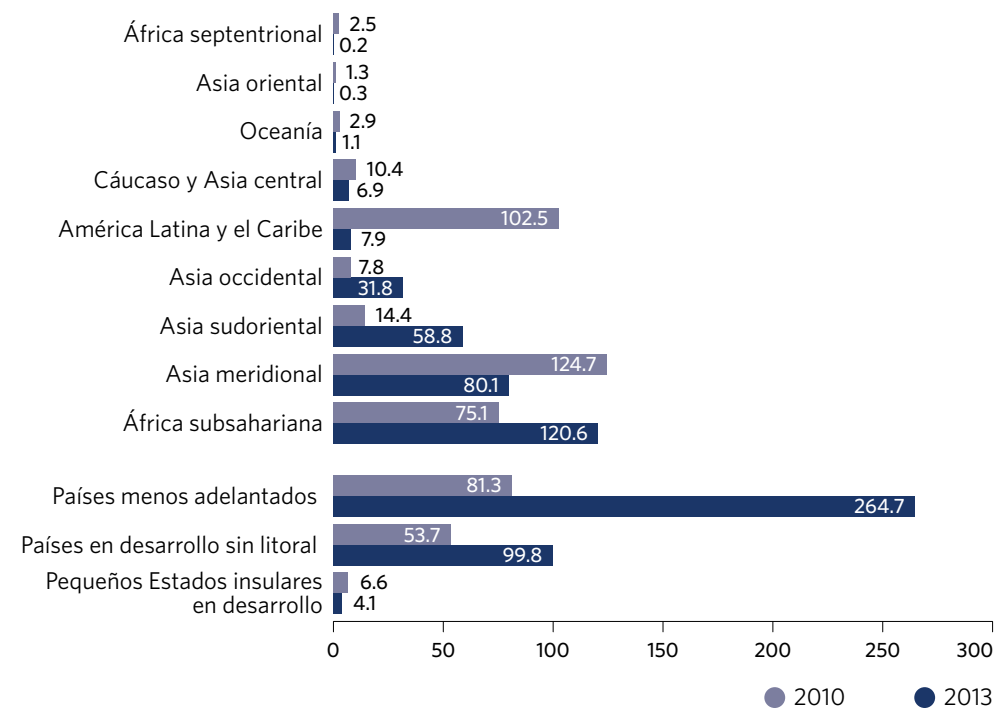

\section{Todavía no se han realizado censos de población y vivienda en todos los países}

Los censos de población y vivienda son una importante fuente de datos desglosados necesarios para formular, implementar y supervisar las políticas de desarrollo. Durante el período de 10 años comprendido entre 2006 y 2015, el $96 \%$ de los países en las regiones desarrolladas realizaron al menos un censo de población y vivienda. La proporción en las regiones en desarrollo en total fue de $88 \%$, cayendo a $67 \%$ y $69 \%$ en Asia meridional y Asia occidental, respectivamente.
Proporción de países que realizaron al menos un censo de población y vivienda en el período 2006-2015 (porcentaje)

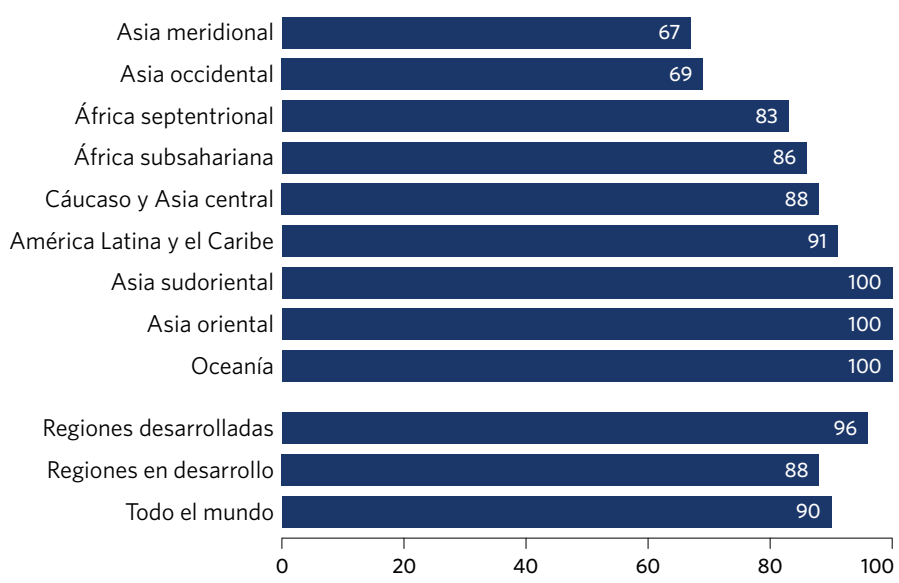

\section{El registro de defunciones, una fuente crucial de datos para los indicadores de desarrollo sostenible relacionados a la salud, continúa lejos de ser universal}

Durante el período comprendido entre 2010 y 2014, se disponían de datos de defunciones para 145 de 230 países y territorios. De estos, 128 tenían los datos completos al menos en un $75 \%$. El promedio de registro de defunciones alcanza su punto más bajo en África y Asia. La información sobre defunciones, en particular cuando es completa y desglosada, es esencial para generar una cantidad de indicadores y estadísticas básicos para la salud.
Número de países cuyos datos de registro de defunción están completos al menos en un $75 \%$, 2010-2014

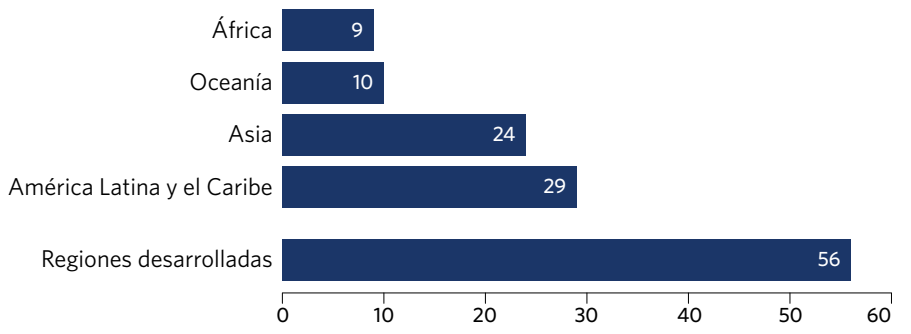




\section{No dejar a nadie atrás}

Al comprometerse con la realización de la Agenda 2030 para el Desarrollo Sostenible, los Estados Miembros reconocieron que la dignidad de la persona es fundamental y que los objetivos y metas de la Agenda deberían cumplirse para todas las naciones y pueblos, y para todos los segmentos de la sociedad. Además, se empeñaron en alcanzar primero a aquellos que están más rezagados.

Asegurar que estos compromisos se traduzcan en una acción eficaz requiere una comprensión precisa de las poblaciones destinatarias. Sin embargo, los datos desglosados necesarios para abordar todos los grupos vulnerables -incluyendo niños, jóvenes, personas con discapacidades, personas que padecen $\mathrm{VIH}$, adultos mayores, indígenas, refugiados, personas desplazadas internamente y migrantes- según lo especifica la Agenda 2030, son escasos. Pocos de los indicadores actuales, por ejemplo, pueden revelar las situaciones particulares de migrantes, refugiados, adultos mayores, personas con discapacidades, minorías y pueblos indígenas.

Sin embargo, incluso con los limitados datos disponibles, está claro que los beneficios del desarrollo no se comparten equitativamente. Los siguientes ejemplos muestran cómo los datos divididos por edad, sexo, nivel de ingreso y lugar de residencia pueden señalar diferencias significativas entre los diversos grupos de población.

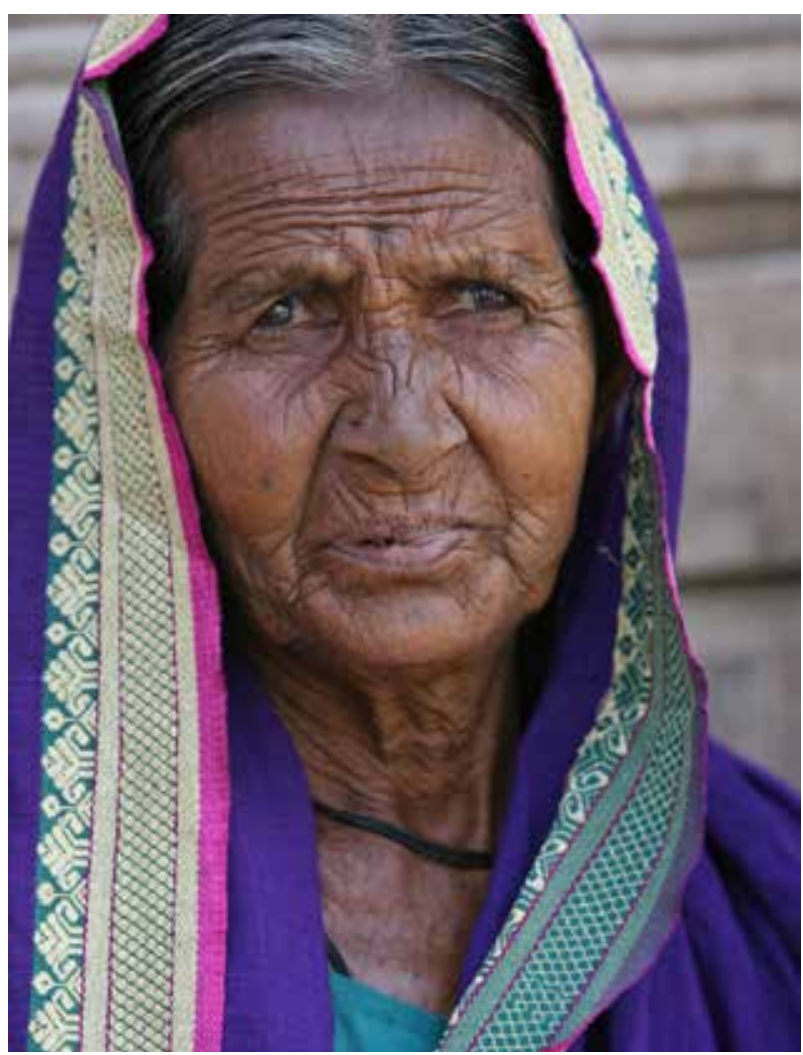

\section{Los hombres jóvenes enfrentan un mayor riesgo de convertirse en víctimas de asesinato y en sus presuntos autores}

Los jóvenes presentan una representación superior entre las víctimas directas e indirectas de violencia. Alrededor de 200.000 homicidios cada año $-43 \%$ de todos los homicidios a nivel global- involucran a niños y adultos entre las edades de 10 y 29 años. Los hombres jóvenes tienen el riesgo más alto de convertirse en víctimas de homicidio, y por lejos las mayores tasas de ser presuntos autores de homicidio. Los niños se encuentran entre aquellos más afectados por la trata de personas y, en varias regiones, comprenden la mayoría de sus víctimas.

Los jóvenes también enfrentan otros desafíos grandes. En 2015, la tasa de desempleo de los jóvenes a nivel mundial (entre personas de 15 a 24 años) fue del 15\%: más de tres veces la tasa para los adultos (4,6\%). En África septentrional y Asia occidental, la tasa de desempleo para los jóvenes alcanzó el $46 \%$ y el 31\%, respectivamente.

* Datos de 2014 o del último año del que se dispone información. 


\section{En todas las regiones en desarrollo, las mujeres más pobres tienen menores probabilidades de contar con asistencia calificada durante el parto}

En Asia meridional y África subsahariana, menos del 30\% de los partos de las mujeres del $20 \%$ más pobre de los hogares son atendidos por personal sanitario especializado, en comparación con más del $80 \%$ de los partos del $20 \%$ más rico de los hogares. A nivel mundial, en 2015, los partos del 20\% más rico tenían más del doble de probabilidades de ser atendidos por personal sanitario especializado en comparación con los del $20 \%$ más pobre ( $89 \%$ contra el $43 \%$ ).

La grave desigualdad de ingresos también afecta otros aspectos del desarrollo sostenible. Los datos de encuestas realizadas en 63 países en desarrollo entre 2008 y 2012 muestran que los niños de los hogares más pobres son casi cuatro veces más propensos a no asistir a la escuela que sus contrapartes de los hogares más ricos. Un análisis de 87 países con datos de encuestas de 2005 a 2014 sugiere que los niños de los hogares más pobres tienen más del doble de probabilidad de sufrir retrasos de crecimiento que sus pares más ricos.
Proporción de partos atendidos por personal sanitario especializado en el $20 \%$ más pobre y el 20\% más rico de los hogares, por región, 2000-2010 o 2015 (porcentaje)

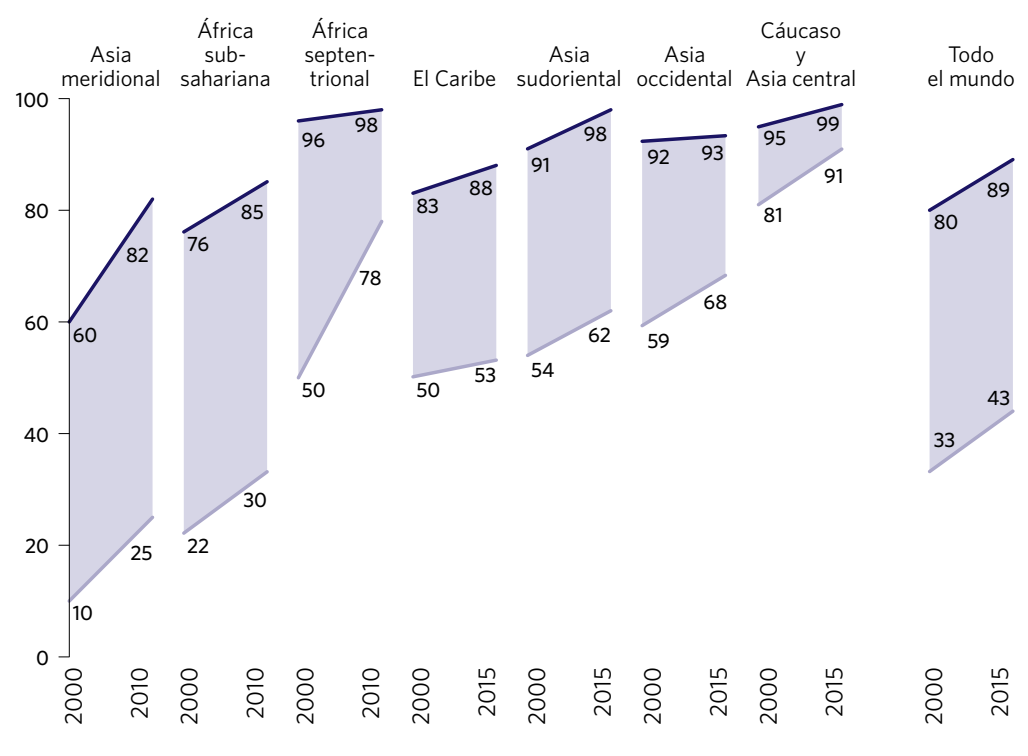

\section{Las personas que viven en zonas rurales están en desventaja en cuanto a muchos servicios sanitarios}

Los sistemas de salud tienden a ser más débiles en zonas rurales y remotas, con menores tasas de cobertura de servicios sanitarios que en los centros urbanos. Por ejemplo, mientras que más del $90 \%$ de los partos en zonas urbanas son atendidos por personal sanitario especializado, la proporción es solamente del $72 \%$ para las zonas rurales. La demanda satisfecha de planificación familiar muestra un régimen similar, con un $70 \%$ de la población urbana que señala que sus necesidades de planificación familiar están satisfechas, en comparación con el $60 \%$ en zonas rurales. Por último, las mejoras en el suministro de agua potable e instalaciones de saneamiento son ambas más predominantes en zonas urbanas que rurales. Las diferencias son incluso más pronunciadas cuando se considera el agua corriente: el $79 \%$ de los habitantes urbanos cuenta con agua corriente en sus hogares o instalaciones en contraste con un tercio de la población rural.
Asistencia calificada durante el parto, demanda de planificación familiar satisfecha mediante métodos modernos, poblaciones que utilizan mejoras en el suministro de agua potable y poblaciones que utilizan mejoras en las instalaciones sanitarias, por zonas urbanas y rurales, $2015^{\star}$ (porcentaje)

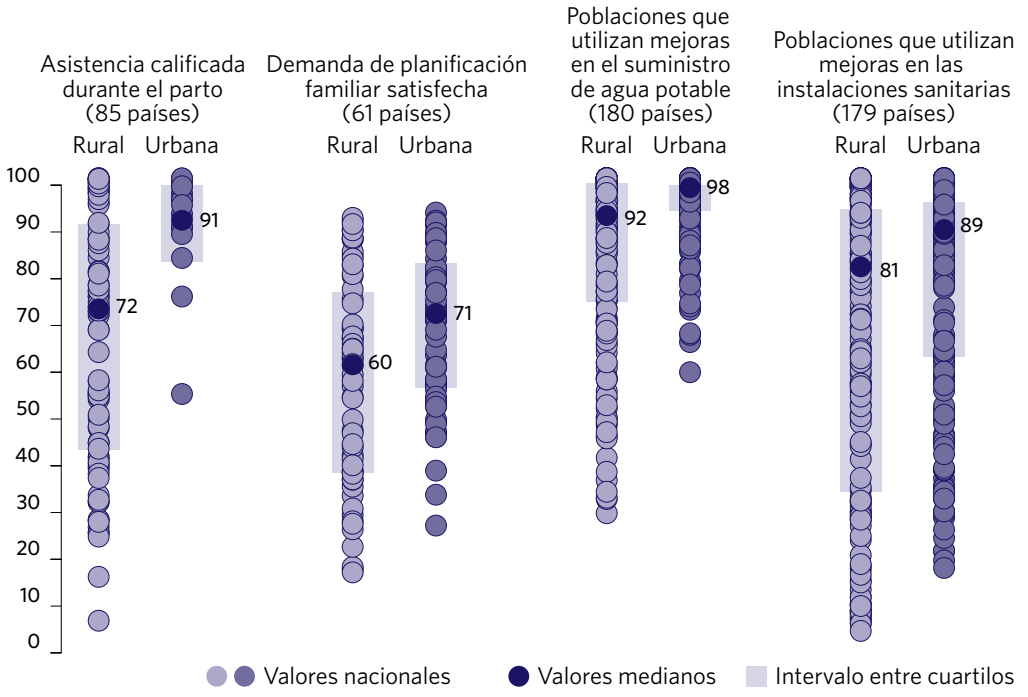

* 2015 o último año del que se disponen datos.

\section{Las poblaciones de los países menos} adelantados tienen el doble de probabilidades de padecer nutrición insuficiente que las poblaciones de las regiones en desarrollo

También se encuentran desigualdades persistentes entre grupos de países en situaciones especiales. Por ejemplo, la prevalencia de la nutrición insuficiente es sustancialmente mayor en los países menos adelantados, los países en desarrollo sin litoral y los pequeños estados insulares en desarrollo que en las regiones en desarrollo en general.
Prevalencia de nutrición insuficiente para grupos seleccionados de países, 2014-2016 (porcentaje)

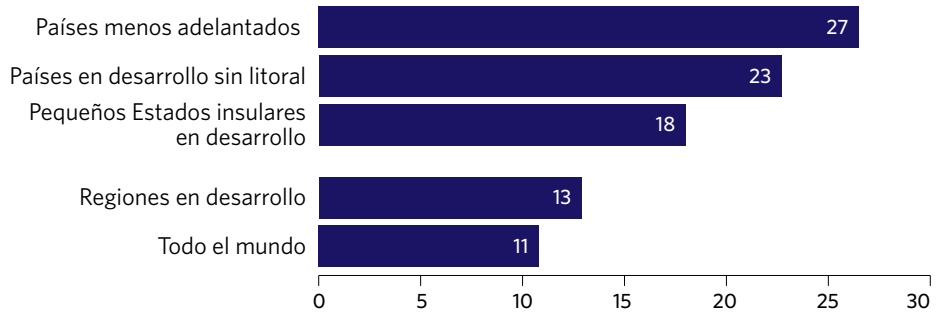




\section{Nota para el lector}

\section{Marco de indicadores mundiales para el seguimiento y el examen de los ODS}

La información presentada en este informe se basa en los últimos datos disponibles a mayo de 2016 sobre los indicadores seleccionados del marco mundial de los ODS. Los indicadores presentados son aquellos para los que existen suficientes datos disponibles para ofrecer un panorama general a nivel regional y mundial. El marco de indicadores mundiales ${ }^{1}$ fue desarrollado por el Grupo Interinstitucional y de Expertos sobre los Indicadores de los ODS (GIEI-ODS) que fuera acordado, como un punto práctico de inicio, en la 47a. sesión de la Comisión de Estadística de las Naciones Unidas en marzo de 2016.

\section{Fuentes de datos y base para este análisis}

Para la mayoría de los indicadores presentados en este informe, los valores representan agregados regionales y/o subregionales. En general, los valores son promedios ponderados de datos por país, utilizando como parámetro la población de referencia. Se calculan a partir de los datos recopilados por organismos internacionales, en base a sus respectivos mandatos y pericias especializadas, de los sistemas estadísticos nacionales. Los datos nacionales provistos al sistema estadístico internacional suelen ajustarse para su comparación internacional y se completan con estimaciones cuando fuera necesario. Según lo decidido por la Comisión de Estadística y conforme a la resolución 2006/6 del Consejo Económico y Social de las Naciones Unidas (ECOSOC), las estimaciones utilizadas para la compilación de indicadores mundiales deben producirse bajo consulta con las

\section{Mejorar la calidad y la disponibilidad de datos}

Los datos de calidad son vitales para que los gobiernos, las organizaciones internacionales, las sociedades civiles, el sector privado y el público en general puedan tomar decisiones fundamentadas y para asegurar una evaluación certera de la implementación de la Agenda 2030. Dicho esto, hacer un seguimiento del progreso de los ODS requiere la recopilación, el procesamiento, el análisis y la difusión de una cantidad sin precedentes de datos y estadísticas a nivel subnacional, nacional, regional y mundial, incluyendo aquellos derivados de sistemas de estadística nacionales y de nuevas e innovadoras fuentes de datos.

Muchos sistemas de estadística nacional en todo el mundo enfrentan serios desafíos en este sentido. Como resultado, la información certera y oportuna acerca de ciertos aspectos de la vida de las personas es desconocida, numerosos grupos y personas permanecen "invisibles" y muchos desafíos de desarrollo siguen sin entenderse claramente. En la resolución 70/1, los Estados Miembros reconocieron el papel crucial que tiene fortalecer la recopilación y la creación de capacidad de datos, y se comprometieron a abordar este vacío (párrafo 57).

Siempre que sea posible, la supervisión mundial debería basarse en datos nacionales comparables y normalizados, obtenidos mediante
Este conjunto de indicadores propone la evaluación del progreso a nivel mundial. La selección de los indicadores en este informe no pretende representar una selección de las metas según su importancia, ya que todas las metas y objetivos tienen igual importancia y deberán ser abordados por los indicadores apropiados.

La composición de las regiones y subregiones en este informe se basa en las divisiones geográficas de las Naciones Unidas,con algunas modificaciones necesarias para crear, en la medida de lo posible, grupos de países en los que se pueda realizar un análisis significativo. ${ }^{2}$

autoridades estadísticas nacionales. La División de Estadística de las Naciones Unidas mantiene una base de los datos y metadatos mundiales, regionales y nacionales disponibles para los indicadores de los ODS que acompañan este informe y éstos estarán disponibles en unstats.un.org/sdgs.

Aunque los valores de los agregados presentados son una forma conveniente de hacer un seguimiento del progreso, la situación de cada país dentro de una región dada puede variar significativamente de los promedios regionales. Presentar los valores agregados para todas las regiones también oscurece otra realidad: la falta, en muchas partes del mundo, de datos adecuados para evaluar las tendencias naturales y para informar y supervisar la implementación de políticas de desarrollo.

mecanismos de presentación de informes bien establecidos de los países al sistema estadístico internacional. Estos mecanismos pueden mejorarse mediante el fortalecimiento de la función de coordinación de las oficinas de estadística nacionales y otras instituciones nacionales. Para llenar los vacíos de datos y mejorar la comparabilidad internacional, los países deberán adoptar normas acordadas internacionalmente, mientras que la comunidad estadística internacional deberá trabajar estrechamente con los asociados en desarrollo y otras partes interesadas para fortalecer la capacidad estadística nacional y mejorar los mecanismos de presentación de informes. Las organizaciones internacionales y regionales y los mecanismos regionales juegan un papel importante para facilitar estos procesos.

El éxito de estas iniciativas mundiales requerirá esfuerzos de creación de capacidad y la movilización de recursos. Además, deberá estudiarse las nuevas fuentes de datos y las nuevas tecnologías para la recopilación de datos y para la integración de distintas fuentes de datos, colaborando con la sociedad civil, el sector privado y los círculos académicos. La integración de la información geoespacial y los datos estadísticos será particularmente importante para la elaboración de una serie de indicadores.

1 La lista completa de indicadores se presenta en el Anexo IV del Informe del Grupo Interinstitucional y de Expertos sobre los Indicadores de los Objetivos de Desarrollo Sostenible (E/CN.3/2016/2/Rev.1) (http://unstats.un.org/unsd/statcom/47th-session/documents/2016-2IAEG-SDGs-Rev1-E.pdf).

2 La composición de estas subregiones se muestra en la siguiente sección "Agrupaciones regionales". 


\section{Agrupaciones regionales}

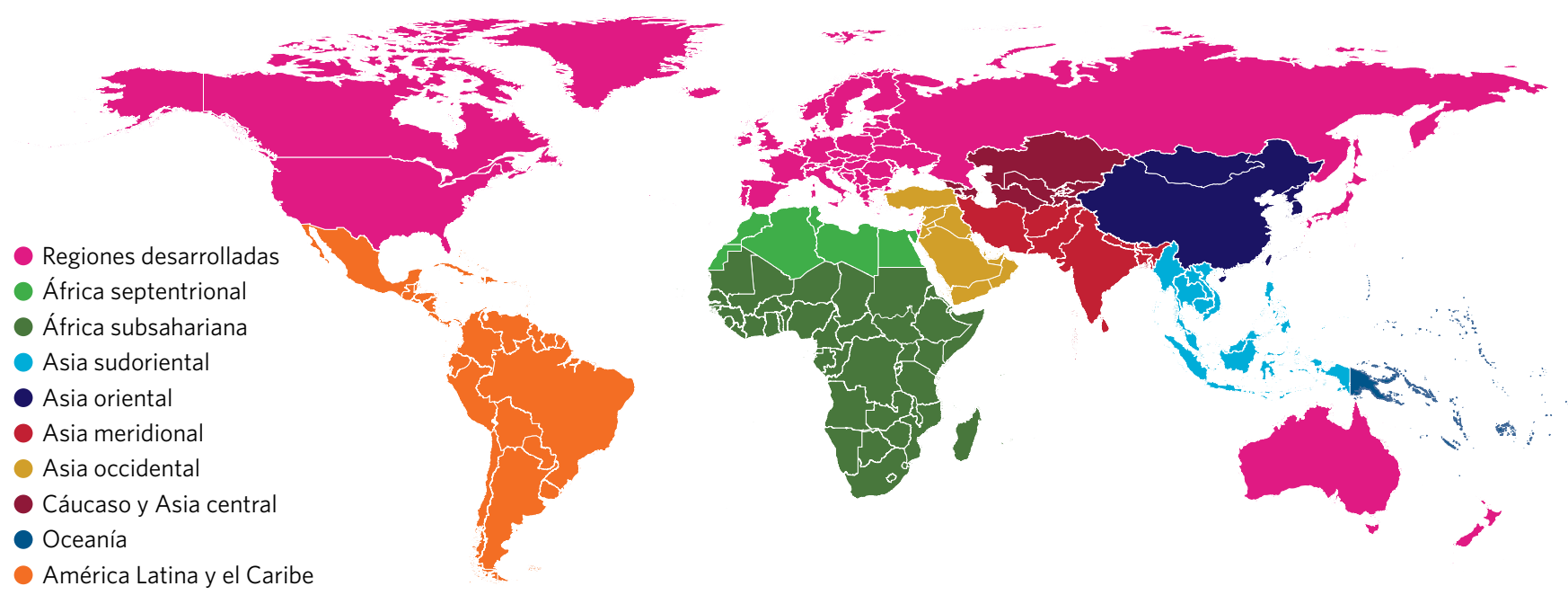

Este informe presenta datos para el mundo en su totalidad y para varias agrupaciones de países. Estas se califican como regiones "en desarrollo" y regiones "desarrolladas". ${ }^{3}$ Las regiones en desarrollo se dividen a su vez en subregiones, las que se muestran en el mapa anterior. Estas agrupaciones regionales están basadas en divisiones geográficas de las Naciones Unidas, con algunas modificaciones necesarias para crear, en la medida de lo posible, grupos de países en los que se pueda efectuar un análisis significativo. Puede encontrarse una lista completa de los países incluidos en cada región y su subregión en unstats.un.org/sdgs.
Las designaciones empleadas y la presentación del material de esta publicación no implican la expresión de opinión alguna por parte del Secretariado de las Naciones Unidas en cuanto a la situación legal de las autoridades de cualquier país, territorio, ciudad o zona, o acerca de la delimitación de sus fronteras o límites.

3 Dado que no existe una norma acordada para la designación de países o zonas "desarrollados" y "en desarrollo" en el sistema de las Naciones Unidas, esta distinción se hace únicamente con propósitos de análisis estadísticos. 
Fotografías:

Portada (c) UNICEF/Yarim Shamsan

Página 12 (c) Banco Mundial/Stanislas Fradelizi

Página 14 (c) UNICEF/Jiro Ose

Página 16 (c) PNUD Picture This/Jean-François Mousseau

Página 18 (c) UNICEF/Giacomo Pirozzi

Página 20 (c) UNICEF/Susan Markisz

Página 22 (c) Banco Mundial/Allison Kwesell

Página 24 (c) Tomasz Juszczak

Página 26 (c) Banco Mundial/Jonathan Ernst

Página 28 (c) Banco Mundial/Gerardo Pesantez

Página 30 (c) UNICEF/Ash Gilbertson

Página 32 (c) UNICEF/Olivier Asselin

Página 34 (c) UNMIT/Martine Perret

Página 36 (c) UNPhoto/Mark Garten

Página 38 (c) Banco Mundial/Curt Carnemark

Página 40 (c) Tomasz Juszczak

Página 42 (c) UNICEF/Jan Grarup

Página 44 (c) UNICEF/Josh Estey

Página 48 (c) Banco Mundial/Simone D. McCourtie

Gráfico: El gráfico en la página 36 proviene de la base de datos de escenarios del Quinto Informe de Evaluación de la CMNUCC/IPCC.

Mapa: El mapa en la página 39 proviene del Programa de Evaluación de las Aguas Transfronterizas (FMAM/PNUMA/COI-UNESCO).

Íconos infográficos: Los íconos infográficos en las páginas 3 a 11 y en la página 19 provienen de thenounproject.com con una licencia NounPro.

Diseño: Unidad de Diseño Gráfico de las Naciones Unidas/DPI

Diseño adicional del informe, diseño gráfico, composición tipográfica y edición de originales: Sección de Preparación de Originales y Corrección de Pruebas/DAGGC

Editora: Lois Jensen

Copyright ( 2016 Naciones Unidas

Reservados todos los derechos a nivel mundial

Las solicitudes para reproducir los extractos o para fotocopiar deben dirigirse al Departamento de Derechos de Autor: http://www.copyright.com.

Cualquier otra pregunta sobre derechos o licencias, como derechos relativos a los subsidios, deben dirigirse a:

United Nations Publications, 300 East 42nd Street, New York, NY, 10017, Estados Unidos de América.

Correo electrónico: publications@un.org; website: http://www.un.org/publications

Publicación de las Naciones Unidas emitida por el Departamento de Asuntos Económicos y Sociales(DESA)

e-ISBN: 978-92-1-058261-2 
El presente informe se basa en una serie de datos maestros establecidos por el Departamento de Asuntos Económicos y Sociales de la Secretaría de las Naciones Unidas, con la contribución de un gran número de organizaciones internacionales y regionales en respuesta a la resolución 70/1 de la Asamblea General (párr. 83) con el fin de proporcionar una evaluación anual sobre el progreso realizado hacia el cumplimiento de los Objetivos de Desarrollo Sostenible. A continuación, se citan las organizaciones internacionales y regionales que contribuyeron a dicho informe. También se ha contado con la colaboración de profesionales nacionales de la estadística, expertos de la sociedad civil y del mundo académico.

ALIANZA DE PEQUEÑOS ESTADOS INSULARES

COMISIÓN ECONÓMICA Y SOCIAL PARA ASIA Y EL PACÍFICO

COMISIÓN ECONÓMICA Y SOCIAL PARA ASIA OCCIDENTAL

COMISIÓN ECONÓMICA PARA ÁFRICA

COMISIÓN ECONÓMICA PARA EUROPA

COMISIÓN ECONÓMICA PARA AMÉRICA LATINA Y EL CARIBE

ORGANIZACIÓN DE LAS NACIONES UNIDAS PARA LA ALIMENTACIÓN Y LA AGRICULTURA

ORGANIZACIÓN DE AVIACIÓN CIVIL INTERNACIONAL

AGENCIA INTERNACIONAL DE LA ENERGÍA

ORGANIZACIÓN INTERNACIONAL DEL TRABAJO

FONDO MONETARIO INTERNACIONAL

AGENCIA INTERNACIONAL DE ENERGÍAS RENOVABLES

UNIÓN INTERNACIONAL DE TELECOMUNICACIONES

CENTRO DE COMERCIO INTERNACIONAL

UNIÓN INTERNACIONAL PARA LA CONSERVACIÓN DE LA NATURALEZA

UNIÓN INTERPARLAMENTARIA

PROGRAMA CONJUNTO DE LAS NACIONES UNIDAS SOBRE EL VIH/SIDA

OFICINA DEL ALTO COMISIONADO DE LAS NACIONES UNIDAS PARA LOS DERECHOS HUMANOS

OFICINA DEL ALTO COMISIONADO DE LAS NACIONES UNIDAS PARA LOS REFUGIADOS

ORGANIZACIÓN DE COOPERACIÓN Y DESARROLLO ECONÓMICOS

CONSORCIO DE ESTADÍSTICAS PARA EL DESARROLLO EN EL SIGLO XXI / PARIS21

SECRETARÍA DEL CONVENIO SOBRE LA DIVERSIDAD BIOLÓGICA

ENERGÍA SOSTENIBLE PARA TODOS

FONDO DE LAS NACIONES UNIDAS PARA EL DESARROLLO DE LA CAPITALIZACIÓN

FONDO DE LAS NACIONES UNIDAS PARA LA INFANCIA

CONFERENCIA DE LAS NACIONES UNIDAS SOBRE COMERCIO Y DESARROLLO

CONVENCIÓN DE LAS NACIONES UNIDAS DE LUCHA CONTRA LA DESERTIFICACIÓN

DEPARTAMENTO DE ASUNTOS ECONÓMICOS Y SOCIALES DE LAS NACIONES UNIDAS

PROGRAMA DE LAS NACIONES UNIDAS PARA EL DESARROLLO

DIVISIÓN DE LAS NACIONES UNIDAS DE ASUNTOS OCEÁNICOS Y DEL DERECHO DEL MAR

ORGANIZACIÓN DE LAS NACIONES UNIDAS PARA LA EDUCACIÓN, LA CIENCIA Y LA CULTURA

ENTIDAD DE LAS NACIONES UNIDAS PARA LA IGUALDAD DE GÉNERO Y EL EMPODERAMIENTO DE LAS MUJERES / ONU-MUJERES

PROGRAMA DE LAS NACIONES UNIDAS PARA EL MEDIO AMBIENTE

CONVENCIÓN MARCO DE LAS NACIONES UNIDAS SOBRE EL CAMBIO CLIMÁTICO

PROGRAMA DE LAS NACIONES UNIDAS PARA LOS ASENTAMIENTOS HUMANOS

ORGANIZACIÓN DE LAS NACIONES UNIDAS PARA EL DESARROLLO INDUSTRIAL

ESTRATEGIA INTERNACIONAL DE LAS NACIONES UNIDAS PARA LA REDUCCIÓN DE LOS DESASTRES

SERVICIO DE LAS NACIONES UNIDAS DE ACTIVIDADES RELATIVAS A LAS MINAS

OFICINA DE LAS NACIONES UNIDAS PARA LA REDUCCIÓN DEL RIESGO DE DESASTRES

OFICINA DEL ESTADO DE DERECHO Y LAS INSTITUCIONES DE SEGURIDAD DE LAS NACIONES UNIDAS

OFICINA DEL ALTO REPRESENTANTE PARA LOS PAÍSES MENOS ADELANTADOS, LOS PAÍSES EN

DESARROLLO SIN LITORAL Y LOS PEQUEÑOS ESTADOS INSULARES EN DESARROLLO

OFICINA DEL ENVIADO DEL SECRETARIO GENERAL DE LAS NACIONES UNIDAS PARA LA JUVENTUD

REPRESENTANTE ESPECIAL DEL SECRETARIO GENERAL DE LAS NACIONES UNIDAS SOBRE LA VIOLENCIA CONTRA LOS NIÑOS

OFICINA DE LAS NACIONES UNIDAS CONTRA LA DROGA Y EL DELITO

OFICINA DE LAS NACIONES UNIDAS DE APOYO A LA CONSOLIDACIÓN DE LA PAZ

FONDO DE POBLACIÓN DE LAS NACIONES UNIDAS

ONU-ENERGÍA

ONU-OCÉANOS

ONU-AGUA

GRUPO DEL BANCO MUNDIAL

ORGANIZACIÓN MUNDIAL DE LA SALUD

ORGANIZACIÓN MUNDIAL DEL TURISMO

ORGANIZACIÓN MUNDIAL DEL COMERCIO

Para más información puede visitar la página web de la División de Estadística de las Naciones Unidas para los Objetivos de Desarrollo Sostenible http://unstats.un.org/sdgs/. 


\section{(4) OBJETIV SOSOSTENIBLE}

4

La nueva Agenda es un compromiso realizado por líderes con todas las personas en todas partes. Es una visión universal, integrada y transformadora de un mundo mejor. Es una agenda para los pueblos, para terminar con la pobreza en todas sus formas. Una agenda para el planeta, nuestro hogar común. Una agenda para la prosperidad compartida, la paz y la cooperación. Una agenda que transmite la urgencia de tomar medidas con respecto al clima. Se fundamenta en la igualdad de género y el respeto por los derechos de todos. Sobre todo, promete no dejar a nadie atrás."

- Secretario General de LAS NaCIONES UnIDAS, BAN KI-MOON 